\title{
FIXAÇÃO E DESENVOLVIMENTO DOS FRUTOS DO TANGOR 'MURCOTE' (Citrus reticulata Blanco x Citrus sinensis L. Osbeck) E DA LIMA ÁCIDA 'TAHITI' (Citrus latifolia Tanaka) COM A UTILIZAÇÃO DE BIORREGULADORES
}

\section{CHRYZ MELINSKI SERCILOTO}

\author{
Dissertação apresentada à Escola \\ Superior de Agricultura "Luiz de \\ Queiroz", Universidade de São Paulo, \\ para obtenção do título de Mestre em \\ Ciências, Área de Concentração: \\ Fisiologia e Bioquímica de Plantas.
}

PIRACICABA

Estado de São Paulo - Brasil

Novembro - 2001 


\title{
FIXAÇÃO E DESENVOLVIMENTO DOS FRUTOS DO \\ TANGOR 'MURCOTE' (Citrus reticulata Blanco x Citrus sinensis L. Osbeck) E DA LIMA ÁCIDA 'TAHITI' (Citrus latifolia Tanaka) COM A UTILIZAÇÃO DE BIORREGULADORES
}

\author{
CHRYZ MELINSKI SERCILOTO
}

Engenheiro Agrônomo

Orientador: Prof. Dr. PAULO ROBERTO DE CAMARGO E CASTRO

Dissertação apresentada à Escola Superior de Agricultura "Luiz de Queiroz", Universidade de São Paulo, para obtenção do título de Mestre em Ciências, Área de Concentração:

Fisiologia

Bioquímica de Plantas.

PIRACICABA

Estado de São Paulo - Brasil

Novembro - 2001 
Dados Internacionais de Catalogação na Publicação (CIP) DIVISÃO DE BIBLIOTECA E DOCUMENTAÇÃO - ESALQ/USP

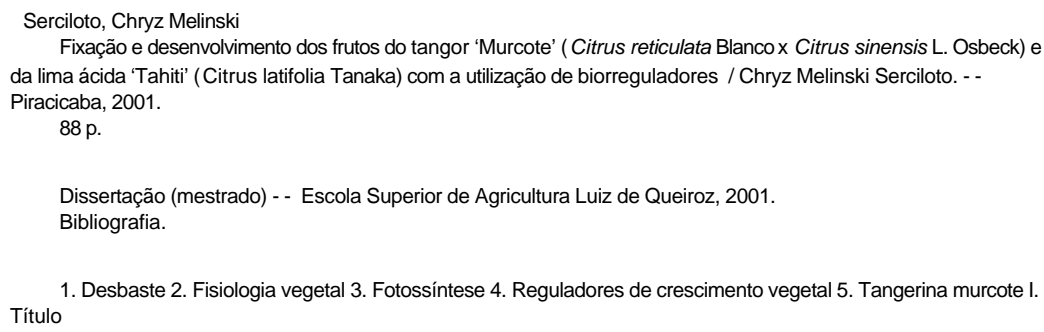

CDD 634.31

\section{"Permitida a cópia total ou parcial deste documento, desde que citada a fonte - $\mathrm{O}$ autor"}


Aos meus pais, Celso e $\mathrm{Ci}$,

à minha avó Sofia

e aos meus irmãos Caio, Camila e Caroline,

pelo grande apoio e incentivo prestados

\section{OFEREÇO}

A todos os citricultores e profissionais da área que, nos momentos bons e ruins, sempre mantiveram o Brasil na posição de maior produtor de citros do mundo.

\section{DEDICO}




\section{AGRADECIMENTOS}

À Escola Superior de Agricultura "Luiz de Queiroz", Universidade de São Paulo, pela possibilidade de realização deste curso.

À Fundação de Amparo à Pesquisa do Estado de São Paulo, pela bolsa de estudos concedida.

Ao Prof. Dr. Paulo Roberto de Camargo e Castro, pela orientação, amizade e confiança em mim depositada para o desenvolvimento da dissertação.

Ao Srs. Cornelius Segeren (in memorian) e Jorge Gibertoni pela cessão dos pomares e auxílio recebido durante a execução dos experimentos.

Ao Prof. Dr. Ricardo Alfredo Kluge, pela grande amizade, apoio e incentivo nas pesquisas realizadas.

Aos técnicos e amigos Alexandre Vendemiatti, Clóvis Dias Fernandes e Naldivio de Souza ("mineirinho") pelo constante auxílio na execução dos experimentos.

Aos professores Dr. Ricardo Ferraz de Oliveira, Dr. Eduardo Caruso Machado e Dr. Angelo Pedro Jacomino pela cessão dos equipamentos utilizados nos experimentos.

Aos Engenheiros Agrônomos Camilo Lázaro Medina, Silvio Tavares e Rafael Vasconcelos Ribeiro pela eventual participação nos trabalhos realizados.

Aos professores do Curso de Fisiologia e Bioquímica de Plantas, Dr. Luiz

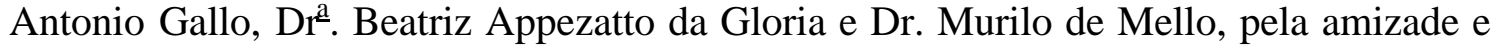
ensinamentos prestados.

Aos meus amigos Daniel, Vitão, Boca, Tiãozinho, Juninho, Mussa e Buldogue pelo incentivo e pelas festas que foram essenciais para o relaxamento mental.

Aos companheiros de república Rafael, Rodrigo, Valter e Luís Fernando por terem me suportado durante todo este tempo. 
Aos amigos de Lavras-MG, Manga, Pacolé, Nenê e Baiano.

Aos colegas da Pós-Graduação Silvio, Elvis, Rafael, Amaral, Ilana, Raquel, Raul, Cristiano, Janaína, Joane, Carol, Catota, Amanda, Romano, Tercílio, Sally, Cecília, André, Chiquinho, Marisa, Liliane e Girleine pelo convívio e amizade.

À Dona Vanda, Fabiane, Daniel, Becari, Henrique pela grande receptividade e amizade.

E a todos aqueles que, de alguma forma, colaboraram na execução deste trabalho.

A DEUS, pela justiça e por ter sempre me guiado aos melhores caminhos. 


\section{SUMÁRIO}

Página

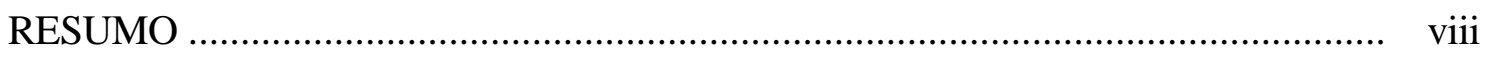

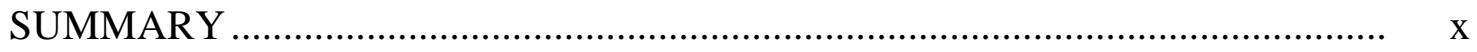

1 INTRODUÇÃ

2 REVISÃO DE LITERATURA ….......................................................... 3

2.1 Desenvolvimento dos frutos cítricos ...................................................... 3

2.1.1 Desbaste dos frutos cítricos....................................................................... 5

2.1.2 Auxinas estimuladoras do desenvolvimento dos frutos ................................ 7

2.1.2.1 Auxinas aplicadas após a queda fisiológica dos frutos ............................... 8

2.1.2.2 Auxinas aplicadas após a antese ...................................................... 11

2.2 Fixação dos frutos cítricos....................................................................... 13

2.2.1 Giberelinas e a fixação dos frutos cítricos .................................................. 14

2.2.2 Auxinas e a fixação dos frutos cítricos ...................................................... 15

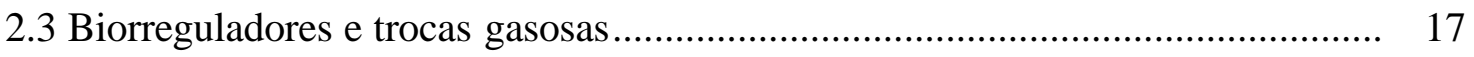

2.4 Fotossíntese e a sua relação com a demanda por carboidratos nos citros........... 20

3 DESENVOLVIMENTO DOS FRUTOS DO TANGOR 'MURCOTE' (Citrus

reticulata Blanco x Citrus sinensis L. Osbeck) COM O USO DE BIORREGULADORES APLICADOS APÓS A QUEDA DAS PÉTALAS ........... 22

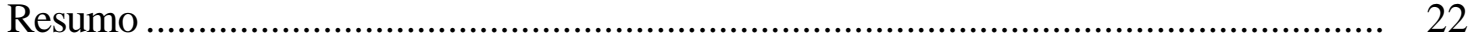

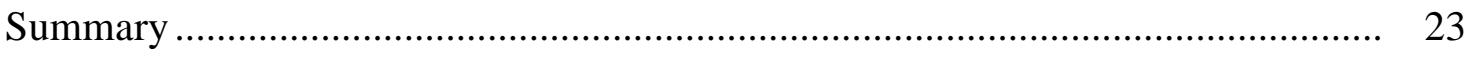

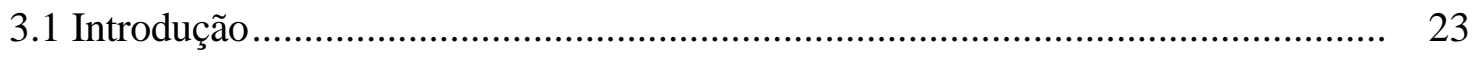

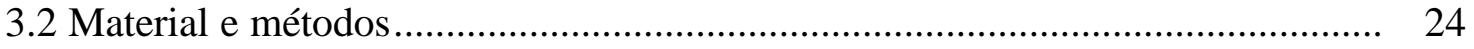

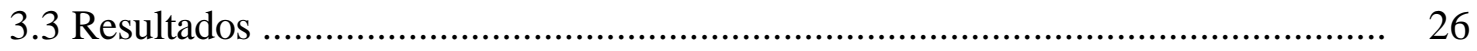

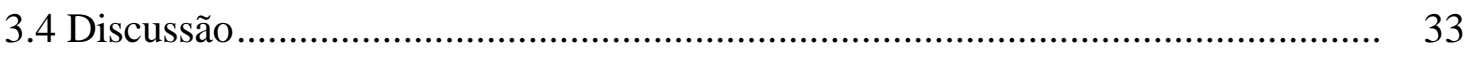


3.7 Conclusões

4 DESBASTE E DESENVOLVIMENTO DOS FRUTOS DO TANGOR MURCOTE (Citrus reticulata Blanco x Citrus sinensis L. Osbeck) COM O USO DE BIORREGULADORES APLICADOS APÓS A QUEDA FISIOLÓGICA DOS FRUTOS

Resumo

Summary 40

4.1 Introdução 40

4.2 Material e métodos 41

4.3 Resultados 44

4.4 Discussão 50

4.5 Conclusões 54

5 FIXAÇÃO DOS FRUTOS DA LIMA ÁCIDA 'TAHITI' (Citrus latifolia Tanaka) COM O USO DE BIORREGULADORES ........................................... 56

Resumo 56

Summary 57

5.1 Introdução. 57

5.2 Material e métodos 58

5.3 Resultados 60

5.4 Discussão 67

5.5 Conclusões 69

6 CONCLUSÕES GERAIS 70 REFERÊNCIAS BIBLIOGRÁFICAS 71 


\title{
FIXAÇÃO E DESENVOLVIMENTO DOS FRUTOS DO TANGOR 'MURCOTE' (Citrus reticulata Blanco x Citrus sinensis L. Osbeck) E DA LIMA ÁCIDA 'TAHITI' (Citrus latifolia Tanaka) COM A UTILIZAÇÃO DE BIORREGULADORES
}

\author{
Autor: Chryz Melinski Serciloto \\ Orientador: Prof. Dr. Paulo Roberto de Camargo e Castro
}

\section{RESUMO}

A alternância de produção, o pequeno tamanho e a baixa capacidade de fixação dos frutos são alguns problemas encontrados em alguns cultivares cítricos. $\mathrm{O}$ presente trabalho foi conduzido em 2000/2001 sob condições de campo, em pomares comerciais de tangor 'Murcote' (Citrus reticulata Blanco x Citrus sinensis L. Osbeck) e de lima ácida 'Tahiti' (Citrus latifolia Tanaka), de 10 e 8 anos de idade, localizados nas cidades de Mogi-Mirim e Taquaritinga-SP, respectivamente. No primeiro experimento, avaliouse o efeito dos biorreguladores etilclozate $200 \mathrm{mg} . \mathrm{L}^{-1}$, Fenotiol $10 \mathrm{mg} . \mathrm{L}^{-1}$, Fengib 1 ml.L ${ }^{-1}$, GA $_{3} 20$ mg.L $\mathrm{L}^{-1}$, 2,4-D 8 mg.L. $\mathrm{L}^{-1}$ e GA 20 mg.L $\mathrm{L}^{-1}+2,4-\mathrm{D} 8 \mathrm{mg} . \mathrm{L}^{-1}$, aplicados após a queda das pétalas, sobre o desbaste e o tamanho dos frutos do tangor 'Murcote'. Nenhum tratamento alterou o número de frutos colhidos e a produtividade (kg/planta). Os tratamentos $\mathrm{GA}_{3} 20 \mathrm{mg} . \mathrm{L}^{-1}+$ 2,4-D $8 \mathrm{mg} . \mathrm{L}^{-1}, \mathrm{GA}_{3} 20 \mathrm{mg} . \mathrm{L}^{-1}$ e Fenotiol $10 \mathrm{mg} . \mathrm{L}^{-1}$ aumentaram o diâmetro $(3,4 \% ; 3,0 \%$ e $3,0 \%)$, a massa média $(7,8 \% ; 8,8 \%$ e 9,5\%) e o número de futos colhidos de maior classe comercial. Nenhum tratamento alterou as características tecnológicas dos frutos (\% suco, brix, acidez, $\mathrm{pH}$, ratio, cor da casca e cor 
do suco). As taxas de assimilação de $\mathrm{CO}_{2}$, transpiração, condutância estomática e o teor de clorofila não foram modificados pelos tratamentos. No segundo experimento avaliouse o efeito dos biorreguladores 3,5,6-TPA $15 \mathrm{mg} . \mathrm{L}^{-1}$, 2,4-DP $50 \mathrm{mg} . \mathrm{L}^{-1}$, Fenotiol 20 $\mathrm{mg} . \mathrm{L}^{-1}$, ethephon $200 \mathrm{mg} \cdot \mathrm{L}^{-1}$ e etilclozate $200 \mathrm{mg} . \mathrm{L}^{-1}$, aplicados após a queda fisiológica dos frutos, sobre o desbaste e o tamanho dos frutos do tangor 'Murcote'. Os tratamentos 3,5,6-TPA $15 \mathrm{mg} . \mathrm{L}^{-1}$, ethephon $200 \mathrm{mg} . \mathrm{L}^{-1}$ e Fenotiol $20 \mathrm{mg} . \mathrm{L}^{-1}$ aumentaram o diâmetro $(7,0 \% ; 6,8 \%$ e $4,4 \%)$, a massa média $(19,1 \% ; 17,3 \%$ e $8,7 \%)$ e o número de frutos colhidos de maior classe comercial. No entanto, os tratamentos 3,5,6-TPA $15 \mathrm{mg} . \mathrm{L}^{-1} \mathrm{e}$ ethephon $200 \mathrm{mg} \cdot \mathrm{L}^{-1}$ diminuíram o número de frutos colhidos $(57,1 \%$ e $47,9 \%)$ e a produtividade $(47,8 \%$ e $37,5 \%) \mathrm{em} \mathrm{kg} / \mathrm{planta}$. O tratamento Fenotiol causou uma diminuição de $0,4{ }^{\circ}$ brix no suco dos frutos. As demais caracterísisticas tecnológicas dos frutos (\% suco, acidez, pH, ratio, cor da casca e cor do suco) não foram afetadas pelos tratamentos. Nenhum tratamento alterou a assimilação de $\mathrm{CO}_{2}$, transpiração, condutância estomática e o teor de clorofila das folhas do tangor 'Murcote'. No terceiro experimento, avaliouse o efeito dos biorreguladores Fenotiol $10 \mathrm{mg} . \mathrm{L}^{-1}$; Fengib $1 \mathrm{ml} . \mathrm{L}^{-}$

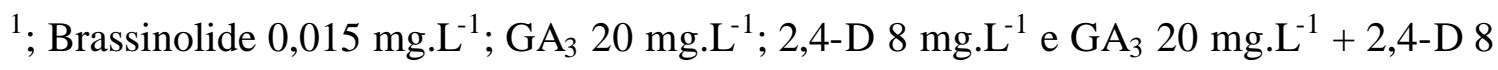
mg. $L^{-1}$ na fixação dos frutos da lima ácida 'Tahiti'. O desenvolvimento vegetativo não foi afetado pelos biorreguladores. Os tratamentos com ácido giberélico $\left(\mathrm{GA}_{3} 20 \mathrm{mg} . \mathrm{L}^{-1}\right.$, Fengib $1 \mathrm{ml} . \mathrm{L}^{-1}$ e GA $30 \mathrm{mg} . \mathrm{L}^{-1}$ + 2,4-D $8 \mathrm{mg} . \mathrm{L}^{-1}$ ) aumentaram a fixação dos frutos da lima ácida 'Tahiti', sendo que a maior fixação de frutos foi causada pelo tratamento $\mathrm{GA}_{3}$ 20 mg. $\mathrm{L}^{-1}+2,4-\mathrm{D} 8 \mathrm{mg} . \mathrm{L}^{-1}$ que promoveu $21,3 \%$ de frutos fixados contra $5,9 \%$ do controle. Os aumentos na fixação promovidos por estes biorreguladores foram acompanhados de acréscimos no teor médio de clorofila e na taxa de assimilação de $\mathrm{CO}_{2}$ das folhas da lima ácida 'Tahiti'. 


\title{
FRUIT SET AND GROWTH OF 'MURCOTT' MANDARIN HYBRID (Citrus reticulata Blanco x Citrus sinensis L. Osbeck) AND 'TAHITI' LIME (Citrus latifolia Tanaka) WITH USE OF BIOREGULATORS
}

\author{
Author: Chryz Melinski Serciloto \\ Adviser: Prof. Dr. Paulo Roberto de Camargo e Castro
}

\section{SUMMARY}

Alternate bearing, small fruits and fruit set are problems of some citrus cultivars. This research was performed at 2000/2001, in comercial orchards of 'Murcott' mandarin hybrid (Citrus reticulata Blanco x Citrus sinensis L. Osbeck) and 'Tahiti' lime (Citrus latifolia Tanaka), with 10 and 8 years old, located in Mogi-Mirim and Taquaritinga-SP, respectively. In the first trial, it was evaluated the effects of bioregulators ethylclozate $200 \mathrm{mg} . \mathrm{L}^{-1}$, Phenothiol $10 \mathrm{mg} . \mathrm{L}^{-1}$, Fengib $1 \mathrm{ml} . \mathrm{L}^{-1}, \mathrm{GA}_{3} 20$ mg. $\mathrm{L}^{-1}, 2,4-\mathrm{D} 8 \mathrm{mg} . \mathrm{L}^{-1}$ and $\mathrm{GA}_{3} 20 \mathrm{mg} . \mathrm{L}^{-1}+2,4-\mathrm{D} 8 \mathrm{mg} . \mathrm{L}^{-1}$ on the fruit thinning and the fruit size of 'Murcott' mandarin hybrid. The treatments were sprayed on whole trees after total petal fall (fruits with approximately $6 \mathrm{~mm}$ of diameter), at a rate of 6 litres per tree. The number of fruits per tree and yield ( $\mathrm{kg} /$ tree) were not affected by the treatments. $\mathrm{GA}_{3} 20 \mathrm{mg} . \mathrm{L}^{-1}+2,4-\mathrm{D} 8 \mathrm{mg} \cdot \mathrm{L}^{-1}, \mathrm{GA}_{3} 20 \mathrm{mg} . \mathrm{L}^{-1}$ and Fenotiol $10 \mathrm{mg} . \mathrm{L}^{-1}$ increased the final fruit size $(3.4 \% ; 3.0 \%$ and $3.0 \%)$, the final fruit weight $(7.8 \% ; 8.8 \%$ and $9.5 \%)$ and the number of fruits of larger comercial size class. The treatments didn't affected juice content, total soluble solids, acidity, $\mathrm{pH}$, juice colour and peel colour. The $\mathrm{CO}_{2}$ 
assimilation, transpiration, stomatal conductance and chlorophyll content were not affected by the treatments. In the second trial, it was evaluated the effects of bioregulators 3,5,6-TPA $15 \mathrm{mg} . \mathrm{L}^{-1}$, 2,4-DP $50 \mathrm{mg} . \mathrm{L}^{-1}$, Phenothiol $20 \mathrm{mg} . \mathrm{L}^{-1}$, ethephon $200 \mathrm{mg} . \mathrm{L}^{-1}$ and ethylclozate $200 \mathrm{mg} . \mathrm{L}^{-1}$ on the fruit thinning and the fruit size of 'Murcott' mandarin hybrid. The treatments were sprayed on whole trees after physiological fruit drop (fruits with approximately $22 \mathrm{~mm}$ of diameter), at a rate of 6 litres per tree. 3,5,6-TPA $15 \mathrm{mg} . \mathrm{L}^{-1}$, ethephon $200 \mathrm{mg} \cdot \mathrm{L}^{-1}$ and Phenothiol $20 \mathrm{mg} . \mathrm{L}^{-1}$ increased the final fruit size $(7.0 \% ; 6.8 \%$ and $4.4 \%)$, the final fruit weight $(19.1 \%$; $17.3 \%$ and $8.7 \%$ ) and the number of fruits of larger comercial size class. However, 3,5,6-TPA $15 \mathrm{mg} . \mathrm{L}^{-1}$ ethephon $200 \mathrm{mg} . \mathrm{L}^{-1}$ decreased the number of fruits per tree $(57.1 \%$ e $47.9 \%)$ and yield $(47.8 \%$ e $37.5 \%)$, in $\mathrm{kg} /$ tree. Phenotiol decreased by 0,4 the total soluble solids. The treatments didn't affected juice content, acidity, $\mathrm{pH}$, juice colour and peel colour. The $\mathrm{CO}_{2}$ assimilation, transpiration, stomatal conductance and chlorophyll content were not affected by the treatments. In the third trial, it was evaluated the effects of bioregulators Phenothiol $10 \mathrm{mg} . \mathrm{L}^{-1}$; Fengib $1 \mathrm{ml} . \mathrm{L}^{-1}$; Brassinolide 0.015 mg.L $\mathrm{L}^{-1} ; \mathrm{GA}_{3} 20 \mathrm{mg} . \mathrm{L}^{-1} ; 2,4-\mathrm{D} 8 \mathrm{mg} \cdot \mathrm{L}^{-1}$ and $\mathrm{GA}_{3} 20 \mathrm{mg} . \mathrm{L}^{-1}+2$,4-D 8 mg. $\mathrm{L}^{-1}$ on the fruit set of 'Tahiti' lime. The bioregulators didn't change the vegetative growth. The treatments with $\mathrm{GA}_{3}\left(\mathrm{GA}_{3} 20 \mathrm{mg} . \mathrm{L}^{-1}\right.$, Fengib $1 \mathrm{ml} . \mathrm{L}^{-1}$ e GA $20 \mathrm{mg} . \mathrm{L}^{-1}+$ 2,4-D $8 \mathrm{mg} . \mathrm{L}^{-1}$ ) increased the fruit set. The best treatment was $\mathrm{GA}_{3} 20 \mathrm{mg} \cdot \mathrm{L}^{-1}+2,4-\mathrm{D} 8$ mg. $\mathrm{L}^{-1}$ that promoted $21.3 \%$ of fruit set against $5.9 \%$ by control. The fruit set was coupled to increases in chlorophyll content and $\mathrm{CO}_{2}$ assimilation by leaves of 'Tahiti' lime. 


\section{INTRODUÇÃO}

Nos últimos anos com a instabilidade dos preços pagos pela indústria citrícola e com o aumento dos custos de produção, os produtores de citros têm necessitado, cada vez mais, de técnicas que permitam a redução de custos e o aumento de sua renda, uma vez que possuem a alternativa de produzirem frutos para consumo "in natura".

Uma opção seria o aumento de produção propriamente dito que proporcionará, consequentemente, um maior faturamento ao produtor. Uma outra seria a tentativa do deslocamento da época de produção para épocas em que há pouca oferta e os preços pagos pela fruta cítrica são bem elevados. Uma terceira seria a produção de frutas para mesa visando o mercado interno, que geralmente gera maiores preços que aqueles pagos pela indústria.

No caso de frutos para o consumo "in natura" o tamanho do fruto é um fator de grande importância, pois o consumidor paga melhores preços por frutos de maior tamanho, sendo que a variação no seu preço pode chegar em até 100\%. O aumento m tamanho dos frutos cítricos pode ser conseguido mediante a utilização de várias técnicas como o anelamento dos ramos, desbaste manual ou químico e através do uso de biorreguladores estimuladores do desenvolvimento dos frutos.

Um outro grande problema encontrado em alguns cultivares cítricos é a sua baixa capacidade de fixação dos frutos. O número de frutos cítricos raramente superam $10 \%$ do número de flores formadas, alcançando valores entre 0,1 e 3,5\% (Agustí et al., 1982; Monselise, 1986), sendo esta característica considerada como o principal fator que limita a produção em citros. Em cultivares que têm a habilidade de florescer em épocas anormais, como as limas, este fator é limitante quando se deseja obter maiores produções extemporâneas. A utilização de métodos como o anelamento de ramos e a 
aplicação de biorreguladores tem sido muito estudada visando a resolver este tipo de problema.

Dentre várias práticas, o uso de biorreguladores é uma técnica que tem sido usada para resolver problemas de obtenção de altas produções, produções extemporâneas e de frutos de maior qualidade, principalmente em relação aos frutos daqueles cultivares destinados ao consumo "in natura".

Em outros países citrícolas, como os Estados Unidos da América e a Espanha, os biorreguladores são muito utilizados e suas técnicas de uso são amplamente difundidas. Já no Brasil, o uso destes biorreguladores começa a ser empregado, porém em pequeno número, visto que possuímos uma grande carência de dados experimentais para os nossos cultivares e para as condições climáticas de nosso país.

O conhecimento das técnicas ideais de aplicação destas substâncias, bem como os efeitos sobre os parâmetros fisiológicos e de colheita são de fundamental importância para nossas condições edafoclimáticas, estabelecendo, deste modo, as melhores substâncias e os cultivares cítricos locais que possam ser submetidos à aplicação destes biorreguladores.

O objetivo deste trabalho foi avaliar o efeito da aplicação de vários biorreguladores sobre a fixação e o desenvolvimento dos frutos e processos fisiológicos relacionados no tangor 'Murcote' (Citrus reticulata Blanco x Citrus sinensis L. Osbeck) e na lima ácida 'Tahiti' (Citrus latifolia Tanaka). 


\section{REVISÃO DE LITERATURA}

\subsection{Desenvolvimento dos frutos cítricos}

O fruto cítrico é uma baga típica chamada hesperídio, onde se distinguem o pericarpo e as sementes. O pericarpo é a parte formada pelo exocarpo, mesocarpo e endocarpo. O exocarpo ou flavedo é a região mais externa e constitui a parte visível da casca, formada por células epidérmicas de cor verde, quando o fruto está imaturo, e de coloração laranja ou amarela quando o fruto está maturo. O mesocarpo ou albedo é a região situada logo abaixo do exocarpo, formado por um tecido branco e esponjoso constituído de células parenquimáticas e que, juntamente com o exocarpo, constitui a casca do fruto. O endocarpo é a porção mais interna do pericarpo e delimita tangencialmente os lóculos que estão repletos de vesículas de suco e delimitados radialmente por algumas membranas delgadas, formadas a partir da epiderme interna dos carpelos, denominadas septos (Agustí et al., 1995a).

Segundo Bain (1958) o desenvolvimento do fruto segue uma curva sigmóide, desde a antese até sua maturação, caracterizada por três períodos bem diferenciados.

A fase I ou período de crescimento exponencial começa na antese e estende-se até o final da queda fisiológica dos frutos, sendo caracterizada por um rápido crescimento do fruto provocado pela divisão celular, com consequente aumento do número de células em todos os tecidos em desenvolvimento, exceto do eixo central. $\mathrm{O}$ aumento do tamanho do fruto é dado, principalmente pelo crescimento da casca, em conseqüência de um aumento no volume do exocarpo através da divisão de suas células 
e também do aumento em volume do mesocarpo através do engrossamento de suas paredes celulares e do tecido vascular. Nessa fase ocorre também um aumento no volume do endocarpo, devido à divisão celular nos septos e nas paredes tangenciais dos lóculos e também ao engrossamento das células centrais dos septos e da alongação radial de suas células tangenciais.

A fase II ou período de crescimento linear se estende por vários meses, desde o final da queda fisiológica dos frutos até o início da sua mudança de cor. Ela se caracteriza por uma grande expansão dos tecidos, acompanhada por um extenso alongamento celular e da formação de um mesocarpo esponjoso, com ausência de divisão celular em quase todos os tecidos, exceto no exocarpo. $\mathrm{O}$ aumento em tamanho nesta fase se deve principalmente ao desenvolvimento dos lóculos, onde as vesículas de suco alcançam seu tamanho máximo e o conteúdo de suco em suas células se eleva.

A fase III ou período de maturação é caracterizada por uma reduzida taxa de crescimento e pelas mudanças que ocorrem no fruto devido a sua maturação. O pequeno incremento em tamanho se deve ao aumento dos segmentos de polpa, ao aumento em largura do eixo central e ao crescimento da casca. A pigmentação da casca é conseqüência da degradação enzimática e da síntese de carotenóides no exocarpo. Os conteúdos de sólidos solúveis, açúcares e compostos nitrogenados aumenta, e o de ácidos livres diminiu progressivamente em conseqüência de um processo de diluição.

Segundo Agustí \& Almela (1991), a causa do desenvolvimento do fruto é a acumulação de metabólitos pelo mesmo. Esta pode ser limitada pela incapacidade do fruto em acumulá- los ou pela sua falta de disponibilidade na própria planta. Estes fatores se encontram intimamente relacionados e a modificação de um deles afeta o outro, atuando sobre a acumulação de metabólitos e sobre a força de dreno, podendo causar o aumento no tamanho do fruto.

Em condições ótimas de cultivo é possível conseguir um aumento no tamanho do fruto mediante a manipulação da planta, modificando suas relações nutricionais endógenas assim como a sua distribuição (Agustí et al., 1995a). Isso pode ser conseguido através de duas formas: 
a) do desbaste dos frutos, aumentando a disponibilidade de metabólitos para os frutos remanescentes, através de uma redução no número de frutos por planta e, portanto, da competição entre os órgãos em desenvolvimento.

b) Incrementando a capacidade do fruto para crescer, modificando em um sentido favorável o equilíbrio hormonal do mesmo.

\subsubsection{Desbaste dos frutos cítricos}

O número de frutos em uma árvore, juntamente com seu peso individual, são os parâmetros básicos que determinam a colheita. $\mathrm{O}$ tamanho dos frutos é um fator que está inversamente relacionado com o número de frutos colhidos por árvore (Goldschimdt \& Monselise, 1977).

A redução no número de frutos, ou desbaste, realizado de forma manual ou química, é uma das técnicas mais aplicadas em todo o mundo visando o aumento do tamanho final do fruto em diversas espécies (Agustí et al., 1995a).

O desbaste químico é uma prática que tem-se mostrado muito eficaz para produzir frutos de alta qualidade e reduzir a alternância de colheitas em vários países como Japão, Austrália e E.U.A. (Agustí et al., 1995a). Dentre as substâncias com poder desbastante, merecem destaque o ácido 2-cloroetil fosfônico (ethephon) e as auxinas ácido etil-5-cloro-1H-indazol-3-acético (etilclozate, Figaron) e ácido naftalenacético (NAA).

Zaragoza et al. $(1990 ; 1992)$ consideraram que o desbaste realizado em plena floração não tem efeito algum, pois a eliminação de algumas flores favorece a fixação do fruto em outras e o número final de frutos permanece constante; que para efeitos consideráveis no aumento de tamanho, deve-se eliminar pelo menos entre 50 a $60 \%$ dos frutos de uma árvore, sempre logo após o final da queda fisiológica dos frutos; e que quando se tem um aumento significativo no tamanho dos frutos, o desbaste causa uma forte diminuição na produção final. 
A ação destes biorreguladores está associada com sua ação sobre a síntese de etileno no fruto tratado. O ethephon libera etileno em contato com o tecido vegetal, já as auxinas quando em elevadas concentrações promovem a síntese de etileno. Nos frutos jovens tratados com estas substâncias, formam-se grandes espaços aéreos entre a parede celular e a membrana protoplasmática das células da zona procambial. A membrana então se deteriora e desaparece e o citoplasma se dispersa. Durante este processo a parede celular se encontra extremamente delgada, e, no período de formação da camada de abscisão, ocorre a autólise das células degeneradas da zona procambial. A atividade celulásica causa a ruptura e a dissolução da parede das células da camada procambial e também inibe a síntese de auxinas o que retardará a diferenciação e a formação dos feixes vasculares, o que favorece a formação da camada de abscisão, impedindo a conexão dos feixes vasculares do lado do fruto e do lado do pedúnculo, provocando a queda do fruto (Iwahori, 1978; Hirose, 1981).

A abscisão dos frutos, em um estágio mais avançado de desenvolvimento, induzida pelo etileno é muito parecida com a abscisão foliar. No início ocorre a diminuição na quantidade de auxina transportada do fruto para o pecíolo. A diminuição de auxinas no pecíolo induz a formação da camada de abscisão, constituída de células pequenas, com feixe vascular reduzido e mecanicamente fracas, localizadas na base do pecíolo. A queda no nível de auxinas no pecíolo aumenta aparentemente a sensibilidade das células da camada de abscisão à ação do etileno que induz a síntese e o transporte de enzimas que atuam sobre a lamela média (pectinases) e a parede celular (celulases). A dissolução total ou parcial da lamela média e da parede celular torna a camada de abscisão ainda mais enfraquecida do ponto de vista mecânico, bastando um vento moderado para provocar a quebra dos feixes vasculares e completar a separação do pecíolo e do fruto do resto da planta (Awad \& Castro, 1983).

O desbaste químico dos frutos não é um processo que ocorre aleatoriamente, pois age seletivamente sobre os frutinhos menores que darão origem aos frutos de menor tamanho, sendo que sua eliminação aumenta o peso médio dos frutos colhidos embora não tenha efeito algum sobre o tamanho dos frutos remanescentes. (Kamuro \& Hirai, 1981). 
O éster etílico do ácido 5-cloroindazol-8-acético (etilclozate; Figaron) é uma auxina sintética estimuladora da síntese de etileno recomendada em outros países nas concentrações de 100 a $200 \mathrm{mg} \cdot \mathrm{L}^{-1}$ para a prática do desbaste, podendo ser aplicada desde após a antese até ao final da queda fisiológica dos frutos (Hirose et al., 1978; Iwahori, 1978; Hirose, 1981). Esse biorregulador pode adiantar a maturação dos frutos, aumentando o teor de sólidos solúveis totais e a coloração dos frutos (Hirose et al., 1978; Kamuro \& Hirai, 1981; Iwaho ri et al., 1986; Li et al., 1990).

Li et al. (1990) avaliaram o efeito do etilclozate em concentrações entre 50 e 400 mg. $\mathrm{L}^{-1} \mathrm{em}$ tangerina 'Bendizau' em diferentes épocas de aplicação (30, 60 e 80 dias após o florescimento). Aos 30 dias após o florescimento, a porcentagem de desbaste aumentou com a concentração, proporcionou uma maior coloração e aumentou o brix e a acidez dos frutos. Aumentos no teor de brix e no índice de coloração também foram obtidos por outros autores (Hirose et al., 1978; Kamuro \& Hirai, 1981; Iwahori et al., 1986; Pons et al., 1989).

O ácido 2-cloroetilfosfônico (ethephon) é um biorregulador que libera etileno em contato com o tecido vegetal com o qual um grande número de trabalhos foram desenvolvidos visando a prática do desbaste (Sanches, 2000).

Chapman (1984) obteve quedas de $42 \%$ e 63,6\% de frutos nas doses de 150 e $300 \mathrm{mg} . \mathrm{L}^{-1}$, respectivamente, em tangor 'Murcote'. As aplicações promoveram um aumento no tamanho dos frutos e evitaram a alternância de produção do ano seguinte.

\subsubsection{Auxinas estimuladoras do desenvolvimento dos frutos}

$\mathrm{O}$ grupo de reguladores vegetais em que se encontram as substâncias mais eficazes para aumentar o tamanho final do fruto é o das auxinas. Todas elas, sem exceção, pertencem às chamadas auxinas de síntese. São substâncias obtidas sinteticamente e que aplicadas às plantas, têm atividade auxínica, pertencendo a maior parte ao grupo dos fenoxiácidos (Agustí \& Almela, 1991). 
Segundo Guardiola et al. (1987, 1988) e Ortolá et al. (1991), o efeito da aplicação de auxinas de síntese sobre o tamanho do fruto é o resultado de, pelo menos, três efeitos independentes: a) um estímulo à abscisão dos frutinhos, o que causa uma redução na competição entre os frutos; b) uma redução transitória da taxa de crescimento dos frutinhos pouco depois do tratamento, causa provável de sua abscisão; c) um estímulo posterior em seu desenvolvimento, devido a uma ação direta sobre o fruto, aumentando sua capacidade para atuar como dreno preferencial.

Dependendo do cultivar, da natureza e da concentração da auxina, as aplicações podem ser realizadas após a queda das pétalas (antese) ou após a queda fisológica dos frutos (Guardiola, 2000).

\subsubsection{Auxinas aplicadas após a queda fisiológica dos frutos}

Várias auxinas sintéticas aplicadas às árvores promovem o desbaste dos frutos. Esta prática que é realizada com a finalidade de produzir frutos de alta qualidade, também reduz a colheita dos mesmos o que pode ser indesejável em várias situações. Para contornar tal problema têm sido realizados alguns experimentos com a finalidade de se avaliar apenas o efeito estimulatório de algumas auxinas. Dentre estas auxinas sintéticas têm-se encontrado excelentes resultados em experimentos realizados com o ácido 2,4-diclorofenoxipropiônico (2,4-DP), ácido 3,5,6-tricloro-2-piridil-oxiacético (3,5,6-TPA) e com o tioéster etílico do ácido 4-cloro-o-tolioxiacético (fenotiol), em algumas regiões citrícolas do mundo (Agustí et al., 1995a).

No caso destas auxinas, a época de aplicação é um fator chave na obtenção de sua resposta. As aplicações devem ser realizadas logo após o final da queda fisiológica dos frutos (Vanniere \& Arcuset, 1989; Agustí et al., 1992; 1993a; 1993b; 1998; Almela et al., 1991). Neste estágio de desenvolvimento ocorre a paralisação da divisão celular,

quando as vesículas ocupam completamente os lóculos e suas células iniciam o crescimento e a acumulação de suco. 
O efeito das auxinas sobre o desenvolvimento dos frutos se dá através de um crescimento generalizado de todos os tecidos do fruto. Somente a polpa é afetada diretamente pela ação da auxina, sendo que o conteúdo de suco e o peso da casca dependem do tamanho do fruto e do tipo de tratamento (ElOtmani et al., 1993). A aplicação de auxinas promove um aumento no tamanho dos lóculos e das vesículas de suco. Como conseqüência deste efeito o fruto aumenta sua capacidade para acumular suco e cresce em maior velocidade. Ocorre ainda um incremento no diâmetro do pedúnculo do fruto, o que indica um incremento na capacidade de dreno do fruto, estimulando o transporte de água e nutrientes, satisfazendo desta forma a alongação celular e aumentando, portanto, seu tamanho. Um atraso em sua época de aplicação promove uma diminuição na resposta, indicando que a capacidade de alongação celular diminui com o tempo e que necessita de uma maior concentração de auxina para se obter a mesma resposta. (Agustí et al., 1991; 1992; 1993b; El-Otmani et al., 1993).

$\mathrm{O}$ ácido 3,5,6-tricloro-2-piridil-oxiacético (3,5,6-TPA) é uma auxina sintética que, em sua formulação ácido livre, tem-se tem mostrado como um grande promotor do desenvolvimento dos frutos cítricos, com desbastes moderados dependentes da época de aplicação e concentração (Agustí et al., 1993b; 1994b; Garcia-Lidón et al., 1993a; 1993b; Zaragoza et al., 1992). A aplicação de 3,5,6-TPA a concentrações entre 10 e 15 $\mathrm{mg} . \mathrm{L}^{-1}$ no final da queda fisiológica dos frutos aumenta, em termos gerais, o tamanho médio dos frutos entre 5\% e 15\%, dependendo do cultivar. Um aumento na concentração para $25 \mathrm{mg} . \mathrm{L}^{-1}$ não tem melhorado a eficácia da resposta (Agustí et al., 1993b).

Agustí et al. (1995b) avaliaram o efeito do 3,5,6-TPA sobre frutos de tangerina 'Clementina'. Foram testadas doses entre 0 a $25 \mathrm{mg} \cdot \mathrm{L}^{-1}$ aplicadas durante e após a queda fisiológica dos frutos, com 11 e $17 \mathrm{~mm}$ de diâmetro, respectivamente. A aplicação de 3,5,6-TPA aumentou significamente o tamanho final dos frutos, dependendo da época e concentrações aplicadas. Aumentos de $8 \mathrm{~mm}$ foram conseguidos com a concentração de $20 \mathrm{mg} . \mathrm{L}^{-1}$ durante a queda fisiológica dos frutos. Retardando-se a aplicação, observou-se um efeito depressivo sobre o desenvolvimento dos frutos. O desbaste dos frutos cresce linearmente com o aumento das concentrações até $20 \mathrm{mg} . \mathrm{L}^{-1}$, com efeito mais marcante durante a primeira época de aplicação, porém sem alcançar diferenças significativas na 
colheita. Houve uma grande diminuição no número de frutos sem padrão comercial (<45 $\mathrm{mm}$ ) e um grande aumento no número de frutos com diâmetros comerciais superiores. A porcentagem de suco e a acidez foram aumentadas significamente, ao contrário dos teores de brix e ratio que não apresentaram diferenças significativas.

A formulação éster butilglicólica do ácido 2,4-diclorofenoxipropiônico (2,4-DP) tem-se mostrado muito eficaz para aumentar o tamanho final dos frutos cítricos (Agustí et al., 1992). Este fenoxiácido tem sido utilizado com muitos bons resultados na Espanha e em outras áreas citrícolas mediterrâneas desde que foi registrado para este uso (Vanniere \& Arcuset, 1989; Agustí et al., 1991).

Aumentos entre $5 \%$ a $10 \%$ no tamanho final dos frutos também têm sido observados quando se aplica doses de 50 a $75 \mathrm{mg} . \mathrm{L}^{-1}$ no final da queda fisiológica dos frutos de tangerina 'Clementina' (Vanniere \& Arcuset, 1989; 1992 Agustí et al., 1991).

A resposta da aplicação do 2,4-DP é linearmente crescente com a sua concentração, com até $100 \mathrm{mg} . \mathrm{L}^{-1}$, para a tangerina 'Clementina Fina' (Agustí et al., 1991; 1992). Já em outros cultivares ocorre um efeito da saturação do produto, necessitando de concentrações menores, entre 50 a $75 \mathrm{mg} . \mathrm{L}^{-1}$, como ocorre nas tangerinas 'Fortune' e 'Satsuma'.

Agustí et al. (1994a) avaliaram o efeito do 2,4-DP sobre o tamanho e qualidade final dos frutos da tangerina 'Satsuma'. O biorregulador foi aplicado nas concentrações de 0 a $100 \mathrm{mg} \cdot \mathrm{L}^{-1}$, após a queda fisiológica dos frutos, com aproximadamente $25 \mathrm{~mm}$ de diâmetro. Houve um aumento significativo de 4 a $5 \mathrm{~mm}$ no diâmetro dos frutos aplicando-se doses entre 50 e $100 \mathrm{mg} . \mathrm{L}^{-1}$. Em doses maiores que $75 \mathrm{mg} . \mathrm{L}^{-1}$ observou-se um desbaste dos frutos, porém sem alcançar diferenças significativas na colheita. Aplicando-se o produto com 20 dias de atraso, quando os frutos possuíam em torno de $30 \mathrm{~mm}$ de diâmetro, a resposta foi marcadamente diminuída, podendo ser recompensada, parcialmente, com o aumento da dosagem. A aplicação do 2,4-DP também contribuiu para o aumento do teor de suco e para a diminuição da quantidade de casca. As características de brix e acidez não foram afetadas.

Almela et al. (1993) aplicando o tioéster etílico do ácido 4-cloro- $O$-tolioxiacético (fenotiol) em concentrações de 10 a $30 \mathrm{mg} \cdot \mathrm{L}^{-1}$ durante o final da queda fisiológica dos 
frutinhos de tangerina 'Clementina' conseguiram um aumento em torno de 5\% no diâmetro médio final dos frutos.

Aznar et al. (1995b) conseguiram aumentos de aproximadamente $10 \%$ no peso médio de frutos de tangerina 'Fortune', sem ocorrer redução no número de frutos por árvore.

Aumentos entre 2 e $3,5 \mathrm{~mm}$ foram conseguidos no diâmetro médio dos frutos da tangerina 'Fortune' com a aplicação de 10 a $20 \mathrm{mg} . \mathrm{L}^{-1}$ de fenotiol sem ocorrer desbaste dos frutos, porém sem incremento significativo na colheita (Agustí et al., 1993a). Aumentando-se a concentração para $30 \mathrm{mg} . \mathrm{L}^{-1}$, houve um desbaste de $25 \%$ dos frutinhos, porém sem afetar a colheita, devido ao aumento do peso individual dos frutos. Neste mesmo experimento, verificando-se a época de aplicação, observou-se que uma antecipação na época de aplicação provoca um aumento no número de frutos desbastados. Quando se aplicou o fenotiol em frutos de tangerina 'Clementina' com 10 mm de diâmetro, quando o normal é de 15 a 20 mm, houve uma abscisão de $20 \%$ e de mais de $30 \%$ dos frutos das árvores tratadas com 20 e $30 \mathrm{mg} \cdot \mathrm{L}^{-1}$ e com uma redução na colheita de 70 kg/árvore para 64 e 60 kg/árvore, respectivamente. De modo contrário, um atraso na época de aplicação diminui fortemente a resposta (Agustí et al., 1993a).

\subsubsection{Auxinas aplicadas após a antese}

Segundo Guardiola \& Garcia-Luis (1997; 2000) a aplicação de auxinas sintéticas, após a queda fisiológica dos frutos, exige grande experiência e agilidade em sua execução, já que o período ideal de resposta é curto. Uma antecipação pode causar um desbaste excessivo dos frutos e, por outro lado, um atraso pode causar uma diminuição na resposta ao aumento em tamanho do fruto.

Aplicações de auxinas sintéticas em pleno florescimento ou semanas após, são de mais fácil execução do que aquelas realizadas após a queda fisiológica dos frutos. Há uma maior facilidade na identificação da época de aplicação e há um maior período de 
tempo para a aplicação, já que, resultados positivos são conseguidos com aplicações realizadas até 6 a 8 semanas após a antese (Guardiola \& Garcia-Luis, 2000).

Aplicações de auxinas sintéticas no florescimento ou algumas semanas após este, promovem um efeito significativo na força de dreno do fruto. Quando se aplicam auxinas que não promovem a síntese de etileno, como o ácido 2,4-diclorofenoxiacético (2,4-D), em baixas concentrações, se obtém um aumento na velocidade de crescimento inicial do fruto, sem provocar desbaste algum (Ortolá et al., 1997).

Em tangerina 'Clementina Esbal', a aplicação de 2,4-D (17-20 mg. $\left.\mathrm{L}^{-1}\right)$, durante o florescimento, aumenta a taxa de crescimento dos frutos e atrasa sua abscisão. Ocorre um aumento no tamanho médio dos frutos e o número de frutos colhidos não é afetado. Respostas positivas com aplicações em até 6 semanas após o florescimento são conseguidas, embora um pouco inferiores (Duarte et al., 1996).

Nas laranjeiras 'Shamouti' e 'Valência', aplicações de 2,4-D 20 mg. $\mathrm{L}^{-1}$ aumentam tanto o tamanho como a fixação dos frutos em aplicações realizadas entre 6 a 8 semanas após o florescimento. No entanto, aplicações realizadas em pleno florescimento não são eficientes (Erner et al., 1993).

O 2,4-D aumenta o tamanho do fruto independentemente do número de flores da árvore, porém, quando o número de flores é elevado, ocorre uma diminuição no número de frutos colhidos (Guardiola \& García-Luis, 1997).

O fenotiol é uma auxina sintética que, aplicada, em concentrações de 10 a 30 $\mathrm{mg} . \mathrm{L}^{-1}$, após a queda fisiológica dos frutos, promove aumentos significativos, em torno de 5\%, no diâmetro médio dos frutos de diversos cultivares de laranjas, tangerinas e seus híbridos, com efeitos variáveis sobre o desbaste (Agustí et al., 1993a; Almela et al., 1993). No entanto resultados semelhantes têm sido obtidos com fenotiol 15 mg. $\mathrm{L}^{-1} \mathrm{e}$ com Fengib (fenotiol 1\% $+\mathrm{GA}_{3} 5 \%$ ) 0,75 $\mathrm{ml} \cdot \mathrm{L}^{-1}$, sem nenhum efeito no número de frutos colhidos em laranja 'Navelina', em aplicações realizadas após a queda das pétalas (Agustí et al., 1996). O Fengib aplicado na dose de 0,75 ml. $\mathrm{L}^{-1}$, durante o pleno florescimento, em tangerina 'Clementina', também provoca um pequeno aumento no tamanho dos frutos, mas em termos de colheita, seu efeito é inconsistente (ElOtmani et al., 1994). 


\subsection{Fixação dos frutos cítricos}

A fixação ou pegamento dos frutos é o fator central que determina a colheita dos citros (Agustí \& Almela, 1991). Esta se acha diretamente relacionada com o número de frutos coletados, sendo que a sua multiplicação pelo peso individual dos frutos determina sua quantia final. $\mathrm{O}$ número de frutos colhidos raramente supera $10 \%$ das flores formadas, alcançando valores entre 0,5 \% e 3,5\% (Agusti et al., 1982; Monselise, 1986). A abscisão de flores e frutos que ocorre logo após o florescimento é resultado, principalmente, da competição destes por água, carboidratos e outros metabólitos, sendo este processo também regulado pelo balanço hormonal da planta (Powell \& Krezdorn, 1977). Segundo Primo-Millo (1993), os fatores que condicionam a fixação dos frutos são a disponibilidade de nutrientes, a disponibilidade hídrica e os níveis hormonais. Segundo Zucconi et al. (1978), todos os fatores que estimulam o crescimento inicial do ovário aumentam a fixação dos frutos. Cultivares sem sementes estão mais sujeitos à queda dos frutos, se ocorrerem variações de temperatura ou qualquer outro tipo de estresse durante ou depois da queda natural dos frutinhos (El-Otmani, 1992). A maior fixação de frutos dos cultivares com sementes provavelmente possa estar relacionado com um maior nível de giberelinas endógenas existente nestes cultivares.

Segundo Talón (1997), deficiências no suprimento de carboidratos assim como um período de déficit hídrico elevam os níveis de ácido abscísico (ABA) que aumenta a síntese do ácido 1-carboxílico 1-amino ciclopropano, precursor do etileno, que posteriormente provocará a abscisão dos frutos cítricos em desenvolvimento.

O envolvimento de hormônios endógenos na capacidade de fixar frutos partenocárpicos já foi demonstrado há cinqüenta anos atrás e confirmado recentemente através de modernas técnicas de análises hormonais. Aumentos significantes são conseguidos através da aplicação de vários biorreguladores (auxinas, giberelinas e citocininas), sendo que o ácido giberélico tem proporcionado os melhores resultados em citros (Guardiola, 1992). 


\subsubsection{Giberelinas e a fixação dos frutos cítricos}

O aumento da concentração de giberelinas nos ovários em desenvolvimento, durante a antese, forma parte do estímulo hormonal que ativa a divisão celular e propicia a fixação do fruto (Talón et al., 1990b). Essas substâncias de crescimento aumentam a capacidade de dreno do fruto por fotoassimilados e minerais. $\mathrm{O}$ aumento na fixação dos frutos devido à aplicação de giberelinas está melhor elucidado para algumas tangerinas e seus híbridos. No caso das laranjas, no entanto, nem sempre os resultados são satisfatórios (Guardiola, 1992).

As giberelinas são substâncias promotoras de crescimento, responsáveis pelo aumento da fixação dos frutos, em vista do aumento da capacidade de dreno por fotoassimilados e minerais (Monselise, 1977; Talón, 1997; Talón et al., 1997).

Segundo Zacarias et al. (1995) as giberelinas suprimem totalmente a elevação dos níveis de ácido abscísico (ABA) após a antese, evitando a produção de etileno e, consequentemente, a abscisão dos frutos.

A época mais adequada para a aplicação de giberelinas ocorre durante a antese e a queda das pétalas, quando os níveis endógenos de giberelinas estão baixos. (Agustí \& Almela, 1991; Talón, 1997). Na maioria dos casos, as giberelinas provocam ao mesmo tempo uma diminuição no tamanho e peso médio dos frutos, em consequiência do aumento de frutos fixados e da maior competição por fotoassimilados.

Quando o ácido giberélico $\left(\mathrm{GA}_{3}\right)$ é pulverizado por toda a extensão da planta, durante a queda das pétalas, ocorre um aumento na fixação dos frutos, principalmente na tangerina 'Clementina' e em seus híbridos, podendo ocorrer uma ligeira diminuição no

diâmetro dos frutos, como conseqüência do aumento do número de frutos fixados (Talón, 1997).

Estudos realizados com ${ }^{14} \mathrm{C}$ mostram que ocorre um aumento na força de dreno dos frutos por fotoassimilados, aumentando a porcentagem de frutos fixados (Monselise \& Goldschimdt, 1982). 
A resposta à aplicação de $\mathrm{GA}_{3}$ varia de acordo com a produtividade da parcela ou do pomar, sendo que ocorrem maiores aumentos na fixação dos frutos em parcelas de baixa produtividade (Talón, 1997).

Concentrações entre 10 e $20 \mathrm{mg} \cdot \mathrm{L}^{-1}$ de $\mathrm{GA}_{3}$ são as mais utilizadas, porém as respostas a estas aplicações não apresentam uniformidade e dependem do cultivar, sendo que em geral as tangerineiras, com exceção da 'Satsuma', são as que melhor respondem a esta aplicação (Castro, 1998).

Segundo Talón (1997) o ácido giberélico não aumenta a fixação dos frutos das variedades de tangerina 'Satsuma' ('Owari' , 'Okitsu', 'Clausellina'), dos híbridos 'Fortune' e 'Nova' e das laranjas, com exceção da cultivar Navelate.

Spósito (1999) testou várias concentrações (10; 25; 50 e 100 mg.L.-1) de ácido giberélico aplicadas durante uma florada extemporânea (março) de lima ácida 'Tahiti' e observou que as concentrações mínimas de $10 \mathrm{mg} \cdot \mathrm{L}^{-1}$ são suficientes para promover a fixação de $12,72 \%$ dos frutos que foi 25 vezes superior ao controle que promoveu apenas $0,46 \%$ de fixação dos frutos.

Segundo Guardiola (1987) as aplicações de ácido giberélico resultam em uma diminuição no tamanho dos frutos, devido a uma maior competição por fotoassimilados provocada pelo aumento do número de frutos fixados. Alguns trabalhos relatam que este biorregulador estimula o crescimento dos frutos quando aplicado em parcelas de baixa produtividade (Van-Rensburg et al., 1996; García Martinez \& García Papi, 1979).

A diversidade de respostas, é decorrente da interação do ácido giberélico com outros hormônios vegetais, dependendo do momento e concentração com que esse biorregulador é aplicado (López, 1993), sendo que a fixação dos frutos ocorre, principalmente, em cultivares que apresentam baixas concentrações de giberelinas endógenas (Talón et al., 1992).

\subsubsection{Auxinas e a fixação dos frutos cítricos}


As auxinas são substâncias preferencialmente promotoras da alongação celular em vez da divisão celular. Embora a concentração endógena de auxinas aumente nos ovários após a antese, aplicações exógenas de auxinas geralmente não aumentam a fixação do fruto em citros (Talón et al., 1997). As concentrações de auxinas são também elevadas durante a fase II, período de alongação celular, sendo neste momento que as aplicações exógenas de auxinas sintéticas são efetivas no aumento do tamanho do fruto (Coggins \& Hield, 1968).

As auxinas podem atuar como agentes aceleradores da abscisão dos frutos. Durante as fases iniciais são consideradas como inibidores, mas uma vez iniciado o processo, as auxinas estimulam a abscisão, devido ao seu papel no estímulo da síntese de etileno. Nos citros, as auxinas sintéticas podem atuar como agentes desbastantes durante a fase de divisão celular ou fase I (Talón et al., 1997).

Talón et al. (1990) consideraram que a baixa capacidade de fixação de frutos partenocárpicos parece estar relacionada com os baixos níveis de giberelinas, com uma grande habilidade em ligar IAA (ácido indolilacético) e a uma baixa capacidade de catabolizar ABA (ácido abscísico) livre para ABA conjugado.

Embora estejam mais relacionadas com o aumento do crescimento do fruto, alguns trabalhos têm relatado que algumas auxinas têm sido efetivas na promoção da fixação dos frutos cítricos.

Para as auxinas sintéticas, na maioria das vezes, não se tem encontrado resultados tão claros como aqueles observados para o ácido giberélico (Wilson, 1983; Guardiola, 1992). Segundo vários autores, a aplicação de 2,4-D tanto em laranjas como em tangerinas não tem gerado bons resultados (Soost \& Burnet, 1961; Krezdorn, 1969; Rivero et al., 1969) assim como a de 2,4,5-T (ácido 2,4,5-triclorofenoxiacético) que aumenta o tamanho final do fruto, porém sem aumento no número de frutos colhidos (Rivero et al., 1969; Cuñat et al., 1974).

Por outro lado, alguns trabalhos têm demonstrado efeitos benéficos das auxinas sobre a fixação dos frutos cítricos. Segundo Wilson (1983), alguns trabalhos realizados na Índia relatam o aumento da fixação dos frutos com a aplicação de 2,4-D (5 a 20 mg.L' ${ }^{1}$ ), PPA (25-100 mg. $\left.\mathrm{L}^{-1}\right)$ e 2,4,5- T (5-10 mg.. $\left.\mathrm{L}^{-1}\right)$. Lima \& Davies (1984) observaram um 
aumento da fixação dos frutos no cultivar 'Washington Navel' com a aplicação de 2,4-D

(10 e $20 \mathrm{mg} . \mathrm{L}^{-1}$ ), porém sem aumento no número final de frutos colhidos, devido a uma maior incidência de frutos rachados e também a uma queda acentuada dos frutos no final do verão.

Agustí et al. (1996) conseguiram aumentos na fixação dos frutos de laranja 'Navelina' com a aplicação de fenotiol $\left(15 \mathrm{mg} \cdot \mathrm{L}^{-1}\right)$, isolado ou em mistura com $\mathrm{GA}_{3}$ (Fengib a $0,15 \%$ ) durante a queda das pétalas.

Aumentos benéficos na quantidade final de frutos fixados na laranja 'Monte Parnaso' foram obtidos com a aplicação de 2,4-D (15 mg. $\left.\mathrm{L}^{-1}\right)$ adicionado a $\mathrm{GA}_{3}$ (5 $\mathrm{mg} . \mathrm{L}^{-1}$ ) logo após a antese ou isolado após a queda natural dos frutos (Koller et al., 1999).

O Brassinolide é um novo biorregulador cujos efeitos ainda não foram totalmente estudados. Em muitos ensaios, tem sido demonstrado que este biorregulador tem efeitos similares ao das auxinas e que geralmente mostra sinergismo com as mesmas (Mandava, 1988).

Aplicações de Brassinolide 0,01 e 0,1 mg. $\mathrm{L}^{-1}$ aumentaram a fixação dos frutos da laranja 'Morita Navel' cultivada sob estufa. No entanto, em condições de campo, somente a concentração de $0,1 \mathrm{mg} \cdot \mathrm{L}^{-1}$ foi eficaz, aumentando o número de frutos colhidos (Sugiyama \& Kuraishi, 1989).

A diferença na resposta às aplicações exógenas de auxinas se devem ao tipo de tratamento, época, cultivar e concentração, e por este motivo, não se tem permitido o desenvolvimento de técnicas práticas visando o aumento da fixação dos frutos com a utilização destas substâncias (Agustí \& Almela, 1991).

\subsection{Biorreguladores e trocas gasosas}

As folhas dos citros são caracterizadas por sua pequena espessura, por ter uma camada de cera na superfície adaxial e pela presença de estômatos na superfície abaxial. Os estômatos têm um papel fundamental nas taxas de perda de água e aquisição de $\mathrm{CO}_{2}$ 
pelas folhas. Eles realizam a regulação das trocas de gases e previnem o desenvolvimento de déficits hídricos foliares. Os estômatos são influenciados por um grande número de fatores ambientais como irradiação, concentração de $\mathrm{CO}_{2}$, umidade, temperatura e hormônios (Syversten \& Lloyd, 1994).

Vários experimentos nas décadas de 40 e 50, utilizando auxinas sintéticas, já demonstravam efeitos sobre os estômatos, e alguns trabalhos mostraram que o ácido naftalenacético (NAA) e o ácido naftaloxiacético (NOXA) causavam a abertura estomática. As auxinas naturais, como o ácido indolilacético (IAA), também têm efeito sobre os estômatos, embora os mesmos não sejam semelhantes àqueles causados pelas auxinas sintéticas (Mansfield \& McAinsh, 1995). Pemadasa (1982) mostrou que aplicações exógenas de IAA causaram aumento da abertura dos estômatos adaxiais, porém sem nenhum efeito sobre os estômatos abaxiais de folhas de espécies herbáceas. Entretanto, quando a abertura dos estômatos abaxiais foi restringida pela redução do suprimento de $\mathrm{K}^{+}$no meio usado para incubação, o IAA aumentou a abertura estomática.

Há também uma grande interação entre o IAA e o $\mathrm{CO}_{2}$ no processo de abertura estomática. Os estômatos normalmente se fecham quando a concentração de $\mathrm{CO}_{2}$ se eleva nas proximidades das células-guarda, porém a expressão desta resposta pode ser dependente da concentração de IAA. Altas concentrações de IAA reduzem o fechamento estomático devido a altas concentrações de $\mathrm{CO}_{2}$, porém o fechamento ocorre novamente com a adição de ácido abscísico (Snaith \& Mainsfield, 1982).

As substâncias químicas que causam mudanças sobre a abertura estomática devem também afetar a taxa de assimilação de $\mathrm{CO}_{2}$ das folhas. $\mathrm{O}$ ácido indolilacético pode estimular a taxa de assimilação de $\mathrm{CO}_{2}$, provavelmente pelo incremento em conjunto da taxa de transporte de elétrons e da fosforilação (Tamas et al., 1974).

Sharma et al. (1990) observaram aumentos na taxa de fotossíntese líquida e na atividade da ribulose 1,5-bifosfato carboxilase (RuBPCase) com a aplicação de ácido indolilacético (20 mg.L ${ }^{-1}$ ) em plantas envasadas de limão cultivar Pant Lemon-1.

Vários trabalhos indicam que as giberelinas também são consideradas como promotoras da fotossíntese. Aplicações de giberelinas estimulam a fotossíntese quando aplicadas em plantas intactas (Arteca \& Dong, 1981). A remoção de frutos em uva 
reduzem a taxa fotossintética das folhas, efeito este associado com o decréscimo de giberelinas nas folhas de plantas onde os frutos foram retirados (Hoad et al., 1977).

Vários trabalhos com citros têm sugerido um possível envolvimento das giberelinas na regulação da acumulação de carboidratos nas folhas (Martinez-Cortina et al., 1989). O aumento dos níveis de carboidratos nas inflorescências e nas folhas cítricas tratadas com $\mathrm{GA}_{3}$ pode ser devido a um aumento da capacidade fotossintética das folhas ou uma a modificação do modelo da distribuição de assimilados na planta (MartinezCortina \& Sanz, 1991). Aplicações de Paclobutrazol, um inibidor da síntese de giberelinas, além de causar uma diminuição na área foliar e na altura das plantas, promovem uma redução na taxa fotossintética em plantas de laranja 'Valência' (Vu \& Yelenosky, 1992).

Há vários trabalhos mostrando que a fixação de carbono pode ser modulada pela demanda de assimilados pelo fruto em crescimento em várias espécies (Tung et al., 1973; DeJong, 1986; Plaut et al., 1987; Wood, 1988) assim como através de aplicações de ácido giberélico (Treharne \& Stoddart, 1968; Broughton et al., 1970; Popova et al., 1987).

Muitos trabalhos têm demonstrado que o ácido giberélico $\left(\mathrm{GA}_{3}\right)$ não tem nenhum efeito sobre a taxa de fotossíntese líquida (Arteca et al., 1985; Harrell \& Williams, 1987; Roper \& Williams, 1989). No trabalho de Martinez-Cortina \& Sanz (1991), aplicações de ácido giberélico (25 mg. $\left.\mathrm{L}^{-1}\right)$ durante a antese em citros, aumentaram o conteúdo de carboidratos nas folhas, porém sem nenhuma relação com o capacidade fotossintética, já que a atividade da RuBPCase foi similar às folhas que não apresentaram aumento no conteúdo de carboidratos. Sharma et al. (1990) observaram que aplicações de $\mathrm{GA}_{3}\left(20 \mathrm{mg} . \mathrm{L}^{-1}\right)$ em plantas envasadas de limão cultivar Pant Lemon1 causam um decréscimo na taxa de fotossíntese líquida e na atividade da RuBPCase.

O etileno é considerado um inibidor da fotossíntese, mas acredita-se que este efeito possa ser devido aos aumentos nos níveis de ácido abscísico (ABA) que causariam o fechamento estomático (Matsushima \& Yonemori, 1981). 
As mudanças nos níveis hormonais que acarretam ajustamentos estomáticos por longos períodos podem ser desejáveis para o controle fotossintético do mesofilo, principalmente em condições de estresse hídrico (Mansfield \& McAinsh, 1995).

\subsection{Fotossíntese e a sua relação com a demanda por carboidratos nos citros}

Vários estudos em plantas com órgãos de grande capacidade de dreno e com a manipulação destes, têm proposto que a força de dreno é um importante fator na manutenção de elevadas taxas fotossintéticas em plantas expostas a ambientes enriquecidos com $\mathrm{CO}_{2}$ (Bowes, 1993).

As árvores cítricas possuem relativamente baixas taxas de fotossíntese. Os estudos com enriquecimento com $\mathrm{CO}_{2}$ mostram que a fotossíntese e a produção de fotoassimilados influem fortemente na produção vegetativa e na produção de frutos (Syversten \& Lloyd, 1994).

Em citros, o movimento do carbono das folhas se dá em direção ao fruto mais próximo. A importação de carbono pelo fruto jovem é relativamente baixa, sendo que a máxima demanda por carboidratos ocorre em frutos maturos, anteriormente à colheita. (Syversten \& Lloyd, 1994).

Em plantas cítricas envasadas, a demanda de carbono pelo fruto e por novos fluxos vegetativos de crescimento, seguidos da remoção das brotações, pode aumentar a fotossíntese (Lenz, 1978). Contudo, o efeito da força de dreno, provocada pelo fruto, na assimilação de $\mathrm{CO}_{2}$ não foi ainda comprovado em condições de campo.

Segundo Bustan \& Goldschmidt (1998), durante os fluxos vegetativos, o desenvolvimento floral, a antese e a fixação do fruto ocorre grande demanda de energia que não pode ser fornecida pela fotossíntese e deve ser obtida pelas reservas de carboidratos existentes nas árvores de citros. Experimentos com carbono marcado indicaram que as reservas de carboidratos foram utilizadas principalmente para suportar o desenvolvimento reprodutivo, enquanto que a fotossíntese das folhas maduras suprem as necessidades do crescimento vegetativo (Akao et al., 1981). Martinez-Cortina \& Sanz (1991) não encontraram diferenças na atividade da RuBPCase em folhas de 
inflorescências de citros com ou sem a presença de frutos, indicando que o aumento na força de dreno no período de fixação dos frutos não aumenta a fixação de carbono. 


\title{
3 DESENVOLVIMENTO DOS FRUTOS DO TANGOR 'MURCOTE' (Citrus reticulata Blanco $\mathbf{x}$ Citrus sinensis $\mathrm{L}$. Osbeck) COM O USO DE BIORREGULADORES APLICADOS APÓS A QUEDA DAS PÉTALAS ${ }^{1}$
}

\author{
CHRYZ MELINSKI SERCILOTO $^{2}$ e PAULO ROBERTO DE CAMARGO E \\ CASTRO $^{3}$
}

\section{Resumo}

Avaliou-se o efeito dos biorreguladores etilclozate $200 \mathrm{mg} . \mathrm{L}^{-1}$, fenotiol $10 \mathrm{mg} . \mathrm{L}^{-}$

1, Fengib 1 ml.L ${ }^{-1}, \mathrm{GA}_{3} 20 \mathrm{mg} \cdot \mathrm{L}^{-1}$, 2,4-D $8 \mathrm{mg} \cdot \mathrm{L}^{-1}$ e $\mathrm{GA}_{3} 20 \mathrm{mg} \cdot \mathrm{L}^{-1}+$ 2,4-D $8 \mathrm{mg} \cdot \mathrm{L}^{-1}$ sobre o desbaste e o tamanho dos frutos do tangor 'Murcote'. Os tratamentos foram aplicados após a completa queda das pétalas (frutos com aproximadamente $6 \mathrm{~mm}$ de diâmetro), sendo gastos aproximadamente 6 litros de solução por planta. Nenhum tratamento alterou o número de frutos colhidos e a produtividade (kg/planta). Os tratamentos $\mathrm{GA}_{3} 20 \mathrm{mg} . \mathrm{L}^{-1}+2,4-\mathrm{D} 8 \mathrm{mg} . \mathrm{L}^{-1}, \mathrm{GA}_{3} 20 \mathrm{mg} \cdot \mathrm{L}^{-1}$ e fenotiol $10 \mathrm{mg} . \mathrm{L}^{-1}$ aumentaram o diâmetro $(3,4 \% ; 3,0 \%$ e $3,0 \%)$, o peso médio $(7,8 \% ; 8,8 \%$ e $9,5 \%)$ e o número de frutos colhidos de maior classe comercial. Nenhum tratamento alterou as caracterísisticas tecnológicas dos frutos (\% suco, brix, acidez, $\mathrm{pH}$, ratio, cor da casca e cor do suco). As taxas de assimilação de $\mathrm{CO}_{2}$, transpiração, condutância estomática e o teor de clorofila não foram alterados pelos tratamentos.

Palavras-chave: Murcote, reguladores vegetais, fotossíntese, tamanho do fruto, desbaste.

\footnotetext{
${ }^{1}$ Financiado pela Fapesp

${ }^{2}$ Pós-graduando em Fisiologia e Bioquímica de Plantas. Departamento de Ciências Biológicas, ESALQUSP. Bolsista Fapesp. e-mail: cmsercil@esalq.usp.br.

${ }^{3}$ Departamento de Ciências Biológicas, ESALQ-USP
} 


\section{Summary}

\section{FRUIT GROWTH OF 'MURCOTT' MANDARIN HYBRID (Citrus reticulata Blanco x Citrus sinensis L. Osbeck) WITH USE OF BIOREGULATORS SPRAYED AFTER THE PETAL FALL}

The effects of bioregulators ethylclozate $200 \mathrm{mg} \cdot \mathrm{L}^{-1}$, phenotiol $10 \mathrm{mg} \cdot \mathrm{L}^{-1}$, Fengib 1 ml.L $\mathrm{L}^{-1}, \mathrm{GA}_{3} 20 \mathrm{mg} \cdot \mathrm{L}^{-1}$, 2,4-D $8 \mathrm{mg} \cdot \mathrm{L}^{-1}$ and GA $20 \mathrm{mg} \cdot \mathrm{L}^{-1}+$ 2,4-D $8 \mathrm{mg} \cdot \mathrm{L}^{-1}$ were evaluated on the fruit thinning and the fruit size of 'Murcott' mandarin hybrid. The treatments were sprayed on whole trees after total petal fall (fruits with approximately 6 $\mathrm{mm}$ of diameter), at a rate of 6 litres per tree. The number of fruits per tree and yeld (kg/tree) were not affected by the treatments. GA $20 \mathrm{mg} \cdot \mathrm{L}^{-1}+2,4-\mathrm{D} 8 \mathrm{mg} \cdot \mathrm{L}^{-1}, \mathrm{GA}_{3} 20$ $\mathrm{mg} . \mathrm{L}^{-1}$ and fenotiol $10 \mathrm{mg} . \mathrm{L}^{-1}$ increased the final fruit size $(3.4 \% ; 3.0 \%$ and $3.0 \%)$, the final fruit weight $(7.8 \% ; 8.8 \%$ and $9.5 \%)$ and the number of fruits of larger comercial size class. The treatments didn't affected juice content, total soluble solids, acidity, $\mathrm{pH}$, juice colour and peel colour. The $\mathrm{CO}_{2}$ assimilation, transpiration, stomatal conductance and chlorophyll content were not affected by the treatments.

Keywords: 'Murcott', 'Honey' orange, growth regulators, photosynthesis, thinning, fruit size

\subsection{Introdução}

O tangor 'Murcote' é um cultivar cítrico que possui alta capacidade de fixação natural de seus frutos, apresentando várias vezes altas produções, o que pode acarretar em um aumento no número de frutos pequenos. Em alguns casos, o excesso de frutos pode apresentar problemas de alternância de produção em anos seguintes o que pode ser eliminado com a prática do desbaste nos anos de produção excessiva. 
O tamanho do fruto é um dos principais fatores da qualidade dos frutos cítricos para o consumo "in natura". Principalmente no caso das tangerinas e tangores, frutos de maior tamanho são de maior aceitação, o consumidor acaba pagando melhores preços e o produtor tem uma maior lucratividade. No caso do tangor 'Murcote', a caixa do tipo A (9-11 dúzias) obtém preços 100 a $120 \%$ maiores do que a caixa tipo C (13-15 dúzias) (FNP: Consultoria e Comércio, 2001).

As aplicações de algumas auxinas sintéticas em pleno florescimento, ou algumas semanas após, podem aumentar o tamanho dos frutos cítricos. As aplicações realizadas durante esta época são mais flexíveis, sendo de mais fácil execução em relação às aplicações realizadas logo após a queda fisiológica dos frutos, que necessitam de maior experiência e agilidade em sua execução.

Este trabalho teve como objetivo avaliar o efeito das aplicações de etilclozate, fenotiol, Fengib, $\mathrm{GA}_{3}, 2,4-\mathrm{D}$ e $\mathrm{GA}_{3}+2,4-\mathrm{D}$ sobre a fixação, tamanho e qualidade interna dos frutos e sobre parâmetros fisiológicos do tangor 'Murcote', em aplicações realizadas logo após o florescimento.

\subsection{Material e métodos}

O experimento foi conduzido em condições de campo, em um pomar comercial composto de árvores de tangor 'Murcote' (Citrus reticulata Blanco x Citrus sinensis L. Osbeck) enxertadas sobre limoeiro 'Cravo' (Citrus limonia L. Osbeck) de aproximadamente 10 anos de idade, com espaçamento de 7 x 4 metros, plantado em latossolo vermelho-amarelo, localizado na Fazenda Santa Esmeralda no município de Mogi-Mirim, SP, situado a $22,52^{\circ}$ de latitude sul e a $46,95^{\circ}$ de longitude oeste. Foram selecionadas árvores homogêneas quanto ao porte, potencial produtivo, estado fitossanitário e nutricional, sendo que cada árvore constituiu uma parcela. Cada tratamento foi composto de dez repetições e o experimento montado em delineamento inteiramente casualizado. Os tratamentos utilizados neste experimento são apresentados na tabela 1. 
Tabela 1. Tratamentos com biorreguladores e concentrações, aplicados após a completa queda das pétalas, em árvores de tangor 'Murcote'.

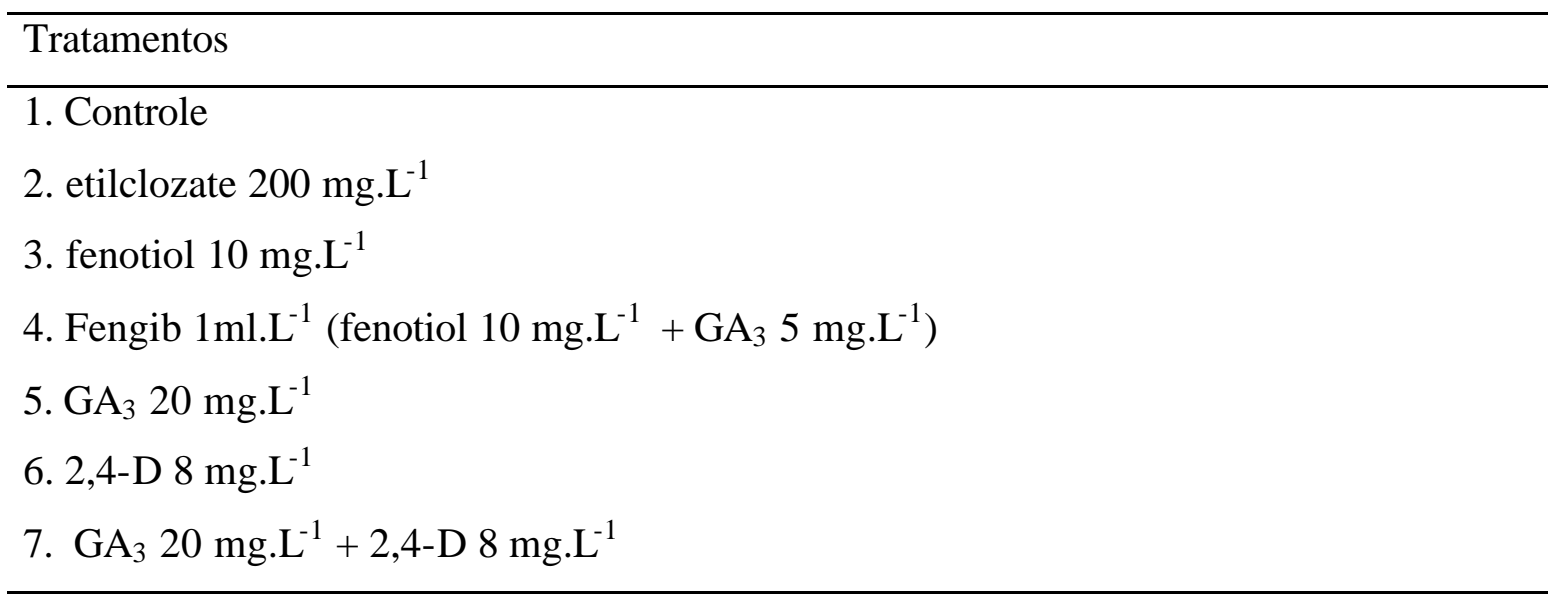

A aplicação dos reguladores vegetais foi realizada logo após a completa queda das pétalas das flores, no dia 3/10/2000, onde os frutos apresentaram diâmetro médio de $6 \mathrm{~mm}$. Os biorreguladores foram acompanhados de espalhante adesivo Silwett L-77 $(0,05 \%)$, sendo gastos aproximadamente 6 litros de calda por planta, em toda a extensão da copa, aplicados através de um pulverizador do tipo pistola.

No dia da aplicação, em cada planta, foram escolhidas quatro ramificações, dispostas em diagonal, e contou-se o número de frutos existentes para determinação do efeito de um posterior desbaste provocado por algum tratamento. Para determinação do diâmetro e crescimento médio dos frutos, foram escolhidos 8 frutos ao acaso, situados no terço médio, em cada planta e as mensurações foram realizadas através de um paquímetro na posição equatorial destes frutos. As avaliações do número de frutos foram realizadas nos dias 7/11, 21/11 e 22/12/2000; 25/01, 22/02 e 22/03/2001 e as avaliações de diâmetro de frutos foram realizadas nos dias 7/11, 21/11 e 22/12/2000; 25/01, 22/02, 22/03 e 22/05/2001.

As avaliações de fotossíntese, transpiração e condutância estomática foram realizadas através de um analisador de $\mathrm{CO}_{2}$ por radiação infra-vermelha (Infra Red Gas Analyser - IRGA, modelo LI-6400, LI-COR) com iluminação própria. A radiação da câmara foi fixada em $1000 \mu \mathrm{mol}$ fótons. $\mathrm{m}^{-2} \cdot \mathrm{s}^{-1}$ e a temperatura em $25{ }^{\circ} \mathrm{C}$. Foram utilizadas as folhas mais próximas aos frutos e voltadas em direção ao sol, situadas no 
terço médio da copa das árvores. As mensurações foram realizadas no dias 7/11/2000. Utilizaram-se 3 plantas/tratamento e uma folha/planta sendo que foram realizadas 3 leituras por folha.

As avaliações de clorofila foram realizadas através de um clorofilômetro (SPAD502, Minolta). As folhas, bem como sua posição, foram as mesmas descritas para as avaliações de fotossíntese. Foram realizadas 10 repetições/tratamento, sendo que se utilizou uma folha por planta. As avaliações foram efetuadas em 22/12/2000.

Por ocasião da colheita, realizada em 08/08/2001 foram determinados o peso total de frutos colhidos/planta e o número de frutos/planta. O tamanho final dos frutos foi avaliado pela mensuração do diâmetro equatorial de uma amostra de 20 frutos/planta, retirados aleatoriamente, com auxílio de um paquímetro. Estes frutos foram posteriormente classificados e formou-se uma distribuição de frequiência de acordo com a classificação comercial de tangerinas sugerida pela Companhia de Entrepostos e Armazéns Gerais do Estado de São Paulo - CEAGESP (2000).

Além disso, nesta mesma data, foram retiradas amostras de 20 frutos/planta para realização das análises tecnológicas. Extraiu-se o suco coado das amostras, previamente pesadas, através de um extrator de suco rotatório, marca Lucre e foram efetuadas as determinações tecnológicas dos frutos: massa do fruto, massa de suco, massa da polpa, teores de ${ }^{\circ}$ brix (através de um refratômetro digital de bancada marca Schimidt Haensch, modelo SR-400), pH, acidez (através de titulação com $\mathrm{NaOH} \mathrm{0,1} \mathrm{N}$, até atingir um valor de pH de 8,1, segundo Carvalho et al., 1990), ratio (relação ${ }^{\circ}$ brix/acidez), cor da casca e do suco (através de um colorímetro marca Minolta modelo CR-300, iluminante D65 e sistema colorimétrico LCh e XYZ para casca e suco, respectivamente).

Os resultados obtidos foram submetidos a análise de variância, sendo que quando houve significância entre os tratamentos as médias foram comparadas através do teste de Duncan ao nível de 5\% de probabilidade, segundo Gomes (1990).

\subsection{Resultados}


$\mathrm{O}$ tratamento $\mathrm{GA}_{3} 20 \mathrm{mg} \cdot \mathrm{L}^{-1}+2,4-\mathrm{D} 8 \mathrm{mg} \cdot \mathrm{L}^{-1}$ promoveu um ligeiro aumento no desbaste dos frutos, diferindo estatisticamente do controle aos 80, 110 e 140 dias após a aplicação. No entanto, na última avaliação, aos 170 dias após a aplicação, a taxa de desbaste provocada pelo mesmo $(22,1 \%)$, não diferiu estatisticamente do tratamento controle, que apresentou um taxa de $12,4 \%$ de desbaste dos frutos, e dos demais tratamentos (tabela 2).

Tabela 2. Efeito de aplicações de biorreguladores, realizadas após a queda das pétalas, sobre a porcentagem de desbaste dos frutos do tangor 'Murcote' aos 80, 110, 140 e 170 dias após a aplicação.

\begin{tabular}{lcccc}
\hline Tratamentos & \multicolumn{4}{c}{ Dias após a aplicação } \\
& 80 & 110 & 140 & 170 \\
\hline Controle & $3,0 \mathrm{~b}$ & $3,5 \mathrm{~b}$ & $5,8 \mathrm{~b}$ & $12,4 \mathrm{a}$ \\
etilclozate $200 \mathrm{mg} \cdot \mathrm{L}^{-1}$ & $1,5 \mathrm{~b}$ & $2,7 \mathrm{~b}$ & $5,8 \mathrm{~b}$ & $14,0 \mathrm{a}$ \\
fenotiol $10 \mathrm{mg} . \mathrm{L}^{-1}$ & $4,0 \mathrm{ab}$ & $5,8 \mathrm{ab}$ & $6,2 \mathrm{~b}$ & $11,1 \mathrm{a}$ \\
Fengib 1ml.L ${ }^{-1}$ & $1,2 \mathrm{~b}$ & $1,7 \mathrm{~b}$ & $3,2 \mathrm{~b}$ & $10,3 \mathrm{a}$ \\
$\mathrm{GA}_{3} 20 \mathrm{mg} \cdot \mathrm{L}^{-1}$ & $2,2 \mathrm{~b}$ & $2,3 \mathrm{~b}$ & $4,7 \mathrm{~b}$ & $12,7 \mathrm{a}$ \\
$2,4-\mathrm{D} 8 \mathrm{mg} \cdot \mathrm{L}^{-1}$ & $5,4 \mathrm{ab}$ & $6,8 \mathrm{ab}$ & $10,1 \mathrm{ab}$ & $15,1 \mathrm{a}$ \\
GA $20 \mathrm{mg} \cdot \mathrm{L}^{-1}+2,4-\mathrm{D} 8 \mathrm{mg} \cdot \mathrm{L}^{-1}$ & $12,0 \mathrm{a}$ & $12,8 \mathrm{a}$ & $15,8 \mathrm{a}$ & $22,1 \mathrm{a}$ \\
F & $2,67^{*}$ & $2,35^{*}$ & $2,51^{*}$ & $1,33^{\mathrm{ns}}$ \\
C.V. $(\%)$ & 74,05 & 69,09 & 57,12 & 44,85 \\
\hline
\end{tabular}

Obs: Letras diferentes, dentro da mesma coluna, indicam diferenças estatísticas pelo teste de Duncan ao nível de 5\% de probabilidade. Valores de F, CV e teste de médias referentes aos dados transformados em raiz quadrada de $\mathrm{x}+0,5$.

ns: não significativo pelo teste $\mathrm{F}$

* significativo pelo teste $\mathrm{F}$ ao nível de 5\% de probabilidade

Aos 80, 110 e 140 dias após a aplicação, vários tratamentos promoveram efeitos depressivos no desenvolvimento dos frutos do tangor 'Murcote' (tabela 3). Somente aos 170 dias após a aplicação é que se verificaram aumentos significativos provocados por algum tratamento sobre o tamanho dos frutos. Nesta época os frutos tratados com Fengib 
1 ml.L $\mathrm{L}^{-1}$ e com GA 20 mg. $\mathrm{L}^{-1}$ já apresentavam diâmetro superior ao controle. Aos 230 dias após a aplicação, os frutos tratados com GA 20 mg.L $\mathrm{L}^{-1}+$ 2,4-D 8 mg.L.-1 apresentaram diâmetro superior ao controle (tabela 3).

Na colheita (08/08/2001), todos os tratamentos apresentaram um diâmetro médio dos frutos superior ao tratamento controle. No entanto, apenas os tratamentos $\mathrm{GA}_{3} 20$ mg. $\mathrm{L}^{-1}+2,4-\mathrm{D} 8 \mathrm{mg} . \mathrm{L}^{-1}$, fenotiol $10 \mathrm{mg} . \mathrm{L}^{-1}$ e $\mathrm{GA}_{3} 20 \mathrm{mg} . \mathrm{L}^{-1}$, que apresentaram valores de diâmetro médio dos frutos de 67,8; 67,6 e 67,6 mm; respectivamente, diferiram do tratamento controle que apresentou frutos com diâmetro médio de 65,6 mm (tabela 4).

Tabela 3. Efeito de aplicações de biorreguladores, realizadas após a queda das pétalas, sobre o diâmetro médio dos frutos (mm) do tangor 'Murcote' aos 80, 110, 140, 170 e 230 dias após a aplicação.

\begin{tabular}{|c|c|c|c|c|c|}
\hline \multirow[t]{2}{*}{ Tratamentos } & \multicolumn{5}{|c|}{ Dias após a aplicação } \\
\hline & 80 & 110 & 140 & 170 & 230 \\
\hline Controle & $34,7 \mathrm{a}$ & $45,9 \mathrm{a}$ & $52,0 \mathrm{a}$ & $55,3 \mathrm{a}$ & $64,3 \mathrm{bc}$ \\
\hline etilclozate $200 \mathrm{mg} \cdot \mathrm{L}^{-1}$ & 35,3 a & $45,0 \mathrm{ab}$ & $51,4 \mathrm{ab}$ & $55,5 \mathrm{a}$ & $63,9 \mathrm{c}$ \\
\hline fenotiol $10 \mathrm{mg} . \mathrm{L}^{-1}$ & $34,8 \mathrm{a}$ & $44,9 \mathrm{ab}$ & $50,5 \mathrm{bc}$ & $56,3 \mathrm{a}$ & $65,6 \mathrm{ab}$ \\
\hline Fengib 1ml.L $\mathrm{L}^{-1}$ & $34,4 \mathrm{a}$ & $44,1 \mathrm{bc}$ & $50,1 \mathrm{bc}$ & $57,3 \mathrm{a}$ & $65,6 \mathrm{ab}$ \\
\hline $\mathrm{GA}_{3} 20 \mathrm{mg} \cdot \mathrm{L}^{-1}$ & $33,2 \mathrm{~b}$ & $42,9 \mathrm{~cd}$ & $49,7 \mathrm{c}$ & $57,3 \mathrm{a}$ & $64,1 \mathrm{bc}$ \\
\hline 2,4-D $8 \mathrm{mg} \cdot \mathrm{L}^{-1}$ & 34,6 a & $44,1 \mathrm{bc}$ & $51,0 \mathrm{abc}$ & $56,3 \mathrm{a}$ & $64,2 \mathrm{bc}$ \\
\hline $\mathrm{GA}_{3} 20 \mathrm{mg} \cdot \mathrm{L}^{-1}+2,4-\mathrm{D} 8 \mathrm{mg} \cdot \mathrm{L}^{-1}$ & $32,4 \mathrm{~b}$ & $41,7 \mathrm{~d}$ & $48,1 \mathrm{~d}$ & 56,6 a & 66,0 a \\
\hline $\mathrm{F}$ & $9,12 * *$ & $8,58 * *$ & $7,7 * *$ & $1,78^{\mathrm{ns}}$ & $3,37 * *$ \\
\hline C.V.(\%) & 3,14 & 3,35 & 2,85 & 3,26 & 2,28 \\
\hline
\end{tabular}

Obs: Letras diferentes, dentro da mesma coluna, indicam diferenças estatísticas pelo teste de Duncan ao nível de $5 \%$ de probabilidade.

ns: não significativo pelo teste $\mathrm{F}$

** significativo pelo teste $\mathrm{F}$ ao nível de $1 \%$ de probabilidade

A figura 1 mostra o efeito dos tratamentos sobre a distribuição de frequência dos frutos do tangor 'Murcote' de acordo com a sua classe comercial, em relação ao 
controle. Observa-se que todos os tratamentos diminuíram a quantidade de frutos de menor diâmetro comercial e aumentaram a quantidade de frutos de maior tamanho e consequentemente de maior valor comercial, sendo que os tratamentos fenotiol $10 \mathrm{mg} . \mathrm{L}^{-}$ ${ }^{1}, \mathrm{GA}_{3} 20 \mathrm{mg} \cdot \mathrm{L}^{-1}$ e $\mathrm{GA}_{3} 20+2,4-\mathrm{D} 8 \mathrm{mg} . \mathrm{L}^{-1}$ proporcionaram os maiores aumentos na quantidade de frutos de maior classe comercial.
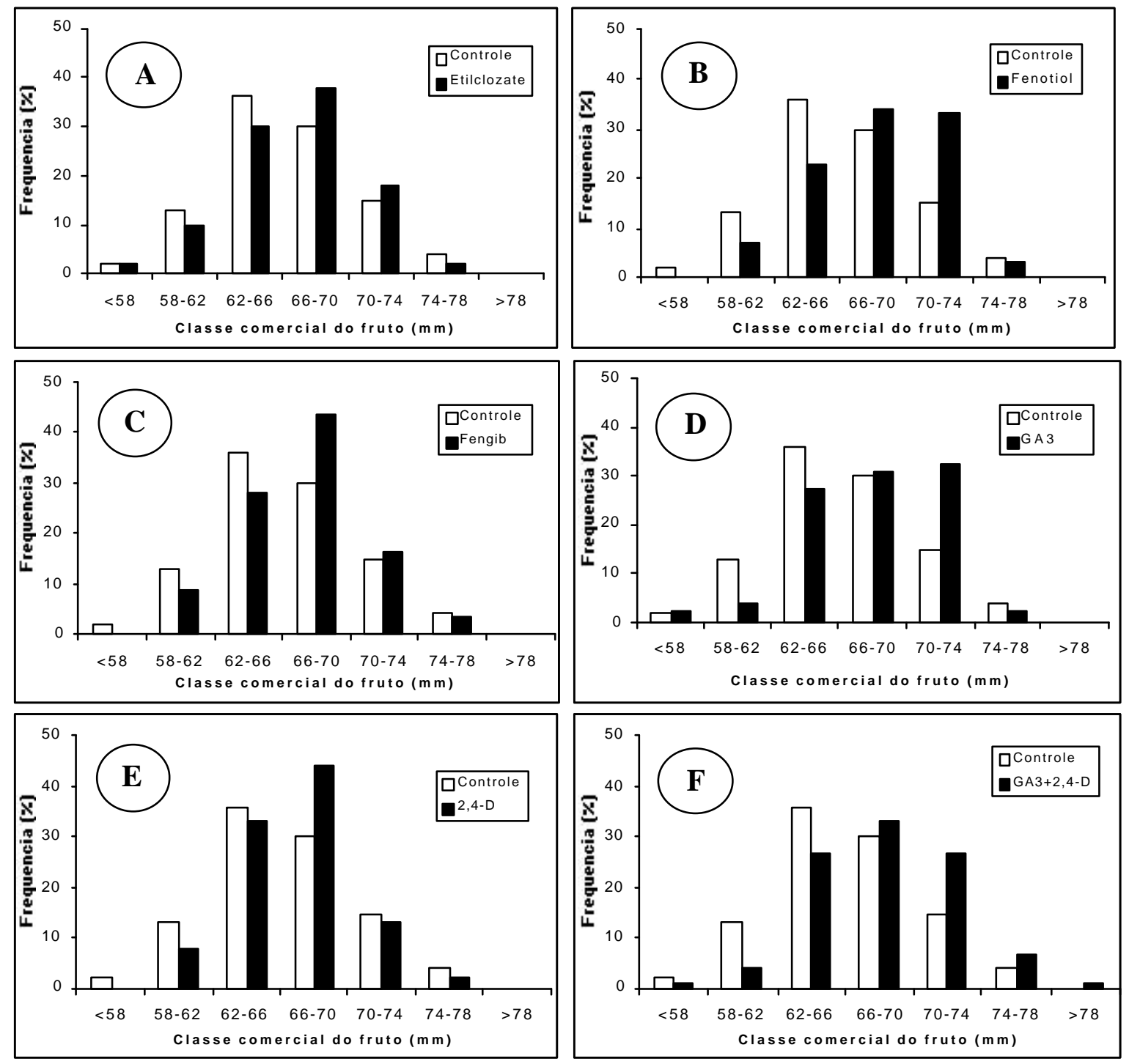

Figura 1 - Efeito dos biorreguladores, aplicados após a queda das pétalas, na distribuição de frequência dos frutos do tangor 'Murcote' de acordo com sua classe comercial. A: etilclozate $200 \mathrm{mg} . \mathrm{L}^{-1}$; B: fenotiol $10 \mathrm{mg} . \mathrm{L}^{-1}$; C: Fengib $1 \mathrm{ml} . \mathrm{L}^{-}$ ${ }^{1}$; D: $\mathrm{GA}_{3} 20 \mathrm{mg} \cdot \mathrm{L}^{-1}$; E: 2,4-D $8 \mathrm{mg} . \mathrm{L}^{-1}$; F: GA $20 \mathrm{mg} . \mathrm{L}^{-1}+2,4-\mathrm{D} 8 \mathrm{mg} \cdot \mathrm{L}^{-1}$. 
Todos os tratamentos promoveram aumentos na massa média dos frutos. Os maiores aumentos foram proporcionados pelos tratamentos fenotiol $10 \mathrm{mg} \cdot \mathrm{L}^{-1}, \mathrm{GA}_{3} 20$ $\mathrm{mg} . \mathrm{L}^{-1}$ e $\mathrm{GA}_{3} 20 \mathrm{mg} . \mathrm{L}^{-1}+2,4-\mathrm{D} 8 \mathrm{mg} . \mathrm{L}^{-1}$ que apresentaram frutos com massas médias de 141,$1 ; 140,3$ e 138,9 gramas, respectivamente, diferindo do tratamento controle que apresentou frutos com massa média de 128,9 gramas (tabela 4).

Observa-se pela tabela 4 que nenhum tratamento proporcionou um aumento ou decréscimo significativos na produção final ( $\mathrm{kg} / \mathrm{planta})$ e também no número de futos colhidos por planta, embora o tratamento 2,4-D $8 \mathrm{mg} . \mathrm{L}^{-1}$ tenha atingido os maiores valores (161,9 kg/planta e 1190 frutos) e o tratamento $\mathrm{GA}_{3} 20 \mathrm{mg} . \mathrm{L}^{-1}$ os menores valores (133, $83 \mathrm{~kg} /$ planta e 959 frutos) em relação ao controle (145,7 kg e 1139 frutos), respectivamente.

Tabela 4. Efeito de aplicações de biorreguladores, realizadas após a queda das pétalas, sobre o número de frutos e parâmetros de colheita do tangor 'Murcote'.

\begin{tabular}{lcccc}
\hline Tratamentos & $\begin{array}{c}\text { Diâmetro } \\
\text { médio dos } \\
\text { Frutos }(\mathrm{mm})\end{array}$ & $\begin{array}{c}\text { Massa média } \\
\text { dos Frutos } \\
(\mathrm{g})\end{array}$ & $\begin{array}{c}\text { Número de } \\
\text { Frutos por } \\
\text { árvore }\end{array}$ & $\begin{array}{c}\text { Produção } \\
\text { (kg por } \\
\text { árvore) }\end{array}$ \\
\hline Controle & $65,6 \mathrm{c}$ & $128,9 \mathrm{c}$ & $1139 \mathrm{a}$ & $145,67 \mathrm{a}$ \\
etilclozate $200 \mathrm{mg} . \mathrm{L}^{-1}$ & $66,0 \mathrm{bc}$ & $130,8 \mathrm{c}$ & $1079 \mathrm{a}$ & $139,00 \mathrm{a}$ \\
fenotiol 10 mg.L. & $67,6 \mathrm{ab}$ & $141,1 \mathrm{a}$ & $1098 \mathrm{a}$ & $152,17 \mathrm{a}$ \\
Fengib 1 ml.L & $66,7 \mathrm{abc}$ & $134,8 \mathrm{abc}$ & $1024 \mathrm{a}$ & $137,25 \mathrm{a}$ \\
GA $_{3} 20 \mathrm{mg} \cdot \mathrm{L}^{-1}$ & $67,6 \mathrm{ab}$ & $140,3 \mathrm{ab}$ & $959 \mathrm{a}$ & $133,83 \mathrm{a}$ \\
2,4-D $8 \mathrm{mg} . \mathrm{L}^{-1}$ & $66,2 \mathrm{abc}$ & $133,2 \mathrm{bc}$ & $1189 \mathrm{a}$ & $161,92 \mathrm{a}$ \\
GA $20 \mathrm{mg} \cdot \mathrm{L}^{-1}+2,4-\mathrm{D} 8 \mathrm{mg} \cdot \mathrm{L}^{-1}$ & $67,8 \mathrm{a}$ & $138,9 \mathrm{ab}$ & $1173 \mathrm{a}$ & $156,33 \mathrm{a}$ \\
F & $3,01 *$ & $4,00 * *$ & $1,64{ }^{\mathrm{ns}}$ & $1,61{ }^{\mathrm{ns}}$ \\
C.V. $(\%)$ & 2,38 & 5,48 & 14,38 & 13,93 \\
\hline
\end{tabular}

Obs: Letras diferentes, dentro da mesma coluna, indicam diferenças estatísticas pelo teste de Duncan ao nível de 5\% de probabilidade.

ns: não significativo pelo teste $\mathrm{F}$ nível de $5 \%$ de probabilidade

* significativo pelo teste $\mathrm{F}$ ao nível de $5 \%$ de probabilidade

** significativo pelo teste $\mathrm{F}$ ao nível de $1 \%$ de probabilidade 
Nenhum tratamento promoveu alterações na porcentagem, $\mathrm{pH}$, acidez, ratio e cor do suco extraído dos frutos. Em relação ao teor de sólidos solúveis totais (brix), os frutos tratados com etilclozate apresentaram a maior média $(13,71)$ em relação a este parâmetro, diferindo estatisticamente apenas dos frutos tratados com GA 20 mg.L $\mathrm{L}^{-1}+$ 2,4-D 8 mg.L. $\mathrm{L}^{-1}(11,7)$, que não diferiu, no entanto do controle $(13,1)$ (tabelas 5a e 5b).

Tabela 5a. Efeito de aplicações de biorreguladores, realizadas após a queda das pétalas, nas características tecnológicas dos frutos de tangor 'Murcote'.

\begin{tabular}{|c|c|c|c|c|}
\hline Tratamentos & $\begin{array}{c}\text { Teor de } \\
\text { Suco }(\%)\end{array}$ & $\begin{array}{c}\text { Suco }+ \\
\text { Polpa }(\%)\end{array}$ & $\begin{array}{c}\text { Cor Casca } \\
\text { (IC) })^{1}\end{array}$ & $\begin{array}{c}\text { Cor do suco } \\
\text { (IC })^{2}\end{array}$ \\
\hline Controle & $46,54 \mathrm{a}$ & $52,70 \mathrm{a}$ & $5,42 \mathrm{a}$ & $38,87 \mathrm{a}$ \\
\hline etilclozate $200 \mathrm{mg} \cdot \mathrm{L}^{-1}$ & 44,75 a & $49,91 \mathrm{a}$ & 5,76 a & 38,96 a \\
\hline fenotiol $10 \mathrm{mg} . \mathrm{L}^{-1}$ & $45,31 \mathrm{a}$ & $51,38 \mathrm{a}$ & $5,16 \mathrm{ab}$ & $39,00 \mathrm{a}$ \\
\hline Fengib $1 \mathrm{ml} . \mathrm{L}^{-1}$ & $45,56 \mathrm{a}$ & $51,56 \mathrm{a}$ & $5,38 \mathrm{a}$ & $38,88 \mathrm{a}$ \\
\hline $\mathrm{GA}_{3} 20 \mathrm{mg} \cdot \mathrm{L}^{-1}$ & $44,50 \mathrm{a}$ & $50,13 \mathrm{a}$ & $5,19 \mathrm{ab}$ & $38,81 \mathrm{a}$ \\
\hline 2,4-D $8 \mathrm{mg} \cdot \mathrm{L}^{-1}$ & 45,99 a & $51,78 \mathrm{a}$ & $4,52 \mathrm{~b}$ & $38,87 \mathrm{a}$ \\
\hline $\mathrm{GA}_{3} 20 \mathrm{mg} \cdot \mathrm{L}^{-1}+2,4-\mathrm{D} 8 \mathrm{mg} \cdot \mathrm{L}^{-1}$ & $44,85 \mathrm{a}$ & 50,08 a & $5,26 \mathrm{ab}$ & $38,89 \mathrm{a}$ \\
\hline $\mathrm{F}$ & $0,97^{\mathrm{ns}}$ & $1,62^{\mathrm{ns}}$ & $2,66^{*}$ & $1,67^{\mathrm{ns}}$ \\
\hline C.V. (\%) & 5,00 & 5,07 & 9,84 & 0,36 \\
\hline
\end{tabular}

Obs: Letras diferentes, dentro da mesma coluna, indicam diferenças estatísticas pelo teste de Duncan ao nível de 5\% de probabilidade.

ns: não significativo pelo teste $\mathrm{F}$ nível de $5 \%$ de probabilidade

* significativo pelo teste $\mathrm{F}$ ao nível de $5 \%$ de probabilidade

$11000 \times$ a / L x b

$243,85+(1,07 X-0,61 Y-2,74 Z)$

O tratamento 2,4-D $8 \mathrm{mg} . \mathrm{L}^{-1}$ reteve o desenvolvimento da cor da casca dos frutos. Este tratamento apresentou um valor médio de índice de cor de casca de 4,52 e diferiu estatisticamente dos tratamentos etilclozate $200 \mathrm{mg} . \mathrm{L}-1$, Fengib e do controle que apresentaram valores de 5,76; 5,38 e 5,42; respectivamente (tabela 5a). 
Tabela 5b. Efeito de aplicações de biorreguladores, realizadas após a queda das pétalas, nas características tecnológicas dos frutos de tangor 'Murcote'.

\begin{tabular}{|c|c|c|c|c|}
\hline Tratamentos & $\mathrm{pH}$ & Acidez (\%) & ${ }^{\circ}$ Brix & Ratio \\
\hline Controle & $3,40 \mathrm{a}$ & $0,80 \mathrm{a}$ & $13,1 \mathrm{a}$ & $16,35 \mathrm{a}$ \\
\hline etilclozate $200 \mathrm{mg} \cdot \mathrm{L}^{-1}$ & $3,43 \mathrm{a}$ & $0,82 \mathrm{a}$ & $13,7 \mathrm{a}$ & $16,65 \mathrm{a}$ \\
\hline fenotiol $10 \mathrm{mg} \cdot \mathrm{L}^{-1}$ & $3,40 \mathrm{a}$ & $0,84 \mathrm{a}$ & $13,1 \mathrm{a}$ & $15,57 \mathrm{a}$ \\
\hline Fengib $1 \mathrm{ml} . \mathrm{L}^{-1}$ & $3,40 \mathrm{a}$ & $0,82 \mathrm{a}$ & $12,9 \mathrm{a}$ & $15,71 \mathrm{a}$ \\
\hline $\mathrm{GA}_{3} 20 \mathrm{mg} \cdot \mathrm{L}^{-1}$ & $3,45 \mathrm{a}$ & $0,83 \mathrm{a}$ & $13,2 \mathrm{a}$ & $15,94 \mathrm{a}$ \\
\hline 2,4-D $8 \mathrm{mg} \cdot \mathrm{L}^{-1}$ & $3,45 \mathrm{a}$ & $0,79 \mathrm{a}$ & $12,7 \mathrm{a}$ & $16,14 \mathrm{a}$ \\
\hline $\mathrm{GA}_{3} 20 \mathrm{mg} \cdot \mathrm{L}^{-1}+2,4-\mathrm{D} 8 \mathrm{mg} \cdot \mathrm{L}^{-1}$ & $3,40 \mathrm{a}$ & $0,81 \mathrm{a}$ & $11,7 \mathrm{a}$ & $15,81 \mathrm{a}$ \\
\hline $\mathrm{F}$ & $1,22^{\mathrm{ns}}$ & $1,66^{\mathrm{ns}}$ & $1,72^{\mathrm{ns}}$ & $1,46^{\mathrm{ns}}$ \\
\hline C.V. (\%) & 2,02 & 5,14 & 11,68 & 6,18 \\
\hline
\end{tabular}

ns: não significativo pelo teste $\mathrm{F}$ ao nível de $5 \%$ de probabilidade

Não houve diferenças entre os tratamentos quanto à taxa de assimilação de $\mathrm{CO}_{2}$, transpiração, condutância estomática e teor de clorofila das folhas do tangor 'Murcote'. Quanto à transpiração e à condutância estomática, observa-se que todos os tratamentos, exceto etilclozate $200 \mathrm{mg} . \mathrm{L}^{-1}$, promoveram uma redução nestes parâmetros. O tratamento $\mathrm{GA}_{3} 20 \mathrm{mg} \cdot \mathrm{L}^{-1}$ promoveu a maior redução para estes parâmetros; 2,101 mmol $\mathrm{H}_{2} \mathrm{Om}^{-2} \mathrm{~s}^{-1}$ e 0,124 mol $\mathrm{H}_{2} \mathrm{Om}^{-2} \mathrm{~s}^{-1}$, respectivamente, porém não diferindo

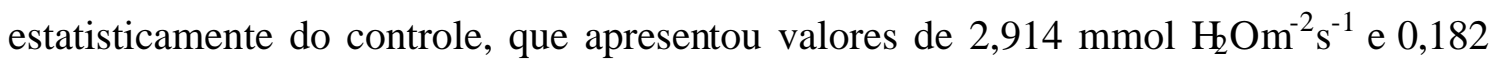
mol $\mathrm{H}_{2} \mathrm{Om}^{-2} \mathrm{~s}^{-1}$ para transpiração e condutância estomática das folhas de tangor 'Murcote'(tabela 6). 
Tabela 6. Efeito de aplicações de biorreguladores, realizadas após a queda das pétalas, sobre parâmetros fisiológicos do tangor 'Murcote' 35 dias após a aplicação.

\begin{tabular}{|c|c|c|c|c|}
\hline Tratamentos & $\begin{array}{c}\text { Assimilação de } \\
\mathrm{CO}_{2} \\
\left(\mu \mathrm{mol} \mathrm{CO} \mathrm{CO}_{2}^{-2} \mathrm{~s}^{-1}\right)\end{array}$ & $\begin{array}{c}\text { transpiração } \\
\text { (mmol H} \mathrm{H}_{2} \mathrm{O} \\
\left.\mathrm{m}^{-2} \mathrm{~s}^{-1}\right)\end{array}$ & $\begin{array}{c}\text { condutância } \\
\text { estomática (mol } \\
\mathrm{H}_{2} \mathrm{Om}^{-2} \mathrm{~s}^{-1} \text { ) }\end{array}$ & $\begin{array}{l}\text { Teor de } \\
\text { clorofila } \\
\text { (SPAD) }\end{array}$ \\
\hline Controle & $9,273 \mathrm{a}$ & $2,902 \mathrm{a}$ & $0,182 \mathrm{a}$ & $66,6 \mathrm{a}$ \\
\hline etilclozate $200 \mathrm{mg} . \mathrm{L}^{-1}$ & $9,417 \mathrm{a}$ & $2,914 \mathrm{a}$ & $0,168 \mathrm{a}$ & $65,1 \mathrm{a}$ \\
\hline fenotiol $10 \mathrm{mg} . \mathrm{L}^{-1}$ & $9,742 \mathrm{a}$ & $2,549 \mathrm{a}$ & $0,154 \mathrm{a}$ & $66,8 \mathrm{a}$ \\
\hline Fengib $1 \mathrm{ml} . \mathrm{L}^{-1}$ & $8,653 \mathrm{a}$ & $2,366 \mathrm{a}$ & $0,139 \mathrm{a}$ & $70,8 \mathrm{a}$ \\
\hline $\mathrm{GA}_{3} 20 \mathrm{mg} \cdot \mathrm{L}^{-1}$ & $8,534 \mathrm{a}$ & $2,101 \mathrm{a}$ & $0,124 \mathrm{a}$ & $67,0 \mathrm{a}$ \\
\hline 2,4-D $8 \mathrm{mg} \cdot \mathrm{L}^{-1}$ & 8,889 a & $2,379 \mathrm{a}$ & $0,154 \mathrm{a}$ & $65,5 \mathrm{a}$ \\
\hline $\mathrm{GA}_{3} 20 \mathrm{mg} \cdot \mathrm{L}^{-1}+2,4-$ & $9,097 \mathrm{a}$ & $2,527 \mathrm{a}$ & $0,160 \mathrm{a}$ & $65,1 \mathrm{a}$ \\
\hline \multicolumn{5}{|l|}{ D $8 \mathrm{mg} \cdot \mathrm{L}^{-1}$} \\
\hline $\mathrm{F}$ & $0,50^{\mathrm{ns}}$ & $2,53^{\mathrm{ns}}$ & $1,35^{\mathrm{ns}}$ & $1,43^{\mathrm{ns}}$ \\
\hline C.V. $(\%)$ & 11,56 & 12,67 & 18,34 & 7,14 \\
\hline
\end{tabular}

ns: não significativo pelo teste $\mathrm{F}$ ao nível de $5 \%$ de probabilidade

\subsection{Discussão}

Neste trabalho, o tratamento etilclozate $200 \mathrm{mg} . \mathrm{L}^{-1}$ não aumentou o desbaste, tamanho e a massa média dos frutos. Esses dados diferem dos trabalhos de Hirose et al. (1978) e de Noma (1981) que consideram o etilclozate como excelente agente desbastante em tangerina 'Satsuma'. Pacheco (1999) observou que a aplicação de etilclozate $25 \mathrm{mg} . \mathrm{L}^{-1}$ promove o desbaste dos frutos em tangerina 'Ponkan'. Porém, quando se utilizou o biorregulador na concentração de $100 \mathrm{mg} \cdot \mathrm{L}^{-1}$ não foi observado efeito algum sobre o desbaste. Segundo vários autores, o poder desbastante das auxinas sintéticas tem-se mostrado muito variável, dependendo do cultivar, do tipo de auxina e da concentração aplicada (Hirose, 1981; Agustí \& Almela, 1991; Wheaton, 1981; 
Greenberg et al., 1992; Guardiola et al., 1988). Segundo Ortolá et al. (1997), o 2,4-D apresenta efeito errático como agente desbastante, por ter ação marginal sobre a síntese de etileno e é mais efetivo como promotor do desenvolvimento. Duarte et al. (1996) e Guardiola (1996) consideram que o 2,4-D tem pouco efeito sobre a queda dos frutinhos, por seu baixo estímulo à síntese de etileno. Wheaton (1981) conseguiu um desbaste significativo dos frutos de tangor 'Murcote', porém com concentrações mais elevadas, entre 25 e $100 \mathrm{mg} . \mathrm{L}^{-1}$. Porém, sabe-se que doses elevadas de 2,4-D, podem causar epinastia das folhas, principalmente nas regiões mais quentes.

As giberelinas estão mais envolvidas com o aumento da fixação do que com o desbaste e o crescimento dos frutos. Em cultivares auto-compatíveis, os níveis de giberelinas aumentam nos ovários durante e após a antese, sendo estes acompanhados por um baixo índice de abscisão. Já em cultivares auto-incompatíveis os níveis de giberelinas não aumentam durante a antese, o que é seguido de uma forte abscisão (Talón et al., 1990; 1994). Este aumento nas concentrações de giberelinas nos ovários em desenvolvimento, durante a antese, forma parte do estímulo hormonal que ativa a divisão celular e propicia a fixação dos frutos. Agustí \& Almela (1991) consideram que a presença de giberelinas no fruto é essencial para sua fixação e que as diferentes respostas obtidas com sua aplicação, entre os cultivares cítricos, são devidas ao conteúdo endógeno dessas substâncias nos ovários. O tangor 'Murcote' é um cultivar cítrico que não apresenta problemas de fixação de frutos, fixando um grande número de frutos em condições normais. Os resultados confirmam os de Talón (1997) que não obteve sucesso no aumento de fixação de frutos com aplicações de ácido giberélico em tangerina 'Satsuma' e no híbrido 'Nova', cultivares estes que não apresentam problemas de fixação de frutos.

$\mathrm{O}$ pequeno aumento na taxa de desbaste causada pela aplicação da mistura $\mathrm{GA}_{3}$ $20 \mathrm{mg} \cdot \mathrm{L}^{-1}+2,4-\mathrm{D} 8 \mathrm{mg} \cdot \mathrm{L}^{-1}$, deve-se, provavelmente, ao método de avaliação utilizado, já que o número de frutos colhidos das árvores submetidas a essa aplicação não diferiu significativamente do número de frutos colhidos das árvores do tratamento controle.

Pela figura 2 observa-se que os biorreguladores provocaram um estímulo direto no desenvolvimento dos frutos do tangor 'Murcote', sendo que o aumento no tamanho 
dos frutos não foi relacionado com uma redução na competição por nutrientes e fotoassimilados, visto que não se observou uma redução no número de frutos colhidos por árvore.

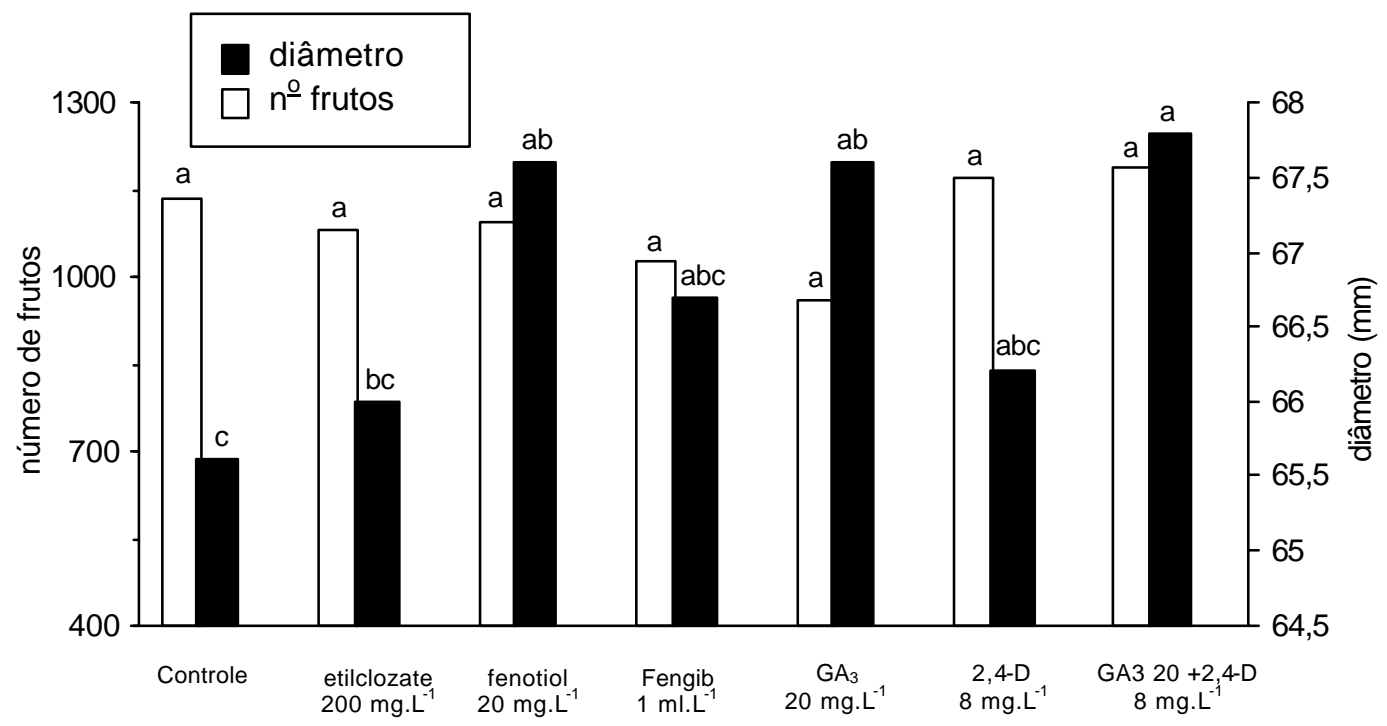

Figura 2 - Efeito dos biorreguladores, plicados após a queda das pétalas. sobre o tamanho final do fruto e o número de frutos colhidos. Obs: letras diferentes indicam diferenças estatísticas entre os tratamentos, dentro de cada parâmetro, pelo teste de Duncan ao nível de 5\% de probabilidade.

Segundo Guardiola (1987), aplicações de ácido giberélico diminuem o tamanho do fruto devido a um aumento na fixação destes, o que causa uma maior competição por nutrientes e carboidratos. Em tangerina 'Clementina', um cultivar com baixa fixação natural, aplicações de $\mathrm{GA}_{3}$ aumentam o número de frutos colhidos assim como o número de frutos de menor tamanho (Fornes et al., 1992). Como o tangor 'Murcote' é um cultivar cítrico que não apresenta problemas de fixação de frutos, assim como as 'Satsumas', fixando um grande número de frutos em condições normais, o ácido giberélico em nossas condições agiu como um estimulador direto no desenvolvimento do fruto, pois a sua ação sobre a fixação foi nula. Este efeito, no entanto, somente foi 
observado quando se aplicou o ácido giberélico em um pequeno número de frutos (VanRensburg et al., 1996) ou em parcelas pouco produtivas de tangerina 'Clementina', que segundo Fornes et al. (1992) confirma o efeito estimulador do fruto em condições de baixa competição.

O efeito não significativo do tratamento 2,4-D $8 \mathrm{mg} \cdot \mathrm{L}^{-1}$ sobre o aumento no tamanho dos frutos deve-se, provavelmente, à baixa resposta do tangor 'Murcote', assim como em 'Satsumas' (Ortells, 1973), a esta substância ou à dosagem utilizada no experimento, já que trabalhos realizados com a aplicação de 2,4-D $20 \mathrm{mg} \cdot \mathrm{L}^{-1}$ durante a floração e após a antese estimularam o desenvolvimento dos frutos do híbrido 'Nova' (Guardiola, 1995) e nos cultivares 'Valência' e 'Ortonique' (Pérez et al., 1992).

Os melhores resultados com aplicações de fenotiol visando o desenvolvimento do fruto são obtidos com aplicações realizadas após o final da queda fisiológica (Agustí et al., 1993a, Almela et al., 1993). Segundo Agustí et al. (1993a), antecipações na época de aplicação em tangerina 'Clementina' podem aumentar o número de frutos desbastados. O aumento no tamanho e peso dos frutos de tangor 'Murcote' devido à aplicação de fenotiol $10 \mathrm{mg} \cdot \mathrm{L}^{-1}$, logo após a queda das pétalas, concordam com os resultados obtidos em laranja 'Navellina' com pulverizações de fenotiol $15 \mathrm{mg} . \mathrm{L}^{-1} \mathrm{na}$ mesma época de aplicação (Agustí et al.,1996). Segundo Guardiola (1995) a aplicação de auxinas, realizada durante ou logo após a antese, promove um aumento seletivo da taxa de crescimento de alguns frutinhos, que apresentarão maior tamanho.

$\mathrm{O}$ resultado observado indica um efeito direto destes biorreguladores sobre o desenvolvimento do fruto, de acordo com trabalhos com outras auxinas sintéticas (Vanniere \& Arcuset, 1989; Agustí et al., 1992, 1994a, 1994b; ElOtmani et al., 1993). Segundo Aznar et al. (1995b), o tratamento com fenotiol promove o crescimento do endocarpo, aumentando o tamanho dos lóculos e das vesículas de suco, sendo este aumento devido a uma ação na expansão e não sobre a divisão celular. Este efeito do fenotiol, consequentemente, provoca um aumento na força de dreno do fruto, como para outras auxinas sintéticas (Stewart et al., 1952; Guardiola \& Lázaro, 1987; Agustí et. al., 1992) e explica o efeito direto no aumento do crescimento do fruto. De acordo com o resultado promovido pelo tratamento fenotiol, a capacidade de crescimento do fruto 
pode estar limitada, devido a baixa concentração de auxinas endógenas durante o período crítico de crescimento do fruto, ou seja, nos primeiros estágios de expansão celular (Takahashi et al., 1975).

$\mathrm{O}$ efeito sobre o crescimento do fruto, obtido com a aplicação de auxinas sintéticas, não altera as características intrínsecas do fruto na maturação. As mudanças que ocorrem se devem exclusivamente, na maior parte dos casos, ao aumento no tamanho do fruto (Agustí et al., 1992). Estas observações estão de acordo com os resultados obtidos neste experimento, com exceção aos tratamentos 2,4-D $8 \mathrm{mg}$. $\mathrm{L}^{-1} \mathrm{e}$ $\mathrm{GA}_{3} 20 \mathrm{mg} . \mathrm{L}^{-1}+2,4-\mathrm{D} 8 \mathrm{mg} . \mathrm{L}^{-1}$ que diminuíram o teor de sólidos solúveis totais. Fica evidente neste experimento que esta diminuição se deve a ação do 2,4-D, que também provocou um atraso na maturação externa dos frutos, diminuindo a desenvolvimento da coloração dos frutos. O 2,4-D é um biorregulador que confere um efeito sinérgico ao ácido giberélico na retenção da coloração dos frutos cítricos, quando aplicado durante a mudança de cor dos frutos (Castro et al., 1997; Barros, 1992). No tangor 'Murcote', a aplicação desta substância logo após a queda das pétalas, provavelmente diminuiu a ação de enzimas responsáveis pelo processo de amadurecimento do fruto, como a degradação de clorofilas e a síntese de açúcares solúveis.

Os resultados deste experimento também contradizem outros trabalhos, onde o etilclozate, na mesma dosagem utilizada, promoveu um aumento no conteúdo de sólidos totais sem afetar a acidez (Pons et al., 1989; Li et al., 1990), já que não foi observado este tipo de resposta.

A diminuição na transpiração, na condutância estomática e consequentemente na fotossíntese, foi devida à ação do biorregulador ou pela menor demanda de carboidratos. Embora o tratamento $\mathrm{GA}_{3} 20 \mathrm{mg} . \mathrm{L}^{-1}$ tenha causado aumentos em peso e tamanho de frutos individuais, as árvores deste tratamento foram as que tenderam a ser menos produtivas. Segundo Lenz (1978), aumentos nas taxas fotossintéticas são detectados em plantas com maior potencial produtivo. Efeitos na redução da fotossíntese e na atividade da RuBPCase foram verificados por Sharma et al. (1990) com aplicação de $\mathrm{GA}_{3} 20 \mathrm{mg} . \mathrm{L}^{-1}$ em folhas jovens de limão cultivar Pant-Lemon. 


\subsection{Conclusões}

a) Os tratamentos $\mathrm{GA}_{3} 20 \mathrm{mg} \cdot \mathrm{L}^{-1}$, fenotiol $10 \mathrm{mg} \cdot \mathrm{L}^{-1}$ e $\mathrm{GA}_{3} 20 \mathrm{mg} \cdot \mathrm{L}^{-1}+2,4-\mathrm{D} 8 \mathrm{mg} \cdot \mathrm{L}^{-}$ 1 , promovem aumentos no tamanho e na massa média dos frutos do tangor 'Murcote'.

b) Os tratamentos $\mathrm{GA}_{3} 20 \mathrm{mg} \cdot \mathrm{L}^{-1}$, fenotiol $10 \mathrm{mg} \cdot \mathrm{L}^{-1}$ e GA $320 \mathrm{mg} \cdot \mathrm{L}^{-1}+2,4-\mathrm{D} 8 \mathrm{mg} \cdot \mathrm{L}^{-1}$ aumentam o número de frutos de maior classe comercial.

c) As características tecnológicas dos frutos e do suco não são afetadas pelos biorreguladores.

d) Não ocorrem alterações na assimilação de $\mathrm{CO}_{2}$, transpiração, condutância estomática e teor de clorofila nas plantas submetidas às aplicações dos biorreguladores. 


\title{
4 DESBASTE E DESENVOLVIMENTO DOS FRUTOS DO TANGOR 'MURCOTE' (Citrus reticulata Blanco x Citrus sinensis L. Osbeck) COM O USO DE BIORREGULADORES APLICADOS APÓS A QUEDA FISIOLÓGICA DOS FRUTOS $^{1}$
}

\author{
CHRYZ MELINSKI SERCILOTO ${ }^{2}$ e PAULO ROBERTO DE CAMARGO E \\ CASTRO $^{3}$
}

\section{Resumo}

Avaliou-se o efeito dos biorreguladores 3,5,6-TPA $15 \mathrm{mg} . \mathrm{L}^{-1}$, 2,4-DP $50 \mathrm{mg} . \mathrm{L}^{-1}$, fenotiol $20 \mathrm{mg} \cdot \mathrm{L}^{-1}$, ethephon $200 \mathrm{mg} \cdot \mathrm{L}^{-1}$ e etilclozate $200 \mathrm{mg} \cdot \mathrm{L}^{-1}$ sobre o desbaste e o tamanho dos frutos do tangor 'Murcote'. Os tratamentos foram aplicados após a queda fisiológica dos frutos (frutos com aproximadamente $22 \mathrm{~mm}$ de diâmetro), sendo gastos aproximadamente 6 litros de solução por planta. Os tratamentos 3,5,6-TPA 15 mg.. ${ }^{-1}$, ethephon $200 \mathrm{mg} \cdot \mathrm{L}^{-1}$ e fenotiol $20 \mathrm{mg} \cdot \mathrm{L}^{-1}$ aumentaram o diâmetro (7,0\%; 6,8\% e 4,4\%), a massa média $(19,1 \% ; 17,3 \%$ e $8,7 \%)$ e o número de frutos colhidos de maior classe comercial. No entanto, os tratamentos 3,5,6-TPA $15 \mathrm{mg} . \mathrm{L}^{-1}$ e ethephon $200 \mathrm{mg} . \mathrm{L}^{-1}$ diminuíram o número de frutos colhidos $(57,1 \%$ e $47,9 \%)$ e a produtividade $(47,8 \%$ e $37,5 \%)$ em $\mathrm{kg} /$ planta. $\mathrm{O}$ tratamento fenotiol causou uma diminuiçâo de $0,4^{\circ}$ brix no suco dos frutos. As demais características tecnológicas dos frutos (\% suco, acidez, $\mathrm{pH}$, ratio, cor da casca e cor do suco) não foram afetadas pelos tratamentos. Nenhum tratamento alterou a assimilação de $\mathrm{CO}_{2}$, transpiração, condutância estomática e o teor de clorofila

\footnotetext{
${ }^{1}$ Financiado pela Fapesp

${ }^{2}$ Pós-graduando em Fisiologia e Bioquímica de Plantas. Departamento de Ciências Biológicas, ESALQUSP. Bolsista Fapesp. e-mail: cmsercil@esalq.usp.br.

${ }^{3}$ Departamento de Ciências Biológicas, ESALQ-USP.
} 
das folhas do tangor 'Murcote'.

Palavras-chave: Murcote, reguladores vegetais, fotossíntese, tamanho do fruto, desbaste.

\section{Summary}

\section{THINNING AND FRUIT GROWTH OF 'MURCOTT' MANDARIN HYBRID (Citrus reticulata Blanco $\mathrm{x}$ Citrus sinensis L. Osbeck) WITH USE OF BIOREGULATORS SPRAYED AFTER THE PHYSIOLOGICAL FRUIT DROP}

The effects of bioregulators 3,5,6-TPA $15 \mathrm{mg} . \mathrm{L}^{-1}$, 2,4-DP $50 \mathrm{mg} . \mathrm{L}^{-1}$, phenotiol

$20 \mathrm{mg} . \mathrm{L}^{-1}$, ethephon $200 \mathrm{mg} \cdot \mathrm{L}^{-1}$ and ethylclozate $200 \mathrm{mg} \cdot \mathrm{L}^{-1}$ were evaluated on the fruit thinning and the fruit size of 'Murcott' mandarin hybrid. The treatments were sprayed on whole trees after physiological fruit drop (fruits with approximately $22 \mathrm{~mm}$ of diameter), at a rate of 6 litres per tree. 3,5,6-TPA $15 \mathrm{mg} . \mathrm{L}^{-1}$, ethephon $200 \mathrm{mg} . \mathrm{L}^{-1}$ and phenotiol 20 mg. $\mathrm{L}^{-1}$ increased the final fruit size $(7.0 \% ; 6.8 \%$ and $4.4 \%)$, the final fruit weight $(19.1 \% ; 17.3 \%$ and $8.7 \%)$ and the number of fruits of larger comercial size class. However, 3,5,6-TPA $15 \mathrm{mg} . \mathrm{L}^{-1}$ and ethephon $200 \mathrm{mg} . \mathrm{L}^{-1}$ decreased the number of fruits per tree $(57.1 \%$ e $47.9 \%)$ and yield $(47.8 \%$ e $37.5 \%)$, in $\mathrm{kg} /$ tree. phenotiol decreased by 0,4 the total soluble solids. The treatments didn't affected juice content, acidity, $\mathrm{pH}$, juice colour and peel colour. The $\mathrm{CO}_{2}$ assimilation, transpiration, stomatal conductance and chlorophyll content were not affected by the treatments.

Keywords: Murcott, 'Honey' orange, growth regulators, photosynthesis, thinning, fruit size

\subsection{Introdução}


O tamanho do fruto é um dos principais fatores na qualidade dos frutos cítricos para o consumo "in natura". Principalmente no caso das tangerinas e tangores, frutos de maior tamanho são de maior aceitação, o consumidor acaba pagando melhores preços e o produtor tem uma maior lucratividade. No caso do tangor 'Murcote', a caixa do tipo A (9-11 dúzias) obtém preços 100 a $120 \%$ maiores do que a caixa tipo C (13-15 dúzias) (FNP: Consultoria e Comércio, 2000).

O tangor 'Murcote' é um cultivar cítrico que possui alta capacidade de fixação natural de seus frutos, apresentando frequentemente altas produções, o que pode acarretar em um aumento no número de frutos pequenos. Em alguns casos, pode apresentar problemas de alternância de produção, o que pode ser eliminado com a prática do desbaste nos anos de alta produção.

Dentre outras práticas que visam a redução do número e o aumento no tamanho dos frutos, como o desbaste manual dos frutos e o anelamento dos ramos, a aplicação de algumas auxinas sintéticas, logo após a queda fisiológica dos frutos, vem sendo utilizada em outros países citrícolas como Espanha e Estados Unidos da América.

Este trabalho teve como objetivo avaliar o efeito das aplicações de 3,5,6-TPA, 2,4-DP, fenotiol, etilclozate e ethephon sobre o desbaste, tamanho e qualidade interna dos frutos e sobre parâmetros fisiológicos do tangor 'Murcote', em aplicações realizadas logo após o final da queda fisiológica dos frutos.

\subsection{Material e Métodos}

O experimento foi conduzido em condições de campo, em um pomar comercial composto de árvores de tangor 'Murcote' (Citrus reticulata Blanco x Citrus sinensis L. Osbeck) enxertadas sobre limoeiro 'Cravo' (Citrus limonia L. Osbeck) de aproximadamente 10 anos de idade, com espaçamento de 7 x 4 metros, plantado em latossolo vermelho-amarelo, localizado na Fazenda Santa Esmeralda no município de Mogi-Mirim, SP, situado a $22,52^{\circ}$ de latitude sul e a $46,95^{\circ}$ de longitude oeste. Foram selecionadas árvores homogêneas quanto ao porte, potencial produtivo, estado 
fitossanitário e nutricional, sendo que cada árvore constituiu uma parcela. Cada tratamento foi composto de dez repetições e o experimento montado em delineamento inteiramente casualizado. Os tratamentos utilizados neste experimento são apresentados na tabela 1.

A aplicação dos biorreguladores foi realizada logo após a queda fisiológica dos frutos, no dia 21/11/2000, onde os frutos apresentavam $22 \mathrm{~mm}$ de diâmetro.

O biorreguladores foram acompanhados de espalhante adesivo Silwett L-77 $(0,05 \%)$, sendo gastos aproximadamente 6 litros de calda por planta, em toda a extensão da copa, aplicados através de um pulverizador do tipo pistola.

Tabela 1. Tratamentos com reguladores vegetais e concentrações, aplicados após o final da queda fisiológica dos frutos em árvores de tangor 'Murcote'.

Tratamentos

1. Controle

2. 3,5,6-TPA $15 \mathrm{mg} . \mathrm{L}^{-1}$

3. 2,4-DP $50 \mathrm{mg} \cdot \mathrm{L}^{-1}$

4. fenotiol $20 \mathrm{mg} . \mathrm{L}^{-1}$

5. etilclozate $200 \mathrm{mg} \cdot \mathrm{L}^{-1}$

6. ethephon $200 \mathrm{mg} . \mathrm{L}^{-1}$

No dia da aplicação, em cada planta, foram escolhidas quatro ramificações, dispostas em diagonal e contou-se o número de frutos existentes para determinação de um posterior efeito do desbaste provocado por algum tratamento. Para determinação do diâmetro e crescimento médio dos frutos, foram escolhidos 8 frutos ao acaso, situados no terço médio de cada planta, sendo as mensurações foram realizadas através de um paquímetro na posição equatorial destes frutos. As avaliações do número de frutos foram realizadas nos dias 21/11 e 22/12/2000; 25/01, 22/02 e 22/03/2001, e as avaliações do diâmetro dos frutos foram realizadas nos dias 21/11 e 22/12/2000; 25/01, 22/02, 22/03 e 22/05/2001. 
As avaliações de fotossíntese, transpiração e condutância estomática foram realizadas através de um analisador de $\mathrm{CO}_{2}$ por radiação infra-vermelha (Infra Red Gas Analyser - IRGA, modelo LI-6400, LI-COR) com iluminação própria. A radiação da câmara foi fixada em $1000 \mu \mathrm{mol}$ fótons. $\mathrm{m}^{-2} \cdot \mathrm{s}^{-1}$ e a temperatura em $25{ }^{\circ} \mathrm{C}$. Foram utilizadas as folhas mais próximas aos frutos e voltadas em direção ao sol, situadas no terço médio da copa das árvores. As mensurações foram realizadas no dia 25/01/2001. Utilizaram-se 3 plantas/tratamento e uma folha/planta sendo que foram realizadas 3 leituras por folha.

As avaliações de clorofila foram realizadas através de um clorofilômetro (SPAD502, Minolta). As folhas, bem como sua posição, foram as mesmas descritas para as avaliações de fotossíntese. Foram realizadas 10 repetições/tratamento, sendo que se utilizou uma folha por planta, sendo as avaliações efetuadas no dia 22/12/2000.

Por ocasião da colheita, realizada em 08/08/2001 foram determinados o peso total de frutos colhidos/planta e o número de frutos/planta. O tamanho final dos frutos foi avaliado pela mensuração do diâmetro equatorial de uma amostra de 20 frutos/planta, retirados aleatoriamente, com auxílio de um paquímetro. Estes frutos foram posteriormente classificados e formou-se uma distribuição de freqüência de acordo com a classificação comercial de tangerinas sugerida pela Companhia de Entrepostos e Armazéns Gerais do Estado de São Paulo (2000).

Além disso, nesta mesma data, foram retiradas amostras de 20 frutos/planta para realização das análises tecnológicas. Extraiu-se o suco coado das amostras, previamente pesadas, através de um extrator de suco rotatório, marca Lucre e foram efetuadas as determinações tecnológicas dos frutos: massa do fruto, massa de suco, massa da polpa, teores de ${ }^{\circ}$ brix (através de um refratômetro digital de bancada marca Schimidt Haensch, modelo SR-400), pH, acidez (através de titulação com $\mathrm{NaOH} \mathrm{0,1} \mathrm{N,} \mathrm{até} \mathrm{atingir} \mathrm{um} \mathrm{valor}$ de pH de 8,1, segundo Carvalho et al., 1990), ratio (relação ${ }^{\circ}$ brix/acidez), cor da casca e do suco (através de um colorímetro marca Minolta modelo CR-300, iluminante D65 e sistema LCh e XYZ para casca e suco, respectivamente). 
Os resultados obtidos foram submetidos a análise de variância, sendo que, quando houve significância entre os tratamentos, as médias foram comparadas através do teste de Duncan ao nível de 5\% de probabilidade, segundo Gomes (1990).

\subsection{Resultados}

Os tratamentos ethephon $200 \mathrm{mg} \cdot \mathrm{L}^{-1}$ e $3,5,6-\mathrm{TPA} 15 \mathrm{mg} \cdot \mathrm{L}^{-1}$ promoveram as maiores taxas de desbaste dos frutos em todas as épocas de avaliação, sendo de 47,5\% e 42,4\% aos 120 dias após a aplicação, diferindo estatisticamente dos demais tratamentos. Os tratamentos etilclozate $200 \mathrm{mg} . \mathrm{L}^{-1}$, fenotiol $20 \mathrm{mg} . \mathrm{L}^{-1}$ e 2,4-DP $50 \mathrm{mg} . \mathrm{L}^{-1}$ causaram um leve desbaste, 19,3; 12,2 e 11,7 \%, respectivamente, porém não diferindo do controle que apresentou 8,5\% de desbaste dos frutos aos 120 dias após a aplicação (tabela 2).

Tabela 2. Efeito de aplicações de biorreguladores, realizadas após a queda fisiológica dos frutos, sobre a porcentagem de desbaste dos frutos do tangor 'Murcote' aos 30, 60, 90 e 120 dias após a aplicação.

\begin{tabular}{lcccc}
\hline Tratamentos & \multicolumn{4}{c}{ Dias após a aplicação } \\
& 30 & 60 & 90 & 120 \\
\hline Controle & $3,1 \mathrm{c}$ & $3,5 \mathrm{c}$ & $4,8 \mathrm{~b}$ & $8,5 \mathrm{~b}$ \\
3,5,6-TPA $15 \mathrm{mg} \cdot \mathrm{L}^{-1}$ & $36,6 \mathrm{a}$ & $38,6 \mathrm{a}$ & $40,6 \mathrm{a}$ & $42,5 \mathrm{a}$ \\
2,4-DP $50 \mathrm{mg} \cdot \mathrm{L}^{-1}$ & $6,4 \mathrm{bc}$ & $7,4 \mathrm{bc}$ & $8,0 \mathrm{~b}$ & $11,7 \mathrm{~b}$ \\
fenotiol $20 \mathrm{mg} \cdot \mathrm{L}^{-1}$ & $4,5 \mathrm{bc}$ & $5,1 \mathrm{bc}$ & $7,6 \mathrm{~b}$ & $12,2 \mathrm{~b}$ \\
ethephon $200 \mathrm{mg} \cdot \mathrm{L}^{-1}$ & $36,3 \mathrm{a}$ & $39,7 \mathrm{a}$ & $42,3 \mathrm{a}$ & $47,5 \mathrm{a}$ \\
etilclozate $200 \mathrm{mg} \cdot \mathrm{L}^{-1}$ & $10,0 \mathrm{~b}$ & $11,2 \mathrm{~b}$ & $11,5 \mathrm{~b}$ & $17,4 \mathrm{~b}$ \\
F & $20,52^{* *}$ & $19,82^{* *}$ & $18,3 * *$ & $12,08 * *$ \\
C.V. $(\%)$ & 39,75 & 39,39 & 37,35 & 35,97
\end{tabular}

Obs: Letras diferentes, dentro da mesma coluna, indicam diferenças estatísticas pelo teste de Duncan ao nível de 5\% de probabilidade. Valores de F, CV e teste de médias referentes aos dados transformados em raiz quadrada de $\mathrm{x}+0,5$.

ns: não significativo pelo teste $\mathrm{F}$

** significativo pelo teste $\mathrm{F}$ ao nível de $1 \%$ de probabilidade 
Nenhum tratamento causou efeito depressivo no desenvolvimento dos frutos do tangor 'Murcote'. O efeito dos tratamentos sobre o tamanho dos frutos variou em função das épocas de avaliação. Aos 30 e 90 dias após a aplicação, os frutos tratados com fenotiol $20 \mathrm{mg} . \mathrm{L}^{-1}$ apresentavam diâmetro superior ao controle. Aos 120 dias após aplicação, os frutos tratados com fenotiol $20 \mathrm{mg} . \mathrm{L}^{-1}$, etilclozate $200 \mathrm{mg} . \mathrm{L}^{-1}$ e ethephon $200 \mathrm{mg} . \mathrm{L}^{-1}$ foram superiores ao controle. Já aos 180 dias após a aplicação, somente o tratamento 3,5,6-TPA $15 \mathrm{mg} . \mathrm{L}^{-1}$, apresentou frutos com diâmetro superior ao controle (tabela 3).

Tabela 3. Efeito de aplicações de biorreguladores, realizadas após a queda fisiológica dos frutos, sobre o diâmetro médio dos frutos ( $\mathrm{mm})$ do tangor 'Murcote' aos 30, 60, 90, 120 e 180 dias após a aplicação.

\begin{tabular}{lccccc}
\hline Tratamentos & \multicolumn{5}{c}{ Dias após a aplicação } \\
& 30 & 60 & 90 & 120 & 180 \\
\hline Controle & $34,2 \mathrm{~b}$ & $43,9 \mathrm{a}$ & $50,5 \mathrm{c}$ & $55,3 \mathrm{~b}$ & $65,2 \mathrm{~b}$ \\
3,5,6-TPA $15 \mathrm{mg} . \mathrm{L}^{-1}$ & $34,4 \mathrm{ab}$ & $45,5 \mathrm{a}$ & $52,8 \mathrm{ab}$ & $57,0 \mathrm{ab}$ & $69,1 \mathrm{a}$ \\
2,4-DP 50 mg.L ${ }^{-1}$ & $33,5 \mathrm{~b}$ & $44,3 \mathrm{a}$ & $50,5 \mathrm{c}$ & $56,2 \mathrm{ab}$ & $66,3 \mathrm{~b}$ \\
fenotiol $20 \mathrm{mg} . \mathrm{L}^{-1}$ & $35,9 \mathrm{a}$ & $45,9 \mathrm{a}$ & $52,9 \mathrm{a}$ & $58,2 \mathrm{a}$ & $66,8 \mathrm{~b}$ \\
ethephon 200 mg.L & $33,0 \mathrm{~b}$ & $45,1 \mathrm{a}$ & $51,6 \mathrm{abc}$ & $57,3 \mathrm{a}$ & $66,4 \mathrm{~b}$ \\
etilclozate 200 mg.L & $33,6 \mathrm{~b}$ & $45,0 \mathrm{a}$ & $51,0 \mathrm{bc}$ & $57,4 \mathrm{a}$ & $65,1 \mathrm{~b}$ \\
F & $3,80 * *$ & $2,15^{\mathrm{ns}}$ & $3,16 *$ & $2,87 *$ & $6,52 * *$ \\
C.V.(\%) & 4,73 & 3,46 & 3,56 & 3,28 & 2,36 \\
\hline
\end{tabular}

Obs: Letras diferentes, dentro da mesma coluna, indicam diferenças estatísticas pelo teste de Duncan ao nível de 5\% de probabilidade.

ns: não significativo pelo teste $\mathrm{F}$

* significativo pelo teste $\mathrm{F}$ ao nível de $5 \%$ de probabilidade

** significativo pelo teste $\mathrm{F}$ ao nível de $1 \%$ de probabilidade

Já, na colheita, 08/08/2001, todos os tratamentos apresentaram um diâmetro médio dos frutos superior ao tratamento controle. Com exceção do tratamento etilclozate 200 mg. $\mathrm{L}^{-1}$, todos os demais tratamentos diferiram estatisticamente do controle que 
apresentou frutos com 65,8 mm de diâmetro médio. Os tratamentos 3,5,6-TPA 15 mg.L.' e ethephon $200 \mathrm{mg} . \mathrm{L}^{-1}$ apresentaram frutos com maior diâmetro médio, sendo de 70,4 e $70,3 \mathrm{~mm}$, respectivamente, seguidos do tratamento fenotiol $20 \mathrm{mg} . \mathrm{L}^{-1}$ que apresentou frutos com diâmetro médio de $68,7 \mathrm{~mm}$ (tabela 4).

Tabela 4. Efeito de aplicações de biorreguladores, realizadas após a queda fisiológica dos frutos, sobre o número de frutos e parâmetros de colheita do tangor 'Murcote'.

\begin{tabular}{|c|c|c|c|c|}
\hline Tratamentos & $\begin{array}{c}\text { Diâmetro médio } \\
\text { Frutos (mm) }\end{array}$ & $\begin{array}{l}\text { massa média } \\
\text { dos Frutos (g) }\end{array}$ & $\begin{array}{c}\text { Número de } \\
\text { Frutos/árvore }\end{array}$ & $\begin{array}{c}\text { Produção } \\
\text { (kg/árvore) }\end{array}$ \\
\hline Controle & $65,8 \mathrm{c}$ & $132,7 \mathrm{c}$ & $1125 \mathrm{a}$ & $149,75 \mathrm{a}$ \\
\hline 3,5,6-TPA $15 \mathrm{mg} \cdot \mathrm{L}^{-1}$ & $70,4 \mathrm{a}$ & $158,0 \mathrm{a}$ & $483 \mathrm{~b}$ & $78,20 \mathrm{c}$ \\
\hline 2,4-DP $50 \mathrm{mg} \cdot \mathrm{L}^{-1}$ & $67,7 \mathrm{~b}$ & $142,4 \mathrm{~b}$ & $890 \mathrm{a}$ & $126,67 \mathrm{ab}$ \\
\hline fenotiol $20 \mathrm{mg} . \mathrm{L}^{-1}$ & $68,7 \mathrm{ab}$ & $144,2 \mathrm{~b}$ & $1052 \mathrm{a}$ & $153,17 \mathrm{a}$ \\
\hline ethephon $200 \mathrm{mg} \cdot \mathrm{L}^{-1}$ & $70,3 \mathrm{a}$ & $155,6 \mathrm{a}$ & $586 \mathrm{~b}$ & $93,50 \mathrm{bc}$ \\
\hline etilclozate $200 \mathrm{mg} \cdot \mathrm{L}^{-1}$ & $67,5 \mathrm{bc}$ & $139,0 \mathrm{bc}$ & 889 a & $124,25 \mathrm{ab}$ \\
\hline $\mathrm{F}$ & $7,73 * *$ & $9,77 * *$ & $7,48 * *$ & $5,81 * *$ \\
\hline C.V. (\%) & 2,82 & 6,41 & 25,18 & 23,49 \\
\hline
\end{tabular}

Obs: Letras diferentes, dentro da mesma coluna, indicam diferenças estatísticas pelo teste de Duncan ao nível de 5\% de probabilidade.

ns: não significativo pelo teste $\mathrm{F}$ nível de $5 \%$ de probabilidade

** significativo pelo teste $\mathrm{F}$ ao nível de $1 \%$ de probabilidade

A figura 1 mostra o efeito dos tratamentos sobre a distribuição de frequência dos frutos do tangor 'Murcote' de acordo com a sua classe comercial, em relação ao controle. Observa-se que todos os tratamentos diminuíram a quantidade de frutos de menor diâmetro comercial e aumentaram a quantidade de frutos de maior tamanho e consequentemente de maior valor comercial. Somente os tratamentos ethephon 200 mg. $L^{-1}$ e 3,5,6-TPA $15 \mathrm{mg} . \mathrm{L}^{-1}$ promoveram a formação de frutos com mais de $78 \mathrm{~mm}$ de diâmetro e diminuíram drasticamente o número de frutos de pequeno tamanho. $\mathrm{O}$ 
tratamento fenotiol $20 \mathrm{mg} \cdot \mathrm{L}^{-1}$ diminuiu da mesma maneira a formação de frutos de pequeno tamanho, porém o aumento do número de frutos de maior tamanho foi um pouco inferior a estes dois tratamentos mencionados anteriormente.
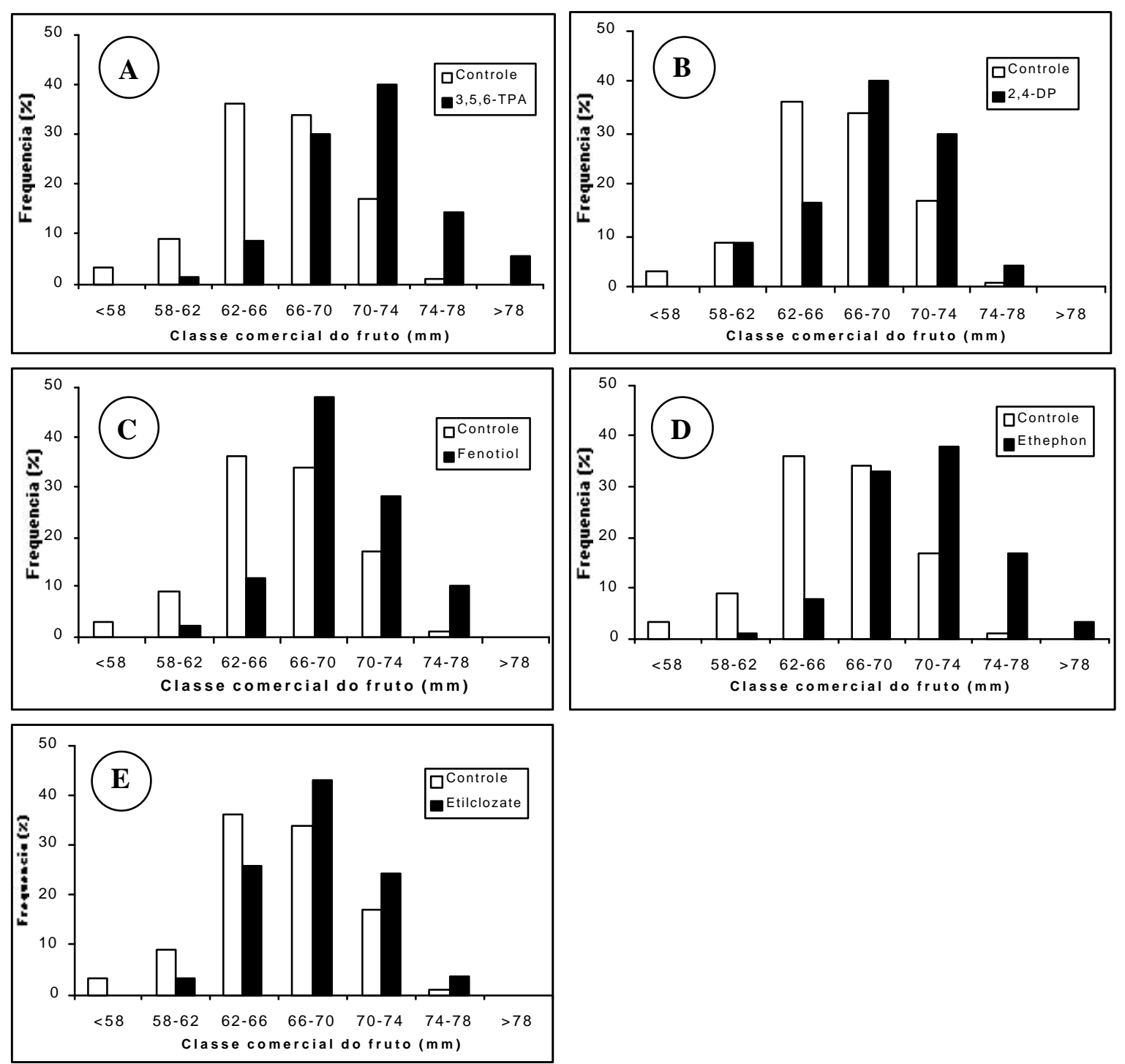

Figura 1 - Efeito dos biorreguladores, aplicados após a queda fisiológica dos frutos, na distribuição de frequência dos frutos do tangor 'Murcote' de acordo com sua classe comercial. A: 3,5,6-TPA $15 \mathrm{mg} . \mathrm{L}^{-1}$; B: 2,4-DP $50 \mathrm{mg} . \mathrm{L}^{-1}$; C: fenotiol $20 \mathrm{mg} . \mathrm{L}^{-1}$; D: ethephon $200 \mathrm{mg} . \mathrm{L}^{-1}$; E: etilclozate $200 \mathrm{mg} . \mathrm{L}^{-1}$. 
Todos os tratamentos promoveram aumentos na massa média dos frutos. Com exceção ao tratamento etilclozate $200 \mathrm{mg} . \mathrm{L}^{-1}$, todos os demais tratamentos diferiram estatisticamente do controle que apresentou frutos com 132,7 gramas de massa média. Os tratamentos 3,5,6-TPA $15 \mathrm{mg} . \mathrm{L}^{-1}$ e ethephon $200 \mathrm{mg} \cdot \mathrm{L}^{-1}$ promoveram o maior aumento na massa média dos frutos, apresentando frutos com 158 e 155,6 gramas, respectivamente. Esses tratamentos diferiram dos tratamentos fenotiol 20 mg.L $\mathrm{L}^{-1}$ e 2,4DP $50 \mathrm{mg} . \mathrm{L}^{-1}$ que apresentaram frutos com massa média de 144,2 e 142,4 gramas, respectivamente (tabela 4$)$.

Observa-se pela tabela 4 que, com exceção a tratamento fenotiol $20 \mathrm{mg} . \mathrm{L}^{-1}$, todos os demais tratamentos, causaram decréscimos na produção das plantas. No entanto, somente os tratamentos 3,5,6-TPA $15 \mathrm{mg} . \mathrm{L}^{-1}$ e ethephon $200 \mathrm{mg} . \mathrm{L}^{-1}$ diferiram estatisticamente do controle, tanto na produção final $(\mathrm{kg} / \mathrm{planta})$ como no número de frutos colhidos por planta. Estes tratamentos, respectivamente, diminuíram a produção em 47,7 e 37,5\% em kg/planta e em 57,1 e 47,9\% no número de frutos colhidos. Os tratamentos 2,4-DP $50 \mathrm{mg} . \mathrm{L}^{-1}$ e etilclozate $200 \mathrm{mg} . \mathrm{L}^{-1}$ causaram, respectivamente, uma redução de 15,4 e 17,0\% na produção em kg/planta e em 15,4 e 15,5\% no número de frutos colhidos.

Nenhum tratamento promoveu alterações na porcentagem, $\mathrm{pH}$, acidez, ratio e cor do suco extraído dos frutos (tabelas 5 a e 5b). Pela tabela 5b, observa-se que em relação ao teor de sólidos solúveis totais ( ${ }^{\circ}$ brix), o tratamento fenotiol $20 \mathrm{mg} . \mathrm{L}^{-1}$ apresentou a menor média $(12,72)$ em relação a este parâmetro, diferindo estatisticamente dos demais tratamentos.

Não houve diferenças estatísticas entre os tratamentos quanto ao índice de cor da casca dos frutos (tabela 5a). 
Tabela 5a. Efeito de aplicações de biorreguladores, realizadas após a queda fisiológica dos frutos, nas características tecnológicas dos frutos de tangor 'Murcote'.

\begin{tabular}{|c|c|c|c|c|}
\hline Tratamentos & $\begin{array}{c}\text { Teor de Suco } \\
(\%)\end{array}$ & $\begin{array}{c}\text { Suco + } \\
\text { Polpa }(\%)\end{array}$ & $\begin{array}{c}\text { Cor da Casca } \\
\text { (IC) }\end{array}$ & $\begin{array}{c}\text { Cor do suco } \\
\text { (IC) }\end{array}$ \\
\hline Controle & $45,95 \mathrm{a}$ & $53,41 \mathrm{a}$ & $4,97 \mathrm{a}$ & $37,81 \mathrm{a}$ \\
\hline 3,5,6-TPA $15 \mathrm{mg} \cdot \mathrm{L}^{-1}$ & $46,47 \mathrm{a}$ & 53,35 a & $5,65 \mathrm{a}$ & $38,14 \mathrm{a}$ \\
\hline 2,4-DP $50 \mathrm{mg} \cdot \mathrm{L}^{-1}$ & $47,13 \mathrm{a}$ & $54,10 \mathrm{a}$ & $5,67 \mathrm{a}$ & $38,01 \mathrm{a}$ \\
\hline fenotiol 20 mg.: $\mathrm{L}^{-1}$ & $46,20 \mathrm{a}$ & $53,29 \mathrm{a}$ & $5,29 \mathrm{a}$ & $38,08 \mathrm{a}$ \\
\hline ethephon $200 \mathrm{mg} . \mathrm{L}^{-1}$ & $47,60 \mathrm{a}$ & $53,72 \mathrm{a}$ & $4,97 \mathrm{a}$ & $38,04 \mathrm{a}$ \\
\hline etilclozate $200 \mathrm{mg} \cdot \mathrm{L}^{-1}$ & $47,79 \mathrm{a}$ & $54,94 \mathrm{a}$ & 5,98 a & $38,08 \mathrm{a}$ \\
\hline $\mathrm{F}$ & $1,51^{\mathrm{ns}}$ & $0,56^{\mathrm{ns}}$ & $1,16^{\mathrm{ns}}$ & $0,89^{\mathrm{ns}}$ \\
\hline C.V. $(\%)$ & 4,09 & 4,74 & 15,83 & 0,99 \\
\hline
\end{tabular}

ns: não significativo pelo teste $\mathrm{F}$ ao nível de $5 \%$ de probabilidade

Tabela 5b. Efeito de aplicações de biorreguladores, realizadas após a queda fisiológica dos frutos, nas características tecnológicas dos frutos de tangor 'Murcote'.

\begin{tabular}{|c|c|c|c|c|}
\hline Tratamentos & $\mathrm{pH}$ & Acidez (\%) & ${ }^{\mathrm{O}}$ Brix & Ratio \\
\hline Controle & $3,47 \mathrm{a}$ & $0,80 \mathrm{a}$ & $13,2 \mathrm{a}$ & $16,55 \mathrm{a}$ \\
\hline 3,5,6-TPA $15 \mathrm{mg} \cdot \mathrm{L}^{-1}$ & $3,52 \mathrm{a}$ & $0,81 \mathrm{a}$ & $13,3 \mathrm{a}$ & $16,43 \mathrm{a}$ \\
\hline 2,4-DP $50 \mathrm{mg} . \mathrm{L}^{-1}$ & $3,47 \mathrm{a}$ & $0,80 \mathrm{a}$ & $13,2 \mathrm{a}$ & $16,57 \mathrm{a}$ \\
\hline fenotiol $20 \mathrm{mg} \cdot \mathrm{L}^{-1}$ & $3,50 \mathrm{a}$ & $0,77 \mathrm{a}$ & $12,7 \mathrm{~b}$ & $16,59 \mathrm{a}$ \\
\hline ethephon $200 \mathrm{mg} . \mathrm{L}^{-1}$ & $3,46 \mathrm{a}$ & $0,79 \mathrm{a}$ & $13,2 \mathrm{a}$ & $16,81 \mathrm{a}$ \\
\hline etilclozate $200 \mathrm{mg} . \mathrm{L}^{-1}$ & $3,49 \mathrm{a}$ & $0,79 \mathrm{a}$ & $13,4 \mathrm{a}$ & $17,01 \mathrm{a}$ \\
\hline $\mathrm{F}$ & $1,76^{\mathrm{ns}}$ & $1,10^{\mathrm{ns}}$ & $3,10^{*}$ & $0,55^{\mathrm{ns}}$ \\
\hline C.V. $(\%)$ & 1,33 & 5,33 & 3,21 & 5,04 \\
\hline
\end{tabular}

Obs: Letras diferentes, dentro da mesma coluna, indicam diferenças estatísticas pelo teste de Duncan ao nível de $5 \%$ de probabilidade.

ns: não significativo pelo teste $\mathrm{F}$ ao nível de $5 \%$ de probabilidade

* significativo pelo teste $\mathrm{F}$ ao nível de $5 \%$ de probabilidade 
O tratamento fenotiol $20 \mathrm{mg} \cdot \mathrm{L}^{-1}$ promoveu a maior taxa de assimilação de $\mathrm{CO}_{2}$ $(12,467)$ em relação ao controle $(10,549)$, porém sem diferenças significativas entre os tratamentos quanto à este parâmetro. Os valores de transpiração e condutância estomática praticamente não foram alterados, não havendo diferenças estatísticas entre os tratamentos. Os teores médios de clorofila das folhas foram maiores nos tratamentos 3,5,6-TPA $15 \mathrm{mg} . \mathrm{L}^{-1}$ e ethephon $200 \mathrm{mg} . \mathrm{L}^{-1}$, porém sem diferir estatisticamente do controle (tabela 6).

Tabela 6. Efeito de aplicações de biorreguladores, realizadas após a queda fisiológica dos frutos, sobre parâmetros fisiológicos do tangor 'Murcote', 65 dias após a aplicação.

\begin{tabular}{|c|c|c|c|c|}
\hline Tratamentos & $\begin{array}{c}\text { Assimilação de } \\
\qquad \mathrm{CO}_{2}(\mu \mathrm{mol} \\
\left.\mathrm{CO}_{2} \mathrm{~m}^{-2} \mathrm{~s}^{-1}\right)\end{array}$ & $\begin{array}{c}\text { Transpiração } \\
(\mathrm{mmol} \\
\left.\mathrm{H}_{2} \mathrm{Om}^{-2} \mathrm{~s}^{-1}\right)\end{array}$ & $\begin{array}{c}\text { Condutância } \\
\text { estomática (mol } \\
\qquad \mathrm{H}_{2} \mathrm{Om}^{-2} \mathrm{~s}^{-1} \text { ) }\end{array}$ & $\begin{array}{c}\text { Teor de } \\
\text { Clorofila } \\
\text { (SPAD) }\end{array}$ \\
\hline Controle & $10,549 \mathrm{a}$ & $2,874 \mathrm{a}$ & $0,197 \mathrm{a}$ & $67,9 \mathrm{a}$ \\
\hline 3,5,6-TPA $15 \mathrm{mg} \cdot \mathrm{L}^{-1}$ & $10,978 \mathrm{a}$ & $2,760 \mathrm{a}$ & $0,194 \mathrm{a}$ & $69,5 \mathrm{a}$ \\
\hline 2,4-DP $50 \mathrm{mg} \cdot \mathrm{L}^{-1}$ & $10,500 \mathrm{a}$ & $2,994 \mathrm{a}$ & $0,185 \mathrm{a}$ & $66,5 \mathrm{a}$ \\
\hline fenotiol $20 \mathrm{mg} \cdot \mathrm{L}^{-1}$ & $12,467 \mathrm{a}$ & $3,320 \mathrm{a}$ & $0,193 \mathrm{a}$ & $66,6 \mathrm{a}$ \\
\hline ethephon $200 \mathrm{mg} . \mathrm{L}^{-1}$ & $11,206 \mathrm{a}$ & $2,854 \mathrm{a}$ & $0,172 \mathrm{a}$ & $69,8 \mathrm{a}$ \\
\hline etilclozate $200 \mathrm{mg} \cdot \mathrm{L}^{-1}$ & $10,773 \mathrm{a}$ & $2,731 \mathrm{a}$ & $0,164 \mathrm{a}$ & $67,2 \mathrm{a}$ \\
\hline $\mathrm{F}$ & $1,06^{\mathrm{ns}}$ & $0,92^{\mathrm{ns}}$ & $0,65^{\mathrm{ns}}$ & $0,90^{\mathrm{ns}}$ \\
\hline C.V. (\%) & 11,09 & 13,33 & 15,62 & 6,86 \\
\hline
\end{tabular}

ns: não significativo pelo teste $\mathrm{F}$ ao nível de $5 \%$ de probabilidade

\subsection{Discussão}

O poder desbastante das auxinas sintéticas tem-se mostrado muito variável, dependendo do cultivar, do tipo de auxina (Hirose, 1981; Agustí \& Almela, 1991; 
Wheaton, 1981; Greenberg et al., 1992; Guardiola et al., 1988) assim como da concentração aplicada (Aznar et al., 1995a, 1995b).

O tratamento 3,5,6-TPA $15 \mathrm{mg} . \mathrm{L}^{-1}$ foi o único que mostrou um efeito desbastante similar ao tratamento ethephon $200 \mathrm{mg} . \mathrm{L}^{-1}$. Segundo vários autores o 3,5,6-TPA é um estimulador direto no desenvolvimento dos frutos cítricos, mas pode causar desbastes consideráveis, dependendo do cultivar, da época de aplicação e concentração utilizada (Agustí et al., 1993b; 1994b; García-Lídon et al., 1993a; 1993b; Zaragoza et al., 1992). Segundo Kojima et al. (1986) e Iwahori \& Oohata (1976) as auxinas em altas concentrações promovem aumentos de ácido abscísico e etileno, provocando a abscisão de frutos jovens. Em nosso experimento, o aumento no tamanho dos frutos promovido pelo tratamento 3,5,6-TPA foi devido à ação de desbaste provocada pelo mesmo, já que os frutos apresentaram tamanho e número similares àqueles do tratamento ethephon 200 mg. $\mathrm{L}^{-1}$ (figura 2). A concentração de $15 \mathrm{mg} \cdot \mathrm{L}^{-1}$ se mostrou ideal para a prática do desbaste, porém excessiva no estímulo direto sobre o crescimento do fruto sem redução no número de frutos.

Os resultados obtidos com a aplicação de ethephon $200 \mathrm{mg} \cdot \mathrm{L}^{-1}$ confirmaram o mesmo como um biorregulador de poder conhecido sobre o desbaste de frutos cítricos conforme os resultados obtidos em tangerina 'Montenegrina' (Marodin, 1987), 'Kinnow' (Farmaham, 1992; Brar et al., 1992), 'Mexerica do Rio' (Castro et al., 1998), 'Ponkan' (Pacheco, 1999) e em tangor 'Murcote' (Vieira, 1985; Chapman, 1984).

Neste trabalho, o tratamento etilclozate $200 \mathrm{mg} . \mathrm{L}^{-1}$ não aumentou o desbaste, tamanho e massa média dos frutos. Este resultado contradiz com outros obtidos por Hirose et al. (1978) e por Noma (1981) em tangerina 'Satsuma' utilizando a mesma concentração. Pacheco (1999) observou que a aplicação de Etilclozate 25 mg.L.-1 promove o desbaste dos frutos em tangerina 'Ponkan'. Porém quando se utilizou o biorregulador na concentração de $100 \mathrm{mg} . \mathrm{L}^{-1}$, não foi observado nenhum efeito sobre o desbaste.

O aumento no tamanho dos frutos observado pelos tratamentos com fenotiol 20 mg.L $L^{-1}$ e 2,4-DP 50 mg.L $L^{-1}$ não se relacionou com a diminuição da produção em $\mathrm{kg} /$ planta e também com o número de frutos por árvore (figura 2). O resultado observado 
indica um efeito direto destas auxinas sobre o desenvolvimento do fruto, de acordo com trabalhos com outras auxinas sintéticas (Vanniere \& Arcuset, 1989; Agustí et al., 1992, 1994a, 1994b; El-Otmani et al., 1993). Resultados semelhantes foram observado por Aznar et al. (1995b) com aplicações de fenotiol $20 \mathrm{mg} . \mathrm{L}^{-1}$ em tangerina 'Fortune', e por Agustí et al. (1994a) com aplicações de 2,4-DP 50 mg.L L $^{-1}$ em tangerina 'Satsuma', onde se observou aumentos de até 3,5 e 4,0 mm, respectivamente, no diâmetro médio dos frutos, sem causar diminuição no número de frutos colhidos por árvore.

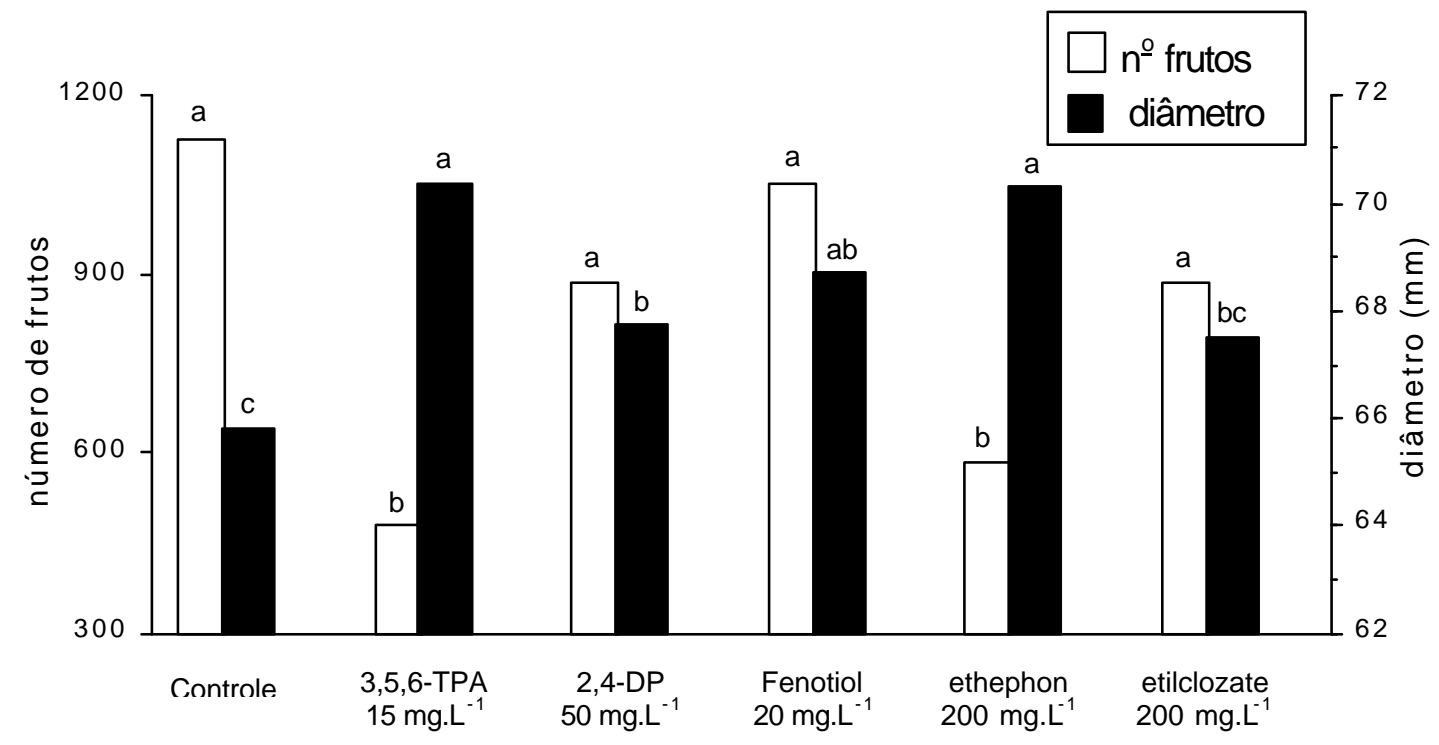

Figura 2 - Efeito dos biorreguladores, aplicados após a queda fisiológica dos frutos, sobre o tamanho final do fruto e o número de frutos colhidos. Obs: letras diferentes indicam diferenças estatísticas entre os tratamentos, dentro de cada parâmetro, pelo teste de Duncan ao nível de 5\% de probabilidade.

$\mathrm{O}$ tratamento com fenotiol apresentou melhores resultados que o 2,4-DP neste experimento. $\mathrm{O}$ efeito da auxina utilizada depende do cultivar em estudo e também da dosagem utilizada. Em tangerina 'Fortune', tratamentos com 3,5,6-TPA e fenotiol foram mais eficazes do que com 2,4-DP, no desenvolvimento dos frutos (Weiland \& Gómez, 1995). Embora os melhores resultados na promoção do crescimento do fruto, sem 
aumento no desbaste, são encontrados com concentrações de 50 mg.L. $\mathrm{L}^{-1}$, El-Otmani et al. (1993) observou que concentrações de $100 \mathrm{mg} . \mathrm{L}^{-1}$ foram mais eficazes do que concentrações de $50 \mathrm{mg} . \mathrm{L}^{-1}$, no aumento do diâmetro de frutos de tangerina 'Fortune' tratados com 2,4-DP. Já Gravina et al. (1997) não encontrou aumentos no diâmetro médio dos frutos de tangor 'Ellendalle', utilizando 2,4-DP a 75 e 150 mg.L.'.

Segundo Aznar et al. (1995b), o tratamento com fenotiol promove o crescimento do endocarpo, aumentando o tamanho dos lóculos e das vesículas de suco, sendo este aumento devido a uma ação na expansão e não sobre a divisão celular. Este efeito do fenotiol provoca consequentemente um aumento na força de dreno do fruto, assim como para outras auxinas sintéticas (Stewart et al., 1952; Guardiola \& Lázaro, 1987; Agustí et al., 1992), e explica o efeito direto no aumento do crescimento do fruto. De acordo com o resultado promovido pelo tratamento fenotiol, a capacidade de crescimento do fruto pode estar limitada devido a baixa concentração de auxinas endógenas durante o período crítico de crescimento do fruto, ou seja, nos primeiros estágios de expansão celular (Takahashi et al., 1975).

O efeito sobre o crescimento do fruto, obtido com a aplicação de auxinas sintéticas, não altera as características intrínsecas do fruto na maturação. As mudanças que ocorrem se devem exclusivamente, na maior parte dos casos, ao aumento no tamanho do fruto (Agustí et al., 1992). Estas observações estão de acordo com os resultados obtidos neste experimento, com exceção ao tratamento fenotiol $20 \mathrm{mg} . \mathrm{L}^{-1}$. Este tratamento provocou maior aumento na força de dreno dos frutos, já que aumentou o tamanho dos mesmos e não causou diminuição no número de frutos. A diminuição no teor de sólidos solúveis totais provavelmente tenha ocorrido devido a uma diluiçãa dos mesmos, onde a taxa de transporte destes não tenha suportado a força de dreno exercida pelos frutos. Embora tenha ocorrido essa diminuição no teor açúcares dos frutos, a qualidade (sabor) dos mesmos não foi afetada, já que houve uma diminuição no teor de acidez, o que acarretou na não modificação na relação sólidos solúveis totais/acidez (ratio).

Os resultados deste experimento também contradizem outros trabalhos, onde o etilclozate, na mesma dosagem utilizada, promoveu um aumento no conteúdo de sólidos 
totais sem afetar a acidez (Pons et al., 1989; Li et al., 1990), já que não foi observado este tipo de resposta. Não foi encontrado também nenhum aumento no teor de suco

promovido pelo tratamento 2,4-DP $50 \mathrm{mg} . \mathrm{L}^{-1}$, discordando do trabalho de El-Otmani et al. (1993), que apresentou um aumento no teor de suco dos frutos de tangerina 'Satsuma' tratados com 2,4-DP.

Agustí et al. (1992) sugere que o tratamento com auxinas aumenta a força de dreno dos frutos e consequentemente estimula a síntese e/ou transporte de fotoassimilados, água e nutrientes das folhas para os frutos. Mauk et al. (1986) mostraram que alguns biorreguladores podem aumentar a assimilação de $\mathrm{CO}_{2}$ pelas folhas e também a translocação de fotoassimilados para os frutos em desenvolvimento. $\mathrm{O}$ aumento na assimilação de $\mathrm{CO}_{2}$, nas folhas próximas aos frutos, do tratamento fenotiol $20 \mathrm{mg} . \mathrm{L}^{-1}$ provavelmente ocorreu devido a um efeito direto sobre a fotossíntese ou a um efeito retroativo provocado pelo maior aumento na força de dreno, promovido por este tratamento, pois segundo Lenz (1978) um aumento na demanda por carboidratos pelos frutos, resulta em um aumento na fotossíntese, em citros.

\subsection{Conclusões}

a) Os tratamentos ethephon $200 \mathrm{mg} . \mathrm{L}^{-1}$ e 3,5,6-TPA $15 \mathrm{mg} . \mathrm{L}^{-1}$ provocam as maiores taxas de desbaste, reduzindo a produção (número de frutos/árvore).

b) Os aumentos no tamanho, na massa média e no número de frutos de maior classe comercial são promovidos pelos tratamentos ethephon $200 \mathrm{mg} . \mathrm{L}^{-1}$, 3,5,6-TPA 15 mg. $\mathrm{L}^{-1}$, fenotiol $20 \mathrm{mg} . \mathrm{L}^{-1}$ e $2,4-\mathrm{DP} 50 \mathrm{mg} . \mathrm{L}^{-1}$.

c) O tratamento fenotiol $20 \mathrm{mg} . \mathrm{L}^{-1}$ reduz o teor de sólidos solúveis totais do suco dos frutos do tangor 'Murcote'. 
d) Não ocorrem alterações na assimilação de $\mathrm{CO}_{2}$, transpiração, condutância estomática e teor de clorofila, das plantas submetidas às aplicações dos biorreguladores. 


\title{
5 FIXAÇÃO DOS FRUTOS DA LIMA ÁCIDA 'TAHITI' (Citrus latifolia Tanaka) COM O USO DE BIORREGULADORES ${ }^{1}$
}

\author{
CHRYZ MELINSKI SERCILOTO ${ }^{2}$ e PAULO ROBERTO DE CAMARGO E \\ CASTRO $^{3}$
}

\section{Resumo}

Avaliou-se o efeito dos biorreguladores fenotiol $10 \mathrm{mg} . \mathrm{L}^{-1}$; Fengib $1 \mathrm{ml} . \mathrm{L}^{-1}$; Brassinolide 0,015 mg. $\mathrm{L}^{-1} ; \mathrm{GA}_{3} 20 \mathrm{mg} . \mathrm{L}^{-1} ; 2,4-\mathrm{D} 8 \mathrm{mg} . \mathrm{L}^{-1}$ e GA $20 \mathrm{mg} \cdot \mathrm{L}^{-1}+2,4-\mathrm{D} 8$ mg. $L^{-1}$ na fixação dos frutos da lima ácida 'Tahiti'. Os tratamentos foram aplicados durante uma florada extemporânea em 19/junho/2001, sendo gastos aproximadamente 7 litros de calda por planta. $\mathrm{O}$ desenvolvimento vegetativo não foi afetado pelos biorreguladores. Os tratamentos com ácido giberélico $\left(\mathrm{GA}_{3} 20 \mathrm{mg} . \mathrm{L}^{-1}\right.$, Fengib $1 \mathrm{ml} . \mathrm{L}^{-1} \mathrm{e}$ $\mathrm{GA}_{3} 20 \mathrm{mg} \cdot \mathrm{L}^{-1}+2,4-\mathrm{D} 8 \mathrm{mg} . \mathrm{L}^{-1}$ ) aumentaram a fixação dos frutos da lima ácida 'Tahiti', sendo que a maior fixação de frutos foi causada pelo tratamento $\mathrm{GA}_{3} 20 \mathrm{mg} \cdot \mathrm{L}^{-1}+2,4-\mathrm{D}$ $8 \mathrm{mg} . \mathrm{L}^{-1}$ que promoveu $21,3 \%$ de frutos fixados contra 5,9\% do controle. Os aumentos na fixação promovidos por estes biorreguladores foram acompanhados de acréscimos no teor médio de clorofila e na taxa de assimilação de $\mathrm{CO}_{2}$ das folhas da lima ácida 'Tahiti'.

Palavras-chave: limão 'Tahiti', reguladores vegetais, fotossíntese, frutificação

\footnotetext{
${ }^{1}$ Financiado pela Fapesp

${ }^{2}$ Pós-graduando em Fisiologia e Bioquímica de Plantas. Departamento de Ciências Biológicas, ESALQUSP. Bolsista Fapesp. e-mail: cmsercil@esalq.usp.br.

${ }^{3}$ Departamento de Ciências Biológicas, ESALQ-USP.
} 


\section{Summary}

\section{FRUIT SET ON 'TAHITI' LIME (Citrus latifolia Tanaka) WITH USE OF BIOREGULATORS}

The effects of bioregulators phenotiol $10 \mathrm{mg} . \mathrm{L}^{-1}$; Fengib $1 \mathrm{ml} . \mathrm{L}^{-1}$; Brassinolide

$0.015 \mathrm{mg} . \mathrm{L}^{-1} ; \mathrm{GA}_{3} 20 \mathrm{mg} . \mathrm{L}^{-1} ; 2,4-\mathrm{D} 8 \mathrm{mg} . \mathrm{L}^{-1}$ and $\mathrm{GA}_{3} 20 \mathrm{mg} . \mathrm{L}^{-1}+2,4-\mathrm{D} 8 \mathrm{mg} . \mathrm{L}^{-1}$ were evaluated on the fruit set of 'Tahiti' lime. The treatments were sprayed on whole trees in off-season flowering at 06/19/2001, at a rate of 7 litres per tree. The bioregulators didn't change the vegetative growth. The treatments with $\mathrm{GA}_{3}\left(\mathrm{GA}_{3} 20 \mathrm{mg} . \mathrm{L}^{-1}\right.$, Fengib $1 \mathrm{ml} . \mathrm{L}^{-1}$ e $\mathrm{GA}_{3} 20 \mathrm{mg} . \mathrm{L}^{-1}+2,4-\mathrm{D} 8 \mathrm{mg} \cdot \mathrm{L}^{-1}$ ) increased the fruit set. The best treatment was $\mathrm{GA}_{3}$ $20 \mathrm{mg} . \mathrm{L}^{-1}+2,4-\mathrm{D} 8 \mathrm{mg} \cdot \mathrm{L}^{-1}$ that promoted $21.3 \%$ of fruit set against $5.9 \%$ by control. The fruit set was coupled to increases in the the chlorophyll content and $\mathrm{CO}_{2}$ assimilation by leaves of 'Tahiti' lime.

Keywords: 'Persian' lime, 'Bearss' lime, growth regulators, fruit set, photosynthesis.

\subsection{Introdução}

A lima ácida 'Tahiti' também conhecida como limão 'Tahiti' é um cultivar cítrico que tem como característica apresentar nas regiões tropicais fluxos de crescimento e de floração contínuos, interrompidos por períodos de déficit hídrico. As sucessivas brotações dão origem a várias floradas, que por sua vez, implicam em diversas colheitas ao longo do ano (Coelho, 1993).

As florações mais abundantes se concentram entre setembro e outubro e os picos de produção estão concentrados entre os meses de janeiro a junho. Nesta época, os preços são mínimos, alcançando valores médios de apenas U\$ 0,18/kg contra U\$ 0,80/kg entre os meses de setembro e novembro, época de maior escassez dos frutos. 
O número de frutos cítricos colhidos não supera $10 \%$ das flores formadas, alcançando valores entre 0,1 e 3,5\% (Agustí et al., 1982; Monselise, 1986).

Em floradas de entressafra, o aumento do número de frutos fixados, e, posteriormente, colhidos, pode ser uma solução altamente viável, promovendo uma maior renda ao produtor.

$\mathrm{O}$ objetivo deste trabalho foi avaliar o efeito das aplicações de $\mathrm{GA}_{3}, 2,4-\mathrm{D}$, $\mathrm{GA}_{3}+2,4-\mathrm{D}$, fenotiol, Fengib e Brassinolide sobre a fixação dos frutos e parâmetros fisiológicos da lima ácida 'Tahiti', em aplicações realizadas em pleno florescimento.

\subsection{Material e métodos}

O experimento foi conduzido em condições de campo, em um pomar comercial composto de árvores de lima ácida 'Tahiti' (Citrus latifolia Tanaka) cultivar 'Quebra Galho' enxertadas sobre limoeiro 'Cravo' (Citrus limonia L. Osbeck), de aproximadamente 8 anos de idade, irrigadas por regime de aspersão, com espaçamento de 8,0 x 4,5 metros, plantado em latossolo vermelho-amarelo textura arenosa, localizado no Sítio Santo Antonio no município de Taquaritinga, SP, situado a $21,41^{\circ}$ de latitude sul e $48,50^{\circ}$ de longitude oeste. Foram selecionadas árvores homogêneas quanto ao porte, potencial produtivo, estado fitossanitário e nutricional, sendo que cada árvore constituiu uma parcela. Cada tratamento foi composto de oito repetições e o experimento montado em delineamento inteiramente casualizado. Os tratamentos utilizados neste experimento são apresentados na tabela 1.

A aplicação dos biorreguladores foi realizada durante a antese de uma florada extemporânea, no dia 19/06/2001. Os biorreguladores foram acompanhados de espalhante adesivo Silwett L-77 (0,05\%), sendo gastos aproximadamente 7 litros de calda por planta, em toda a extensão da copa, aplicados através de um pulverizador do tipo pistola. 
Tabela 1. Tratamentos com biorreguladores e concentrações, aplicados durante a antese, em árvores de lima ácida 'Tahiti'.

\section{Tratamentos}

1. Controle

2. fenotiol $10 \mathrm{mg} \cdot \mathrm{L}^{-1}$

3. Fengib $1 \mathrm{ml} \cdot \mathrm{L}^{-1}$ (fenotiol $10 \mathrm{mg} \cdot \mathrm{L}^{-1}+\mathrm{GA}_{3} 20 \mathrm{mg} \cdot \mathrm{L}^{-1}$ )

4. Brassinolide $0,015 \mathrm{mg} \cdot \mathrm{L}^{-1}$

5. $\mathrm{GA}_{3} 20 \mathrm{mg} \cdot \mathrm{L}^{-1}$

6. 2,4-D $8 \mathrm{mg} . \mathrm{L}^{-1}$

7. $\mathrm{GA}_{3} 20 \mathrm{mg} \cdot \mathrm{L}^{-1}+2,4-\mathrm{D} 8 \mathrm{mg} \cdot \mathrm{L}^{-1}$

Em cada planta, foram escolhidas quatro ramificações, dispostas em diagonal, para determinação da porcentagem média de fixação dos frutos e do número e comprimento total de brotações. As avaliações foram realizadas nos dias 19/06, 12/07, 08/08, 22/09/2001 e 4/10/2001.

As avaliações de fotossíntese, transpiração e condutância estomática foram realizadas através de um analisador de $\mathrm{CO}_{2}$ por radiação infra-vermelha (Infra Red Gas Analyser - IRGA, modelo LI-6400, LI-COR) com iluminação natural ao longo do dia, às $8: 00,10: 00,12: 00,14: 00$ e 16:00 horas. Por motivo de uma melhor realização das medidas, selecionaram-se para a determinação apenas os tratamentos com os melhores resultados até o dia 8/08/2001 $\left(\mathrm{GA}_{3} 20 \mathrm{mg} . \mathrm{L}^{-1}\right.$; fenotiol $10 \mathrm{mg} . \mathrm{L}^{-1}+\mathrm{GA}_{3} 20 \mathrm{mg} \cdot \mathrm{L}^{-1}$ e $\left.\mathrm{GA}_{3} 20 \mathrm{mg} \cdot \mathrm{L}^{-1}+2,4-\mathrm{D} 8 \mathrm{mg} \cdot \mathrm{L}^{-1}\right)$ e o controle. Foram utilizadas as folhas expostas ao durante ao longo de todo o dia, situadas no terço médio da copa das árvores. As mensurações foram realizadas nos dias 9/08 e 10/08/2001. Utilizaram-se 3 plantas/tratamento e duas folhas/planta sendo realizada 1 leitura por folha até completa estabilização das trocas gasosas.

As avaliações de clorofila foram realizadas através de um clorofilômetro (SPAD502, Minolta). As folhas, bem como sua posição, foram as mesmas descritas para as avaliações de fotossíntese. Foram realizadas 8 repetições/tratamento, sendo que se utilizou duas folhas por tratamento. As avaliações foram realizadas em 09/08/2001. 
Os resultados obtidos foram submetidos a análise de variância, sendo que, quando houve significância entre os tratamentos, as médias foram comparadas através do teste de Duncan ao nível de 5\% de probabilidade, segundo Gomes (1990).

\subsection{Resultados}

Em nenhuma data de avaliação foram verificados efeitos de algum biorregulador sobre o número e o comprimento total de brotações/ramo, não sendo verificadas diferenças estatísticas nestes dois parâmetros (tabelas 2 e 3 ).

Tabela 2. Efeito de aplicações de biorreguladores, realizadas durante a antese, sobre a número médio de brotações da lima ácida 'Tahiti' aos 23, 50 e 107 dias após a aplicação.

\begin{tabular}{lccc}
\hline Tratamentos & \multicolumn{3}{c}{ Dias após a aplicação } \\
& 23 & 50 & 107 \\
\hline Controle & $1,09 \mathrm{a}$ & $1,16 \mathrm{a}$ & $1,28 \mathrm{a}$ \\
fenotiol $10 \mathrm{mg} . \mathrm{L}^{-1}$ & $1,19 \mathrm{a}$ & $1,53 \mathrm{a}$ & $1,63 \mathrm{a}$ \\
Fengib $1 \mathrm{ml} . \mathrm{L}^{-1}$ & $1,09 \mathrm{a}$ & $1,16 \mathrm{a}$ & $1,34 \mathrm{a}$ \\
Brassinolide 0,015 mg.L ${ }^{-1}$ & $1,09 \mathrm{a}$ & $1,37 \mathrm{a}$ & $1,38 \mathrm{a}$ \\
$\mathrm{GA}_{3} 20 \mathrm{mg} . \mathrm{L}^{-1}$ & $1,00 \mathrm{a}$ & $1,22 \mathrm{a}$ & $1,19 \mathrm{a}$ \\
2,4-D $8 \mathrm{mg} . \mathrm{L}^{-1}$ & $1,03 \mathrm{a}$ & $1,19 \mathrm{a}$ & $1,22 \mathrm{a}$ \\
GA $20 \mathrm{mg} \cdot \mathrm{L}^{-1}+2,4-\mathrm{D} 8 \mathrm{mg} \cdot \mathrm{L}^{-1}$ & $1,09 \mathrm{a}$ & $1,22 \mathrm{a}$ & $1,19 \mathrm{a}$ \\
F & $0,92^{\mathrm{ns}}$ & $1,98^{\mathrm{ns}}$ & $1,91^{\mathrm{ns}}$ \\
C.V. $(\%)$ & 16,09 & 22,24 & 24,05 \\
\hline
\end{tabular}

ns: não significativo pelo teste $\mathrm{F}$ ao nível de $5 \%$ de probabilidade. 
Tabela 3. Efeito de aplicações de biorreguladores, realizadas durante a antese, sobre o comprimento total das brotações/ramo da lima ácida 'Tahiti' aos 23, 50 e 107 dias após a aplicação.

\begin{tabular}{lccc}
\hline Tratamentos & \multicolumn{3}{c}{ Dias após a aplicação } \\
& 23 & 50 & 107 \\
\hline Controle & $22,5 \mathrm{a}$ & $22,5 \mathrm{a}$ & $24,8 \mathrm{a}$ \\
fenotiol $10 \mathrm{mg} . \mathrm{L}^{-1}$ & $27,0 \mathrm{a}$ & $31,6 \mathrm{a}$ & $36,5 \mathrm{a}$ \\
Fengib 1ml.L ${ }^{-1}$ & $23,9 \mathrm{a}$ & $25,5 \mathrm{a}$ & $28,1 \mathrm{a}$ \\
Brassinolide 0,015 mg.L ${ }^{-1}$ & $22,4 \mathrm{a}$ & $26,9 \mathrm{a}$ & $29,1 \mathrm{a}$ \\
GA $20 \mathrm{mg} \cdot \mathrm{L}^{-1}$ & $17,1 \mathrm{a}$ & $23,9 \mathrm{a}$ & $24,4 \mathrm{a}$ \\
2,4-D $8 \mathrm{mg} . \mathrm{L}^{-1}$ & $25,4 \mathrm{a}$ & $27,4 \mathrm{a}$ & $28,8 \mathrm{a}$ \\
GA $20 \mathrm{mg} \cdot \mathrm{L}^{-1}+2,4-\mathrm{D} 8 \mathrm{mg} . \mathrm{L}^{-1}$ & $25,4 \mathrm{a}$ & $27,5 \mathrm{a}$ & $26,6 \mathrm{a}$ \\
F & $1,47^{\mathrm{ns}}$ & $1,55^{\mathrm{ns}}$ & $1,88^{\mathrm{ns}}$ \\
C.V. $(\%)$ & 32,10 & 26,90 & 29,54 \\
\hline
\end{tabular}

ns: não significativo pelo teste $\mathrm{F}$ ao nível de $5 \%$ de probabilidade.

A partir dos 50 dias após a aplicação, verificaram-se aumentos na fixação dos frutos da lima ácida 'Tahiti', provocados pelos biorreguladores, embora não tenham sido verificadas diferenças estatísticas em relação ao controle. Nesta data, todos os tratamentos que continham ácido giberélico promoveram os maiores aumentos na fixação dos frutos (tabela 4).

Na última data de avaliação (107 dias após a aplicação), todos os tratamentos com ácido giberélico isolado $\left(\mathrm{GA}_{3} 20 \mathrm{mg} . \mathrm{L}^{-1}\right)$ ou em combinação (Fengib 1ml.L ${ }^{-1} \mathrm{GA}_{3}$ $\left.20 \mathrm{mg} . \mathrm{L}^{-1}+2,4-\mathrm{D} 8 \mathrm{mg} . \mathrm{L}^{-1}\right)$ e 2,4-D $8 \mathrm{mg} \cdot \mathrm{L}^{-1}$, promoveram aumentos na porcentagem de fixação dos frutos da lima ácida 'Tahiti'. No entanto, somente a combinação $\mathrm{GA}_{3} 20$ mg. $\mathrm{L}^{-1}+2,4-\mathrm{D} 8 \mathrm{mg} . \mathrm{L}^{-1}$ ), que promoveu a fixação de $21,25 \%$ dos frutos, diferiu estatisticamente do controle que obteve 5,94\% de frutos fixados (figura 1). 
Tabela 4. Efeito de aplicações de biorreguladores, realizadas durante a antese, sobre a porcentagem de frutos fixados da lima ácida 'Tahiti' aos 23, 50 e 107 dias após a aplicação

\begin{tabular}{|c|c|c|c|}
\hline \multirow[t]{2}{*}{ Tratamentos } & \multicolumn{3}{|c|}{ Dias após a aplicação } \\
\hline & 23 & 50 & 107 \\
\hline Controle & $84,7 \mathrm{a}$ & $15,1 \mathrm{ab}$ & $5,9 \mathrm{bc}$ \\
\hline fenotiol $10 \mathrm{mg} . \mathrm{L}^{-1}$ & $70,8 \mathrm{a}$ & $7,2 \mathrm{c}$ & $3,1 \mathrm{c}$ \\
\hline Fengib $1 \mathrm{ml} . \mathrm{L}^{-1}$ & $84,4 \mathrm{a}$ & $17,0 \mathrm{ab}$ & $9,8 \mathrm{bc}$ \\
\hline Brassinolide $0,015 \mathrm{mg} . \mathrm{L}^{-1}$ & $80,6 \mathrm{a}$ & $8,7 \mathrm{bc}$ & $5,9 \mathrm{bc}$ \\
\hline $\mathrm{GA}_{3} 20 \mathrm{mg} \cdot \mathrm{L}^{-1}$ & $76,0 \mathrm{a}$ & $18,1 \mathrm{ab}$ & $12,0 \mathrm{ab}$ \\
\hline 2,4-D $8 \mathrm{mg} \cdot \mathrm{L}^{-1}$ & $86,7 \mathrm{a}$ & $11,2 \mathrm{~b}$ & $8,2 \mathrm{bc}$ \\
\hline $\mathrm{GA}_{3} 20 \mathrm{mg} \cdot \mathrm{L}^{-1}+2,4-\mathrm{D} 8 \mathrm{mg} \cdot \mathrm{L}^{-1}$ & 80,6 a & $29,0 \mathrm{a}$ & $21,2 \mathrm{a}$ \\
\hline $\mathrm{F}$ & $9,9^{\mathrm{ns}}$ & $2,52 *$ & $4,11 * *$ \\
\hline C.V. $(\%)$ & 9,89 & 46,10 & 48,56 \\
\hline
\end{tabular}

Obs: Letras diferentes, dentro da mesma coluna, indicam diferenças estatísticas pelo teste de Duncan ao nível de 5\% de probabilidade. Valores de F, CV e teste de médias referentes aos dados transformados em raiz quadrada de $\mathrm{x}+0,5$.

ns: não significativo pelo teste $\mathrm{F}$ ao nível de $5 \%$ de probabilidade.

* $\quad$ significativo pelo teste $\mathrm{F}$ ao nível de $5 \%$ de probabilidade.

** $\quad$ significativo pelo teste $\mathrm{F}$ ao nível de $1 \%$ de probabilidade.

As folhas das árvores que foram submetidas aos tratamentos $\mathrm{GA}_{3} 20 \mathrm{mg} . \mathrm{L}^{-1} \mathrm{e}$ $\mathrm{GA}_{3} 20 \mathrm{mg} . \mathrm{L}^{-1}+2,4-\mathrm{D} 8 \mathrm{mg} . \mathrm{L}^{-1}$ apresentaram as maiores taxas de assimilação de $\mathrm{CO}_{2}$ às 8:00 $\left(3,54\right.$ e 3,40 $\left.\mu \mathrm{mol} \mathrm{CO}_{2} \mathrm{~m}^{-2} \mathrm{~s}^{-1}\right), 10: 00\left(1,98\right.$ e 2,10 $\left.\mu \mathrm{mol} \mathrm{CO}_{2} \mathrm{~m}^{-2} \mathrm{~s}^{-1}\right)$ e 12:00 horas $\left(1,64\right.$ e 1,68 $\left.\mu \mathrm{mol} \mathrm{CO} \mathrm{Cm}^{-2} \mathrm{~s}^{-1}\right)$, respectivamente, diferindo estatisticamente das folhas das árvores controle que apresentaram valores de 2,90; 1,67 e $1,32 \mu \mathrm{mol} \mathrm{CO}_{2} \mathrm{~m}^{-2} \mathrm{~s}^{-1}$, nos respectivos horários. Às 14:00 e às 16:00 horas não foram observadas diferenças estatísticas entre os tratamentos. $\mathrm{O}$ tratamento Fengib $1 \mathrm{ml} . \mathrm{L}^{-1}$ não diferiu do controle em todos os horários de avaliação (figura 2). 


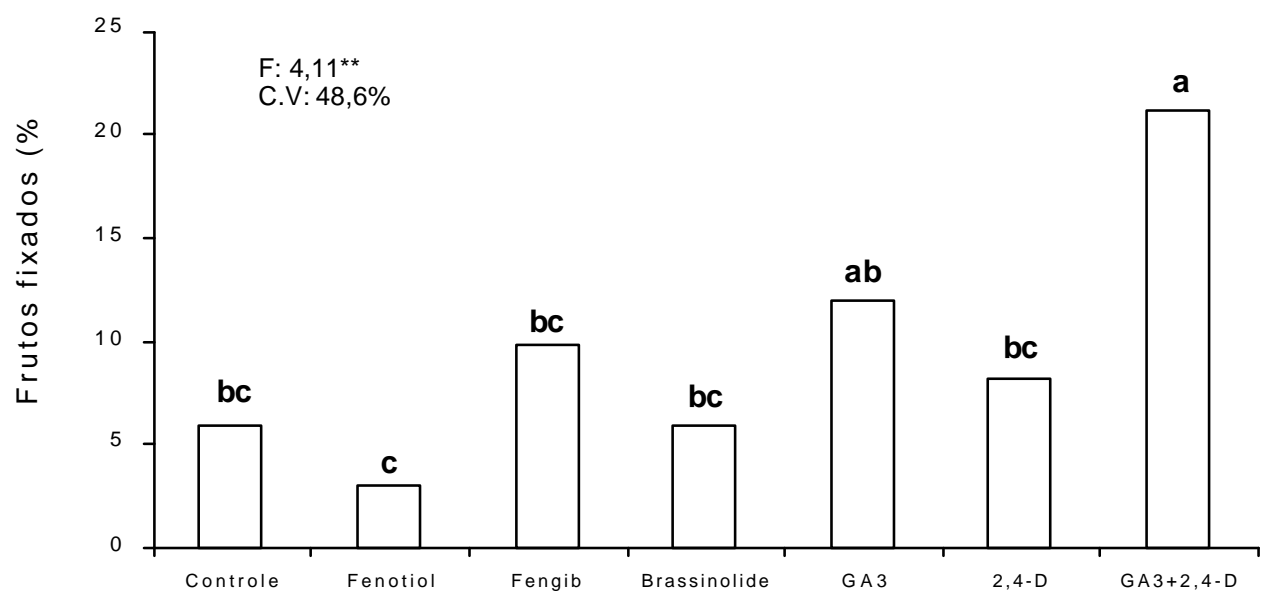

Figura 1 - Efeito dos biorreguladores sobre a porcentagem de frutos fixados da lima ácida 'Tahiti' aos 107 dias após a aplicação.

Quanto ao parâmetro transpiração, somente no terceiro horário de avaliação (12:00 horas) verificou-se diferença estatística entre os tratamentos. Neste horário, as folhas das árvores do tratamento $\mathrm{GA}_{3} 20 \mathrm{mg} . \mathrm{L}^{-1}$ apresentaram as maiores taxas de

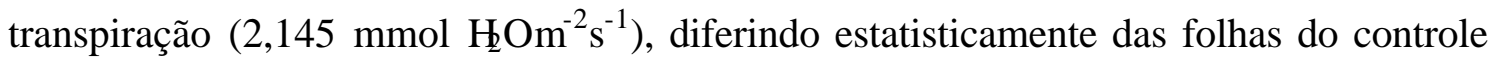
$\left(1,045 \mathrm{mmol} \mathrm{H}_{2} \mathrm{Om}^{-2} \mathrm{~s}^{-1}\right)$ (tabela 5).

Em nenhum horário de avaliação foram observadas diferenças estatísticas entre os tratamentos sobre os valores de condutância estomática (tabela 6). 

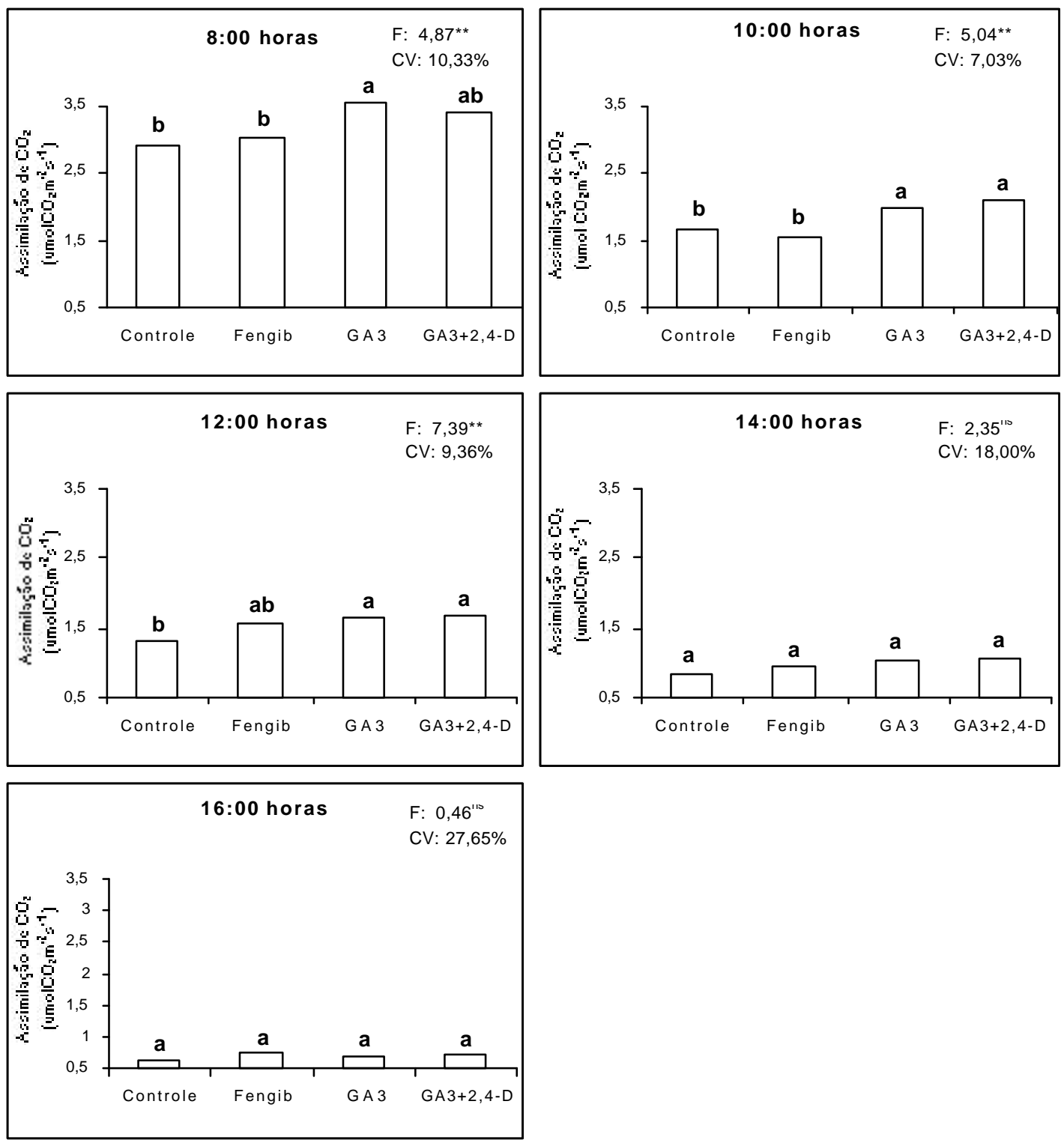

Figura 2: Efeito do Fengib 1 ml.L ${ }^{-1}, \mathrm{GA}_{3} 20 \mathrm{mg} . \mathrm{L}^{-1}$ e $\mathrm{GA}_{3}+2,4-\mathrm{D} 8 \mathrm{mg} . \mathrm{L}^{-1}$ sobre a fotossíntese (assimilação de $\mathrm{CO}_{2}$ ) das folhas da lima ácida 'Tahiti' ao longo do $51^{\circ}$ dia após a aplicação. Obs: letras diferentes indicam diferenças estatísticas entre os tratamentos, dentro de cada horário, pelo teste de Duncan ao nível de $5 \%$ de probabilidade. 
Tabela 5. Efeito de aplicações de biorreguladores, realizadas durante a antese, sobre a taxa transpiratória (mmol $\left.\mathrm{H}_{2} \mathrm{Om}^{-2} \mathrm{~s}^{-1}\right)$ das folhas da lima ácida 'Tahiti' ao longo do $51^{\circ}$ dia após a aplicação.

\begin{tabular}{|c|c|c|c|c|c|}
\hline \multirow[t]{2}{*}{ Tratamentos } & \multicolumn{5}{|c|}{ Horário } \\
\hline & $8: 00$ & $10: 00$ & $12: 00$ & $14: 00$ & $16: 00$ \\
\hline Controle & $0,742 \mathrm{a}$ & $1,180 \mathrm{a}$ & $1,045 \mathrm{~b}$ & $1,502 \mathrm{a}$ & $0,925 \mathrm{a}$ \\
\hline Fengib $1 \mathrm{ml} . \mathrm{L}^{-1}$ & $0,498 \mathrm{a}$ & $1,058 \mathrm{a}$ & $1,172 \mathrm{~b}$ & $1,215 \mathrm{a}$ & $0,725 \mathrm{a}$ \\
\hline $\mathrm{GA}_{3} 20 \mathrm{mg} \cdot \mathrm{L}^{-1}$ & $0,995 \mathrm{a}$ & $1,492 \mathrm{a}$ & $2,145 \mathrm{a}$ & $1,775 \mathrm{a}$ & $1,008 \mathrm{a}$ \\
\hline $\mathrm{GA}_{3} 20 \mathrm{mg} \cdot \mathrm{L}^{-1}+2,4-\mathrm{D} 8 \mathrm{mg} \cdot \mathrm{L}^{-1}$ & 0,793 a & $1,317 \mathrm{a}$ & $1,488 \mathrm{ab}$ & $1,538 \mathrm{a}$ & $0,752 \mathrm{a}$ \\
\hline $\mathrm{F}$ & $2,10^{\mathrm{ns}}$ & $1,36^{\mathrm{ns}}$ & $3,65^{*}$ & $1,66^{\mathrm{ns}}$ & $2,62^{\mathrm{ns}}$ \\
\hline C.V. $(\%)$ & 45,6 & 31,04 & 42,28 & 28,93 & 24,22 \\
\hline
\end{tabular}

Obs: Letras diferentes, dentro da mesma coluna, indicam diferenças estatísticas pelo teste de Duncan ao nível de $5 \%$ de probabilidade.

ns: não significativo pelo teste $\mathrm{F}$ ao nível de $5 \%$ de probabilidade.

* $\quad$ significativo pelo teste $\mathrm{F}$ ao nível de $5 \%$ de probabilidade.

Tabela 6. Efeito de aplicações de biorreguladores, realizadas durante a antese, sobre a condutância estomática ( $\mathrm{mol} \mathrm{H}_{2} \mathrm{O} \mathrm{m}^{-2} \mathrm{~s}^{-1}$ ) das folhas da lima ácida 'Tahiti' ao longo do $51^{\circ}$ dia após a aplicação.

\begin{tabular}{|c|c|c|c|c|c|}
\hline \multirow[t]{2}{*}{ Tratamentos } & \multicolumn{5}{|c|}{ Horário } \\
\hline & 8:00 & 10:00 & $12: 00$ & 14:00 & $16: 00$ \\
\hline Controle & $0,045 \mathrm{a}$ & $0,043 \mathrm{a}$ & $0,030 \mathrm{a}$ & $0,033 \mathrm{a}$ & $0,018 \mathrm{a}$ \\
\hline Fengib $1 \mathrm{ml} . \mathrm{L}^{-1}$ & $0,021 \mathrm{a}$ & $0,031 \mathrm{a}$ & $0,027 \mathrm{a}$ & $0,023 \mathrm{a}$ & $0,014 \mathrm{a}$ \\
\hline $\mathrm{GA}_{3} 20 \mathrm{mg} \cdot \mathrm{L}^{-1}$ & $0,043 \mathrm{a}$ & $0,043 \mathrm{a}$ & $0,046 \mathrm{a}$ & $0,032 \mathrm{a}$ & $0,022 \mathrm{a}$ \\
\hline $\mathrm{GA}_{3} 20 \mathrm{mg} \cdot \mathrm{L}^{-1}+2,4-\mathrm{D} 8 \mathrm{mg} \cdot \mathrm{L}^{-1}$ & $0,033 \mathrm{a}$ & $0,033 \mathrm{a}$ & $0,029 \mathrm{a}$ & $0,027 \mathrm{a}$ & $0,017 \mathrm{a}$ \\
\hline $\mathrm{F}$ & $2,33^{\mathrm{ns}}$ & $1,22^{\mathrm{ns}}$ & $1,98^{\mathrm{ns}}$ & $1,62^{\mathrm{ns}}$ & $2,64^{\mathrm{ns}}$ \\
\hline C.V. $(\%)$ & 49,98 & 38,96 & 45,65 & 30,55 & 26,28 \\
\hline
\end{tabular}

ns: não significativo pelo teste $\mathrm{F}$ ao nível de $5 \%$ de probabilidade. 
Os tratamentos $\mathrm{GA}_{3} 20 \mathrm{mg} . \mathrm{L}^{-1} ; 2,4-\mathrm{D} 8 \mathrm{mg} . \mathrm{L}^{-1}$; Fengib $1 \mathrm{ml} . \mathrm{L}^{-1}$ e fenotiol 10 mg. $L^{-1}$ promoveram aumentos no teor de clorofila das folhas da lima ácida 'Tahiti'. As folhas submetidas a estes tratamentos leituras médias de 71,3;69,4; 69,1 e 67,3; realizadas pelo clorofilômetero, respectivamente. Já as folhas do controle apresentaram leitura média de 65,6. Apenas o tratamento $\mathrm{GA}_{3} 20 \mathrm{mg} \cdot \mathrm{L}^{-1}$ diferiu estatisticamente do controle. Os tratamentos 2,4-D $8 \mathrm{mg} . \mathrm{L}^{-1}$, Fengib $1 \mathrm{ml} . \mathrm{L}^{-1}$ e fenotiol $10 \mathrm{mg} . \mathrm{L}^{-1}$ apresentaram médias estatisticamente semelhantes ao controle e ao tratamento $\mathrm{GA}_{3} 20$ mg. $L^{-1}$ (figura 3).

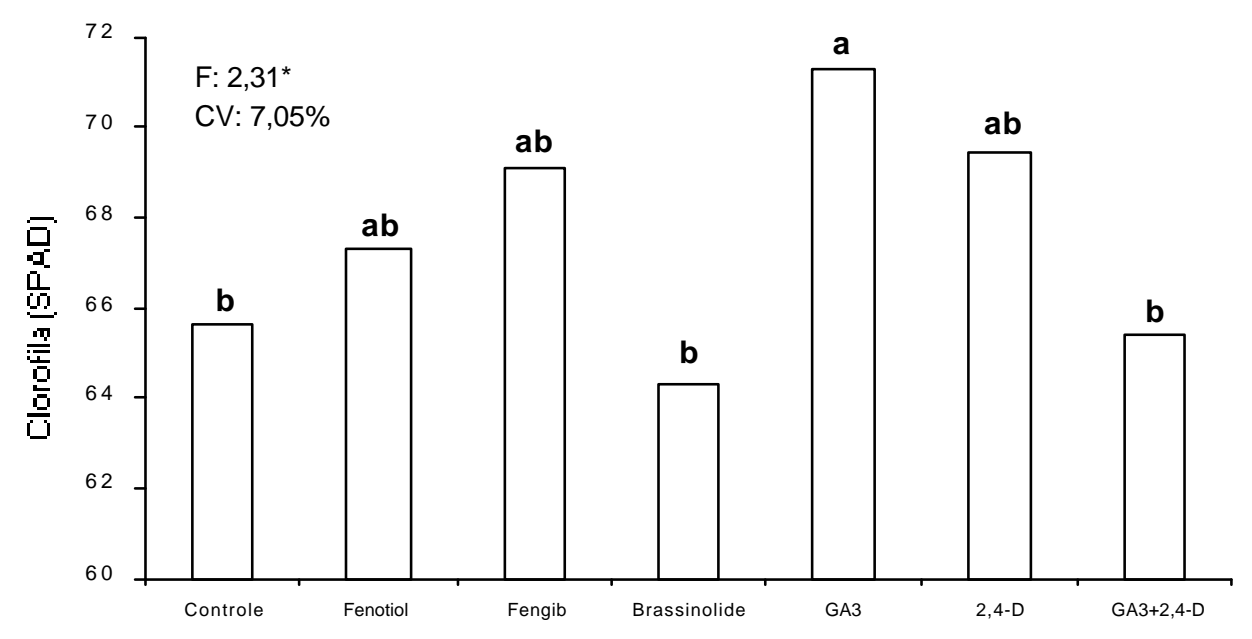

Figura 3: Efeito dos biorreguladores sobre o teor médio de clorofila das folhas da lima ácida 'Tahiti' no 51ํ dia após a aplicação. Obs: Letras diferentes indicam diferenças estatísticas entre os tratamentos pelo teste de Duncan ao nível de $5 \%$ de probabilidade. 


\subsection{Discussão}

Neste experimento os biorreguladores não afetaram o desenvolvimento vegetativo da lima ácida 'Tahiti', já que o número e comprimento total das brotações não foram afetados até a última data de avaliação (107 dias após a aplicação), apresentando desenvolvimento similar ao controle. Segundo Guardiola (1992), a presença de frutos pode exercer um efeito inibidor no crescimento vegetivo, o que não foi verificado neste experimento até 107 dias após a aplicação dos biorreguladores.

Os resultados observados confirmam a ação do ácido giberélico sobre a fixação dos frutos cítricos. Doses entre 3 a $20 \mathrm{mg} . \mathrm{L}^{-1}$ promovem a fixação de frutos de outros cultivares cítricos com aplicações realizadas durante a antese (Talón, 1997; Talón et al., 1997; Agustí \& Almela, 1991; ElOtmani et al., 1992; Fornes et al., 1992). Embora tenham ocorrido aumentos pouco mais de duas vezes em relação ao controle testemunha, os resultados da fixação dos frutos promovida pelo tratamento $\mathrm{GA}_{3} 20 \mathrm{mg} \cdot \mathrm{L}^{-1}$ estão próximos aos resultados obtidos por Spósito (1999) que observou 12,7\% de fixação dos frutos, porém sendo 25 vezes maior ao resultado obtido pelo controle que atingiu apenas $0,64 \%$ de fixação dos frutos.

Segundo vários autores, o 2,4-D não promove a fixação de alguns frutos cítricos (Soost \& Burnet, 1961; Krezdorn, 1969; Rivero et al., 1969). Aumentos na fixação dos frutos promovidos por 2,4-D (20 mg. $\left.\mathrm{L}^{-1}\right)$ são relatados no trabalho de Wilson (1983). Segundo Talón et al. (1997) algumas auxinas têm a habilidade tem agir como inibidoras da abscisão, desde que o processo de abscisão não tenha se iniciado. Observa-se no presente trabalho que o 2,4-D agiu sinergicamente ao ácido giberélico, promovendo a maior fixação dos frutos da lima ácida 'Tahiti'. Alguns trabalhos citam este efeito sinérgico entre as duas substâncias, porém, quando aplicados na mudança da cor dos frutos e visando aumentar a permanência destes na árvore (Castro et al., 1997; Barros, 1992). Os resultados obtidos com esta combinação estão mais próximos ao trabalho desenvolvido por Koller (1999) que obteve aumentos na fixação da laranjeira 'Monte

Parnaso' com duas aplicações de GA 5 mg.L $\mathrm{L}^{-1}+2,4-\mathrm{D} 15 \mathrm{mg} . \mathrm{L}^{-1}$, sendo uma na antese e outra durante a queda fisiológica dos frutos. 
A ausência de aumentos na fixação dos frutos, obtidos com os tratamentos fenotiol $10 \mathrm{mg} . \mathrm{L}^{-1}$ e Brassinolide $0,015 \mathrm{mg} . \mathrm{L}^{-1}$, discordam de outros resultados positivos conseguidos com aplicações de fenotiol $15 \mathrm{mg} . \mathrm{L}^{-1}$ em laranja 'Navelina' (Agustí et al., 1996) e com aplicações de Brassinolide em laranja 'Morita Navel' (Sugiyama \& Kuraishi, 1989).

As maiores taxas de assimilação de $\mathrm{CO}_{2}$ (fotossíntese), observadas nas folhas dos tratamentos $\mathrm{GA}_{3} 20 \mathrm{mg} . \mathrm{L}^{-1}$ e $\mathrm{GA}_{3} 20 \mathrm{mg} . \mathrm{L}^{-1}+2,4-\mathrm{D} 8 \mathrm{mg} . \mathrm{L}^{-1}$ devem-se à uma ação direta do(s) biorregulador(es) ou a um efeito retroativo devido ao aumento na força de dreno gerada, já que as plantas submetidas a estes dois tratamentos apresentaram as maiores porcentagens de fixação de frutos.

Segundo Arteca \& Dong (1981), aplicações de giberelinas exógenas estimulam a taxa de fotossíntese de plantas intactas. Em citros, aplicações de Paclobutrazol, um inibidor da síntese de giberelinas, reduzem as taxas de fotossíntese (Vu \& Yelenosky, 1992). Aumentos nas taxas de fotossíntese também foram verificadas com aplicações de auxinas (IAA) em citros (Sharma et al., 1990).

$\mathrm{O}$ aumento na força de dreno gerada pelos biorreguladores pode ter estimulado a síntese e/ou o transporte de fotoassimilados, água e nutrientes das folhas para os frutos. Lenz (1978) considera que um aumento na demanda de carboidratos pelos frutos pode acarretar em um aumento na fotossíntese das folhas cítricas.

Mauk et al. (1986) verificaram que biorreguladores podem aumentar a assimilação de $\mathrm{CO}_{2}$ pelas folhas, assim como a translocação de fotoassimilados para os frutos em desenvolvimento. $\mathrm{O}$ aumento na taxa de fotossíntese provocada pelo ácido giberélico pode estar relacionado com os aumentos provocados por este biorregulador no teor de clotrofila das folhas. Segundo Syversten \& Lloyd (1994) a assimilação de $\mathrm{CO}_{2}$ é também limitada pela atividade da taxa de transporte de elétrons. Esta, é dependente da irradiação absorvida pelas folhas, que por sua vez aumenta com o teor de clorofila das folhas. 


\subsection{Conclusões}

a) A aplicação dos biorreguladores não afeta o desenvolvimento vegetativo das plantas.

b) $\mathrm{O}$ tratamento $\mathrm{GA}_{3} 20 \mathrm{mg} \cdot \mathrm{L}^{-1}+2,4-\mathrm{D} 8 \mathrm{mg} \cdot \mathrm{L}^{-1}$ promove a maior fixação dos frutos da lima ácida 'Tahiti'.

c) Os tratamentos $\mathrm{GA}_{3} 20 \mathrm{mg} \cdot \mathrm{L}^{-1}$ e $\mathrm{GA}_{3} 20 \mathrm{mg} \cdot \mathrm{L}^{-1}+2,4-\mathrm{D} 8 \mathrm{mg} \cdot \mathrm{L}^{-1}$ promovem aumentos na taxa de assimilação de $\mathrm{CO}_{2}$.

d) O tratamento $\mathrm{GA}_{3} 20 \mathrm{mg} . \mathrm{L}^{-1}$ causa um aumento no teor médio de clorofila das folhas. 


\section{CONCLUSÕES GERAIS}

A aplicação dos biorreguladores $\mathrm{GA}_{3} 20 \mathrm{mg} . \mathrm{L}-1+2,4-\mathrm{D} 8 \mathrm{mg} \cdot \mathrm{L}^{-1}, \mathrm{GA}_{3} 20$ mg. $\mathrm{L}^{-1}$ e fenotiol $10 \mathrm{mg} . \mathrm{L}^{-1}$, após a queda das pétalas, proporcionaram, respectivamente, aumentos de 3,4; 3,0 e 3,0\% no diâmetro e de 7,8; 8,8 e 9,5\% na massa média dos frutos, sem causar nenhum efeito sobre o número de frutos e a produção, e sem afetar as qualidades tecnológicas dos frutos e as características fisiológicas estudadas do tangor 'Murcote'.

A aplicação dos biorreguladores 3,5,6-TPA $15 \mathrm{mg} . \mathrm{L}^{-1}$, ethephon $200 \mathrm{mg} . \mathrm{L}^{-1} \mathrm{e}$ fenotiol $20 \mathrm{mg} . \mathrm{L}^{-1}$ após a queda fisiológica dos frutos proporcionaram, respectivamente, aumentos de 7,0; 6,8 e 4,4\% no tamanho e de 19,1; 17,3 e 8,7\% na massa média dos frutos. No entanto, as aplicações de 3,5,6-TPA $15 \mathrm{mg} . \mathrm{L}^{-1}$ e ethephon $200 \mathrm{mg} . \mathrm{L}^{-1}$ provocaram, respectivamente, uma diminuição de $57,1 \%$ e $47,9 \%$ no número de frutos e de $47,8 \%$ e $37,5 \%$ na produção, o que não foi observado com o tratamento fenotiol 20 mg. $\mathrm{L}^{-1}$. Entretanto, o tratamento fenotiol $20 \mathrm{mg} \cdot \mathrm{L}^{-1}$ provocou uma diminuição de 0,4 ${ }^{\circ}$ brix em relação ao controle, porém sem afetar o ratio (brix/acidez). Os efeitos dos biorreguladores sobre o desbaste e tamanho dos frutos não causaram modificações nas características fisiológicas estudadas do tangor 'Murcote'.

Os tratamentos com ácido giberélico $\left(\mathrm{GA}_{3} 20 \mathrm{mg} \cdot \mathrm{L}^{-1}\right.$, Fengib $1 \mathrm{ml} . \mathrm{L}^{-1}$ e GA 320 mg. $\mathrm{L}^{-1}+2,4-\mathrm{D} 8 \mathrm{mg} . \mathrm{L}^{-1}$ ) aumentam a fixação dos frutos da lima ácida 'Tahiti', sendo que a maior fixação de frutos é proporcionada pelo tratamento $\mathrm{GA}_{3} 20 \mathrm{mg}$. $\mathrm{L}^{-1}+2,4-\mathrm{D} 8$ mg. $L^{-1}$ fixando $21,3 \%$ de frutos fixados contra $5,9 \%$ do controle. Os aumentos na fixação promovidos por estes biorreguladores não afetam o desenvolvimento vegetativo e são acompanhados de acréscimos no teor médio de clorofila e na taxa de assimilação de $\mathrm{CO}_{2}$ das folhas da lima ácida 'Tahiti'. 


\section{REFERÊNCIAS BIBLIOGRÁFICAS}

AGUSTÍ, M.; ALMELA, V. Aplicación de fitorreguladores en citricultura. Barcelona: Aedos, 1991. 261p.

AGUSTÍ, M.; ALMELA, V.; PONS, J. Efecto del 2,4-DP sobre el desarollo y tamaño final del fruto de la mandarina 'Clementina Fina' ( Citrus reticulata Blanco ). Levante Agricola, v. 307/308, p. 4-12, 1991.

AGUSTÍ, M.; GARCIA-MARI, F.; GUARDIOLA, J.L. The influence of flowering intensity on the shedding of reproductive structures in sweet orange. Scientia Horticulturae, v.17, p.343-352, 1982.

AGUSTÍ, M.; ALMELA, V.; AZNAR, M.; EL-OTMANI, M.; PONS, J. Satsuma mandarin fruit size increased by 2,4-DP. HortScience, v.29, p.279-281, 1994a.

AGUSTÍ, M.; ALMELA, V.; JUAN, M.; AZNAR, M. Efecto del Fengib sobre el cuajado y calidad del fruto en los agrios. Agricola Vergel, v.1, p.184-190, 1996.

AGUSTÍ, M.; ALMELA, V.; AZNAR, M.; JUAN, M.; ERES, V. Desarrollo y tamaño final del fruto en los agrios. Valência: Generalitat Valenciana, 1995a. 80p.

AGUSTÍ, M.; ALMELA, V.; AZNAR, M.; PONS, J.; EL-OTMANI, M. The use of 2,4DP to improve fruit size in citrus. Proceedings of the International Society of Citriculture, v.1, p.423-427, 1992. 
AGUSTÍ, M.; ALMELA, V.; JUAN, M.; AZNAR, M.; FERRIZ, R. Aumento del tamaño del fruto en mandarinas mediante la aplicación de fenotiol. Levante Agricola, n.322, p.22-27, 1993a.

AGUSTÍ, M.; EL-OTMANI, M.; AZNAR, M.; JUAN, M. ALMELA, V. Effect of 3,5,6trichloro-2-pyridyloxyacetic acid on Clementine early fruitlet development and on fruit size at maturity. Journal of Horticultural Science, v.70, p.955-962, 1995b.

AGUSTÍ, M.; ALMELA, V.; JUAN, M.; AZNAR, M.; ZARAGOZA, S.; PRIMOMILLO, E. Aplicación de 3,5,6-TPA para aumentar el tamaño del fruto en los agrios. Levante Agricola, n.323, p.117-126, 1993 b.

AGUSTÍ, M.; ALMELA, V.; JUAN, M.; PRIMO-MILLO, E.; TRENOR, I.; ZARAGOZA, S. Effect of 3,5,6-trichloro-2-pyridyl-oxyacetic acid on fruit size and yield of 'Clausellina' mandarin. Journal of Horticultural Science, v.69, p.219-223, 1994b.

AGUSTÍ, M.; ALMELA, V.; ZARAGOZA, S.; JUAN, M.; TRENOR, I.; ALONSO, E.; PRIMO-MILLO, E. Técnicas para mejorar el tamaño del fruto de naranjas y mandarinas. Cuadernos de Tecnologia Agrária. Série Citricultura, n.3, p. 1-15, 1998.

AKAO, S.; TSUKAHARA, S.; HISADA, H.; ONO, S. Contribution of photosynthetic assimilates to development of flower and spring flush in Citrus unshiu Marc. Journal of Japanese Society of Horticultural Science, v.50, p.1-9, 1981.

ALMELA, V.; AGUSTÍ, M.; JUAN, M.; AZNAR, M. Mejora de la producion y del tamaño del fruto de Clementina Oronules. Actas de Horticultura, v.9, p.384-389, 1993. 
ALMELA, V.; EL-OTMANI, M.; PONS, J.; AGUSTÍ, M. Aumento del tamaño final del fruto mediante la aplicación del 2,4-DP. Levante Agricola, n.309/310, p.86-94, 1991.

ARTECA, R.N.; DONG, C.H. Increased photosynthetic rates following gibberellic acid treatments to the roots of tomato plants. Photosynthesis Research, v.2, p.343-349, 1981.

ARTECA, R.N.; HOLCOMB, E.J.; SCHLAGNHAUFER, C.; TSAI, D.S. Effects of root applications of gibberellic acid on photosynthesis, tarnspiration, and growth of geranium plants. HortScience, v.20, p.925-927, 1985.

AWAD, M.; CASTRO, P.R.C. Introdução à fisiologia vegetal. São Paulo: Nobel, 1983. $177 \mathrm{p}$.

AZNAR, M.; ALMELA, V.; JUAN, J.; EL-OTMANI, M.; AGUSTÍ, M. Efecto de la aplicacion del 3,5,6-tricloro-2-piridiloxiacetico sobre la abscision y el desarrollo del fruto de la mandarina 'Oronules'. Investigación Agraria, v.10, n.1, p.31-37, 1995a.

AZNAR, M.; ALMELA, V.; JUAN, M.; EL-OTMANI, M.; AGUSTÍ, M. Effect of the synthetic auxin phenotiol on fruit development of 'Fortune' mandarin. Journal of Horticultural Science, v.20, p.617-621, 1995 b.

BAIN, J.M. Morphological, anatomical and physiological changes in the developing fruit of the Valencia orange (Citrus sinensis (L.) Osbeck). Australian Journal of Botany, v.6, p.1-24, 1958. 
BARROS, S.A. Efeito das aplicações pré-colheita de fitorreguladores, no desenvolvimento final e maturação do fruto da tangerina 'Poncan' (Citrus reticulata Blanco). Botucatu, 1992. 107p. Dissertação (Mestrado) - Faculdade de Ciências Agrárias, Universidade Estadual Paulista “Júlio de Mesquita Filho”.

BOWES, G. Facing the inevitable: plants and increasing atmospheric $\mathrm{CO}_{2}$. Annual Review of Plant Physiology and Plant Molecular Biology, v.44, p.309-332, 1993.

BRAR, S.S.; MINHAS, P.P.S.; KAUNDAL, G.S.; SUBHADRABANDHU, S. Chemical thinning of Kinnow mandarin. Acta Horticulturae, n.321, p.443-448, 1992.

BROUGHTON, W.J.; HELLMUTH, E.O; YEUNG, D. Role of glucose in development of the gibberellin response in peas. Biochimica et Biophisica Acta, v.26, p.491-500, 1970.

BUSTAN, A.; GOLDSCHIMDT, E.E. Estimating the cost of flowering in a grapefruit tree. Plant Cell Environment, v.21, p.217-224, 1998.

CARVAlHO, C.R.L. MANTOVANI, D.M.B.; CARVALHO, P.R.N.; MORAES, R.M.M. Análises químicas de alimentos. Campinas: ITAL, 1990, 121p.

CASTRO, P.R.C. Reguladores vegetais na citricultura tropical. In: SEMINÁRIO INTERNACIONAL DE CITROS, 5., Bebedouro, 1998. Anais. Campinas: Fundação Cargill, 1998. p.463-479.

CASTRO, P.R.C; MEDINA, C.L.; PACHECO, A.C. Potencialidade para a utilização de reguladores vegetais na citricultura brasileira. Laranja, v.17, n.1, p.109-121, 1997. 
CASTRO, P.R.C.; PACHECO, A.C; MEDINA, C.L. Effects of NAA, ethephon and figaron on postbloom thinning of Citrus deliciosa Tem. 'Do rio' mandarin. In: INTERNATIONAL HORTICULTURAL CONGRESS, 25., Bruxelas, 1998. Proceedings. Bruxelas, 1998. p.128.

COMPANHIA DE ENTREPOSTOS E ARMAZÉNS GERAIS DO ESTADO DE SÃO PAULO. Centro de Qualidade em Horticultura. Programa Brasileiro para a melhoria dos padrões comerciais e emblagens de hortigranjeiros: classificação das tangerinas. São Paulo, 2000. 1v.

CHAPMAN, J.C. Ethephon as a fruit thinning agent for 'Murcott' mandarins. Scientia Horticulturae, v.24, p.135-141, 1984.

COELHO, Y.S. Lima ácida 'Tahiti' para exportação. Brasília: FRUPEX, 1993. 35p. (FRUPEX. Publicações Técnicas, 1).

COGGINS, C.W.; HIELD, H.Z. Plant growth regulators. In: REUTHER, W.; BATCHELOR, L.D.; WEBBER, H.J. (Ed.). The citrus industry. Berkley: University of California, 1968. v.2, p.371-389.

CUÑAT, P.; GARCÍA, J.L.; CAROT, V.; PICO, F.; VAYA, J.L. Fitorreguladores en fruticultura. Aplicaciones del ácido giberélico $\left(\mathrm{GA}_{3}\right)$ y ácido 2,4,5triclorofenoxipropiónico para mejorar la productividad del Clementino sin hueso. Revista Agroquimica y Tecnologia de Alimentos, v.14, p.106-112, 1974.

DE JONG, T.M. Fruit effects on photosynthesis in Prunus persica. Physiologia Plantarum, v.66, p.149-153, 1986. 
DUARTE, A.M.M.; TRINDADE, D.T.G.; GUARDIOLA, J.L. Thinning of 'Esbal' Clementine with 2,4-dichlorophenoxiacetic acid. Influence on yield, fruit size and fruit quality. Proceedings of the International Society of Citriculture, v.2, p.929933, 1996.

EL-OTMANI, M. Usos principais de reguladores de crescimento na produção de citros. In: SEMINÁRIO INTERNACIONAL DE CITROS: FISIOLOGIA, 2.,Campinas, 1992. Anais. Campinas: Fundação Cargill, 1992. p.43-51.

EL-OTMANI, M.; AGUSTÍ, M.; AZNAR, M.; ALMELA, V. Improving the size of 'Fortune' mandarin fruits by the auxin 2,4-DP. Scientia Horticulturae, v.55, p.283290, 1993.

EL-OTMANI,M.; BEM-ISMAIL, M.C.; AIT-OUBAHOU, A.; ACHOURI, M. Growth regulators use on 'Clementine' mandarin to improve fruit set. Proceedings of the International Society of Citriculture, v.1, p.500-502, 1994.

ERNER, Y.; KAPLAN, Y.; BRACHA A.; HAMON, M. Increasing fruit size using auxins and potassium. Acta Horticulturae, n.329, p.112-119, 1993.

FARMAHAN, H.L. Chemical thinning improves "off" year crop harvest in Kinnow mandarin. Horticultural Journal, v.5, n.2, p.67-72, 1992.

FNP CONSULTORIA \& COMÉRCIO. AGRIANUAL 2001: anuário da agricultura brasileira. São Paulo, 2000. 303p.

FORNES, F.; VAN-RENSBURG, P.J.J.; SÁNCHEZ-PERALES, M.; GUARDIOLA, J.L. Fruit setting treatments effects on two Clementine mandarin cultivars. Proceedings of the International Society of Citriculture, v.1, p.489-492, 1992. 
GARCIA-LIDÓN, A.; MOLINA, R.; ESPINOSA, A.; GARCIA-LEGAZ, M.F.; PORRAS-CASTILLO, I. Aclareo químico en limón. Efecto sobre el tamaño del fruto. Actas de Horticultura, v.9, p.396-400, 1993a.

GARCIA-LIDÓN, A.; MOLINA, R.; ESPINOSA, A.; GARCIA-LEGAZ, M.F.; PORRAS-CASTILLO, I. Engorde de frutos en limón fino mediante la auxina de síntesis 3,5,6-TPA. Aclareo químico, efectos sobre el tamaño y calidad de fruto. Levante Agricola, v.323, p.123-126, 1993 b.

GARCÍA-MARTINEZ, J.L.; GARCÍA-PAPI, M.A. The influence of gibberellic acid, 2,4-dichlorophenoxyacetic acid and 6-benzylaminopurine on fruit set of Clementine mandarin. Scientia Horticulturae, v.10, p.285-294, 1979.

GOLDSCHIMDT, E.E.; MONSELISE, S.P. Physiological assumptions toward the development of a citrus fruiting model. Proceedings of the International Society of Citriculture, v.2, p.668-672, 1977.

GOMES, F.P. Curso de estatística experimental. 13.ed. São Paulo: Nobel, 1990. $468 p$.

GRAVINA, A.; ARBIZA, H.; BOZZO, A; LASERRE, E.; ARIAS, M.; RONCA, F. Synthetic auxins evaluation on fruit size and yield in 'Ellendale' tangor. Acta Horticulturae, n.463, p.413-418, 1997.

GREENBERG, J.; HERTZANO, Y.; ESHEL, G. Effects of 2,4-d, ethephon and NAA on fruit size and yield of 'Star Ruby' red grapefruit. Proceedings of the International Society of Citriculture, v.1, p.520-523, 1992.

GUARDIOLA, J.L. Factores internos que determinam el tamaño del fruto en los agrios. Levante Agricola, n.279/280, p.247-250, 1987. 
GUARDIOLA, J.L. Fruit set and growth. In: INTERNATIONAL SEMINAR ON CITRUS, 2., Jaboticabal, 1992. Proceedings. Jaboticabal: Funep, 1992. p.1-29.

GUARDIOLA, J.L. Auxinas de síntesis y desarrollo del fruto: estrategias de uso y mecanismos de acción. Levante Agricola, n.333, p.288-298, 1995.

GUARDIOLA, J.L. Synthetic auxins and citrus fruit size. Strategies of use and mechanism of action. Proceedings of the International Society of Citriculture, v.2, p.953-960, 1996.

GUARDIOLA, J.L.; GARCÍA-LUIS, A. Thinning effects on citrus yield and fruit size. Acta Horticulturae, n.463, p.463-473, 1997.

GUARDIOLA, J.L.; GARCÍA-LUIS, A. Increase size in citrus. Thinning and stimulation of fruit growth. Plant Growth Regulation, v.31, p.121-132, 2000.

GUARDIOLA, J.L.; LAZARO, E. The effect of synthetic auxins on fruit growth and anatomical development in 'Satsuma' mandarin. Scientia Horticulturae, v.31, p.119$130,1987$.

GUARDIOLA, J.L.; ALMELA, V.; BARRÉS, M.T. Dual effect of auxins on fruit growth in 'Satsuma' mandarin. Scientia Horticulturae, v.34, p.229-237, 1988.

HARREL, D.C.; WILLIAMS, L.E. Net CO2 assimilation rate of grape vine leaves in response to trunk girdling and gibberellic acid application. Plant Physiology, v.83, p.457-459, 1987. 
HIROSE, K. Development of chemical thinners of commercial use for Satsuma mandarin in Japan. Proceedings of the International Society of Citriculture, v.1, p.256-260, 1981.

HIROSE, K.; IWAGARI, I.; SUZUKI, K. IZAA (5-chloroindazol-8-acetic acid ethyl ester) as a new thinning agent Satsuma mandarin. Proceedings of the International Society of Citriculture, v.1, p.270-273, 1978.

HOAD, G.V.; LOVEYS, B.R.; SKENEK, G.M. The effect of fruit-removal on cytokinins and gibberellic-like substances. Planta, v.136, p.25-30, 1977.

IWAHORI, S. Use of growth regulators in the control of cropping of mandarin varieties. Proceedings of the International Society of Citriculture, v.1, p.263-269, 1978.

IWAHORI, S.; OOHATA, J.T. Chemical thinning of 'Satsuma' mandarin (Citrus unshiu Marc.) fruit by 1-naphtalene acetic acid: role of etylene and cellulose. Scientia Horticulturae, v.4, p.167-174, 1976.

IWAHORI, S.; TOMINAGA, S.; OOHATA, J.T. Ethylclozate accerelates colouration and enhances fruit quality of Ponkan, Citrus reticulata Blanco. Scientia Horticulturae, v.28, p.243-250, 1986.

KAMURO, Y.; HIRAI, S.K. Physiological activity of ethychlozate. Fruit thinning and maturity aaccelerating effects for citrus. Proceedings of the International Society of Citriculture, v.1, p.260-263, 1981.

KOJIMA, K.; GOTO, A.; NAKASHIMA, S. Effects of uniconazole-P on abscission and endogenous ABA, IAA, and GA-like substances levels of Satsuma mandarin frutlet. Bioscience, Biotechnology and Biochemistry, v.60, n.5, p.901-902, 1986. 
KOLLER, O.C.; SCHÄFER, G.; SARTORI, I.A.; SCHWARZ, S.F.; LIMA, J.G. Efeito da anelagem, fitorreguladores e fungicidas sobre a fixação de frutos na laranjeira 'Monte Parnaso'. Revista Brasileira de Fruticultura, v.21, n.1, p.70-73, 1999.

KREZDORN, A.H. The use of growth regulators to improve fruit set in citrus. In: INTERNATIONAL CITRUS CONGRESS, 1., 1969. Proceedings, v.3, 1969, p.1113-1119.

LENZ, F. Photosynthesis and respiration of as dependent upon fruit load. Proceedings of the International Society of Citriculture, v.1, p.70-71, 1978.

LI, S.Y.; YE, M.E.; HE, R.B.; XUN, H.; JIANG, D.H.; CHEN, H.B.; FU, D.Y. The effect of Figaron on fruit thinning and fruit quality of Bendizau. Acta Horticulturae Sinica, v.17, n.3, p.191-196, 1990.

LIMA, J.E.O; DAVIES, F.S. Growth regulators, fruit drop, yields and quality of Navel orange in Florida. Journal of American Society for Horticultural Science. v.109, p.81-84, 1984.

LÓPEZ, J.G.O. Los reguladores de crescimento o fithormonas. Aplicaciones práticas en frutales. Hortofruticultura, v.3, n.64, 1993.

MANDAVA, N.B. Plant growth-promoting brassinosteroids. Annual Review of Plant Physiolgy and Plant Molecular Biology, v.39, p.23-52, 1988.

MANSFIELD, T.A.; McAINSH, M.R. Hormones as regulators of water balance. In: DAVIES, P.J (Ed.). Plant hormones: physiology, biochemistry and molecular biology. 2.ed. Dordrecht: Kluwer Academic, 1995. p.598-616. 
MARODIN, G.A.B. Raleio químico e manual de frutinhos de tangerineira (Citrus deliciosa Tenore) cv. Montenegrina. Porto Alegre, 1987. 124p. Dissertação (Mestrado) - Universidade Federal do Rio Grande do Sul.

MARTINEZ-CORTINA, C.; SANZ, A. Comparison between the effect of the fruit and exogenous $\mathrm{GA}_{3}$-applications on source-sink relationships in Citrus sprouts. Annals of Botany, v.68, p.143-149, 1991.

MARTINEZ-CORTINA, C.; SANZ, A.; GUARDIOLA, J.L. Possible involvement of gibberellins on leaf expansion and carbohydrate accumulation in Citrus. Gartenbauwissenchaft, v.54, p.268-272, 1989.

MATSUSHIMA, J.; YONEMORI, K. Effect of ethylene on fruit drop, growth, photosynthesis, diffusive resistance and abscisic acis of citrus tress. Proceedings of the International of Citriculture, v.1, p.304-307, 1981.

MAUK, C.S.; BAUSHER, M.G.; YELENOVSKY, G. Influence of growth regulator treatments on dry matter production, fruit abscission, and 14C-assimilate partioning in citrus. Journal of Plant Growth Regulator, v.5, p.111-120, 1986.

MONSELISE, S.P. Citrus fruit development: endogenous systems and external regulation. Proceedings of the International Society of Citriculture, v.2, p.664668, 1977.

MONSELISE, S.P. Citrus. In: MONSELISE, S.P. (Ed.) Handboock of fruit set and development. Boca Raton: CRC Press, 1986. p.87-108.

MONSELISE, S.P.; GOLDSCHIMDT, E.E. Alternate bearing in the fruit trees. Horticultural Review, v.4, p.128-173, 1982. 
NOMA, Y. Effect of ethyl 5-chloro-1H-3-indazolylacetate on fruit thinning of Satsuma mandarin (Citrus unshiu Marc.). Proceedings of the International Society of Citriculture, v.1, p.271-275, 1981.

ORTELLS, R.C. Influencia de diversos fitorreguladores sobre las variedades de mandarina Satsuma y Clementina. In: CONGRESSO MUNDIAL DE CITRICULTURA, 1., Murcia, 1973. Anais. Murcia, 1973, v.2, p.383-391.

ORTOLÁ, A.G.; MONERRI, F.; GUARDIOLA, J.L. The use of nafhtalene acetic acid as a fruit growth enhancer in Satsuma mandarin: a comparison with the fruit thinning effect. Scientia Horticulturae, v.47, p.15-25, 1991.

ORTOLÁ, A.G.; MONERRI, F.; GUARDIOLA, J.L. Fruitlet age and inflorescence characteristics affect the thinning and the increase in fruitlet growth rate induced by auxin applications in Citrus. Acta Horticulturae, n.463, p.501-508, 1997.

PACHECO, A.C. Desbaste químico em tangerina 'Ponkan' (Citrus reticulata Blanco) com a autilização de reguladores vegetais: aspectos fisiológicos e tecnológicos. Piracicaba, 1999. 90p. Dissertação (Mestrado) - Escola Superior de Agricultura "Luiz de Queiroz”, Universidade de São Paulo.

PEMADASA, M.A. Differential abaxial and adaxial stomatal responses to indole-3acetic acid in Commelina communis L. New Phytologist, v.90, p.209-211, 1982.

PÉREZ, M.; POZO, L.; ANON, R.; OLIVA, H.; NORIEGA, C.; GORDILlO, M.; ARANGUREN, M.; VENTO, O.; MARTINEZ, A. CASTILlO, M.; BUSTO, R.; YANEZ, O.; BOROTTO, A.; DEL-BUSTO, R. Growth regulators on citrus crop under cuban tropical conditions. Proceedings of the International Society of Citriculture, v.1, p.503-508, 1992. 
PLAUT, Z.; MAYORAL, M.L.; REINHOLD, L. Effect of altered sink:source ratio on photosynthetic metabolism in source leaves. Plant Physiology, v.85, p.786-791, 1987.

PONS, J.; ALMELA, V.; AGUSTÍ, M. Efectos de las aplicaciones de Figaron (Ethilclozate) en la maduración de las mandarinas 'Oroval' y 'Satsuma'. Levante Agricola, v.289/290, p.19-24, 1989.

POPOVA, L.P.; TSONEV, T.D; VAKLINOVA, S.G. Regulating role of GA3 on photosynthetic and respiratory carbon metabolism in barley leaves, In: BIGGINS, J. Progress in photosynthesis research. Dordrecht: Martinus Nijhoff, 1987. v.3, p.669-674.

POWELL, A.A.; KREZDORN, A.H. Influence of fruit-setting treatment on translocation of $14 \mathrm{C}$-metabolites in citrus during flowering. Journal of the American Society for Horticultural Science, v.102, p.709-714, 1977.

PRIMO-MILLO, E. Regulacion del cuajado del fruto en los citricos. In: CONGRESSO DE CITRICULTURA DE LA PLANA, 1., Valência, 1993. Anais. Valência: Ajunta de Nules, 1993. p.57-74.

RIVERO, J.M.; VEYRAT, P.; BARREDA, D.G. Improving fruit set in Clementine mandarin with chemical treatments in Spain. In: INTERNACIONAL CITRUS SYMPOSIUM, 1. Proceedings. v.3, 1969, p.1121-1124.

ROPER, T.R.; WILLIAMS, L.E. Net CO2 assimilation and carbohydrate partioning of grapevine leaves in response to trunk girdling application. Plant Physiology, v.89, p.1136-1140, 1989. 
SANCHES, F.R. Aplicação de biorreguladores vegetais: aspectos fisiológicos e aplicações práticas na citricultura mundial. Jaboticabal: Funep, 2000. 160p.

SHARMA, S.K. Photosynthetic characteristics and productivity in citrus. Effect of solar photosynthetic photon flux density, water stress and growth regulators. Indian Journal of Horticulture, v.47, n.1, p.41-48, 1990.

SNAITH, P.J.; MAINSFIELD, T.A. Control of the $\mathrm{CO}_{2}$ responses of stomat by indol-3acetic acid and abscisic acid. Journal of Experimental Botany, v.33, p.360-365, 1982.

SOOST, R.K.; BURNETT, R.H. Effects of gibberellin on yield and fruit characteristics of Clementine mandarin. Proceedings of the American Society of Horticultural Science, v.77, p.194-201, 1961.

SPÓSITO, M.B. Fixação de frutos de limeira ácida 'Tahiti', sua relação com o acúmulo de graus-dia e a aplicação de ácido giberélico. Piracicaba, 1998. 67p. Dissertação (Mestrado)- Escola Superior de Agricultura "Luiz de Queiroz", Universidade de São Paulo.

STEWART, W.S.; HIELD, H.Z.; BRANNAMAN, B.L. Effects of 2,4-D and related substances on fruit-drop, yield, size and quality of Washington Navel oranges. Hilgardia, v.21, p.161-193, 1952.

SUGIYAMA, K.; KURAISHI, S. Stimulation of fruit set of 'Morita' navel orange with brassinolide. Acta Horticulturae, n. 239, p.345-348, 1989.

SYVERSTEN, J.P.; LLOYD, J.J. Citrus. In: SCHAFFER, B; ANDERSEN, P.C. (Ed..). Handbook of environmental physiology of fruit crops: subtropical and tropical crops. Boca Raton: CRC Press, 1994. v.2, p.65-99. 
TAKAHASHI, N.; YAMAGUCHI, I.; KONO, T.; IGOSHI, M.; HIROSE, K.; SUZUKI, K. Characterization of plant growth substances in Citrus unshiu and their change in fruit development. Plant and Cell Physiology, v.16, p.1101-1111, 1975.

TALÓN, M. Regulación del cuajado del fruto en cítricos: evidencias y conceptos. Levante Agricola, n.338, p.27-37, 1997.

TALÓN, M.; HEDDEN, P.; PRIMO-MILLO, E. Gibberellins in Citrus sinensis: A comparison between seeded and seedless varieties. Journal of Plant Growth Regulators, v.9, p.201-206, 1990.

TALÓN, M.; ZACARIAS, L.; PRIMO-MILLO, E. Hormonal changes associated with fruit set and development in mandarins differing in their parthenocarpic ability. Physiologia Plantarum. v.79, p.400-406, 1990.

TALÓN, M.; ZACARIAS, L.; PRIMO-MILLO, E. Gibberellins and parthenocarpic ability in development ovaries of seedless mandarins. Plant Physiology, v.99, p.1575-1581, 1992.

TALÓN, M.; ZACARIAS, L.; PRIMO-MILLO, E. Role of gibberellins in parthenocarpic development of seedless mandarins. Proceedings of the International Society of Citriculture, v.1, p.465-467, 1994.

TALÓN, M.; TADEO, F.R; BEM-CHEIK, W.; GOMEZ-CARDENAS, A.; MEHOUACHI, J.; PEREZ-BOTELLA, J.; PRIMO-MILLO, E. Hormonal regulation of fruit set and abscission in citrus: Classical concepts and new evidence. Acta Horticulturae, n.463, p.209-217, 1997. 
TAMAS, I.A.; SCHWARTZ, J.M.; HAGIN, J.M.; SIMMONDS, R. Hormonal control of photosynthesis in isolated chloroplasts.. In: BIELESKI, R.L.; FERGUSON, A.R.; CRESSWELL, M.M. Mechanisms of regulation of plant growth. Wellington: Royal Society of New Zealand, 1974. p.261-268.

TREHARNE, K.J.; STODDART, J.L. Effects of gibberellin on photosynthesis in red clover (Trifolium pratense L.). Nature, v.220, p.457-458, 1968.

TUNG, H.F.; BROUGHTON, W.J.; LENZ, F. Effects of fruit on ribulosediphosphate carboxylase in Citrus madurensis leaves. Experientia, v.29, p.271-272, 1973.

VANNIERE, H.; ARCUSET, P. Amélioration du calibres des Clementines en Corse par lémploi du dichlorprop. Fruits, v.44, p.393-400, 1989.

VANNIERE, H.; ARCUSET, P. Fruit size improvement in 'Common Clementine' mandarin by using dichlorprop. Proceedings of the International Congress of Citriculture, v.1, p.524-526, 1992.

VAN-RENSBURG, P.J.J.; PENG, S.; WOLSTENHOLME, B.N.; GUARDIOLA, J.L. Fruit size in citrus: The action and interaction between gibberellic acid and 2,4-DP on Clementine fruit growth and size. Proceedings of the International Society of Citriculture, v.1, p.80, 1996.

VIEIRA, A. Efeitos de reguladores vegetais no raleamento e na qualidade dos frutos da tangerina 'Clementina' (Citrus reticulata Blanco) e do tangor 'Murcote' (Citrus reticulata Blanco x Citrus sinensis L. Osbeck). Piracicaba, 1985. 118p. Dissertação (Mestrado)- Escola Superior de Agricultura "Luiz de Queiroz", Universidade de São Paulo. 
VU, J.C.V.; YELENOSKY, G. Growth and photosynthesis of sweet orange plants treated with paclobutrazol. Journal of Plant Growth Regulation, v.11, n.2, p.85-89, 1992.

WEILAND, C.; GÓMEZ, G. Aumento del calibre final del fruto en Citrus deliciosa cv. 'Fortuna' mediante la aplicación de 2,4-DP, fenotiol y 3,5,6-TPA. Fruticultura Profesional, n.68, p.30-36, 1995.

WHEATON, T.A. Fruit thinning of Florida mandarins using plant growth regulators. Proceedings of the International Society of Citriculture, v.1, p.263-268, 1981.

WILSON, W.C. The use of exogenous plant growth regulators on Citrus. In: NICKELL, L.G. (Ed.). Plant growth regulating chemicals. Boca Raton: CRC Press, 1983. v.1, p.207-232.

WOOD, B.W. Fruiting affects photosynthesis and senescence of pecan leaves. Journal of the American Society forHorticultural Scince, v.113, p.432-436, 1988.

ZACARIAS, L.; TALÓN, M.; BEM-CHEIKH, W. LAFUENTE, M.T.; PRIMOMILLO, E. Abscisic acid increses in nongrowing and paclobutrazol traeted fruits of seedless mandarins. Physiologia Plantarum, v.95, p.613-619, 1995.

ZARAGOZA, S.; TRENOR, I.; ALONSO, E. Influencia del aclareo sobre el calibre xcomercial de los frutos de la Satsuma Clausellina. Actas de Horticultura, v.6, p.113-118, 1990.

ZARAGOZA, S.; TRENOR, I; AlONSO, E.; PRIMO-MILlO, E.; AGUSTÍ, M. Treatments to increase the final fruit size on Satsuma Clausellina. Proceedings of the International Society of Citriculture, v.2, p.725-728, 1992. 
ZUCCONI, F.; MONSELISE, S.P.; GOREN, R. Growth abscission relationships in developing orange fruit. Scientia Horticulturae, n.9, p.137-146, 1978. 